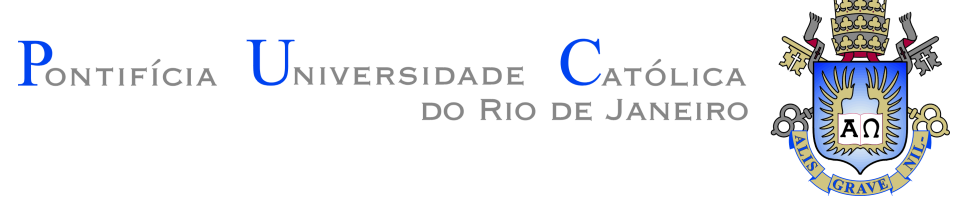

Gustavo Garcia Momm Assessment of slamming loads on subsea
structures using the SPH method

Dissertation presented to the Programa de Pós-Graduação em Engenharia Mecânica of the Departamento de Engenharia Mecânica do Centro Técnico Científico da PUC-Rio, as partial fulfillment of the requirements for the degree of Mestre em Engenharia Mecânica.

Advisor: Prof. Ivan Fabio Mota de Menezes 


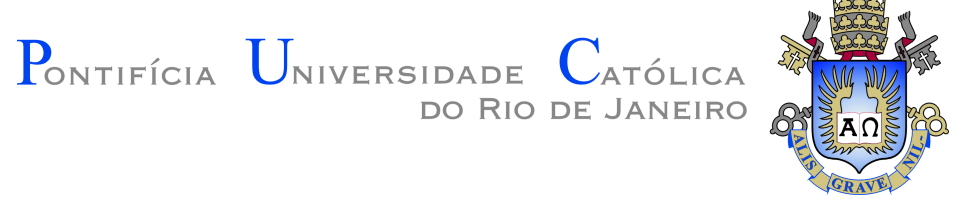

Gustavo Garcia Momm

\section{Assessment of slamming loads on subsea structures using the SPH method}

Dissertation presented to the Programa de Pós-Graduação em Engenharia Mecânica of the Departamento de Engenharia Mecânica do Centro Técnico Científico da PUC-Rio, as partial fulfillment of the requirements for the degree of Mestre.

Prof. Ivan Fabio Mota de Menezes

Advisor

Departmento de Engenharia Mecânica - PUC-Rio

Prof. Marcelo de Andrade Dreux

Departamento de Engenharia Mecânica - PUC-Rio

Dr. Allan Carre de Oliveira Petróleo Brasileiro S.A. - PETROBRAS

Prof. Márcio da Silveira Carvalho

Coordinator of the Centro Técnico Científico - PUC-Rio 
All rights reserved.

\section{Gustavo Garcia Momm}

Graduated in Mechanical Engineering in 2006 at Universidade Federal de Santa Catarina (UFSC), Brazil. Works as Subsea Engineer in Petrobras, where is envolved with concept design and technical specification of oil and gas subsea equipment.

Bibliographic data

Momm, Gustavo Garcia

Assessment of slamming loads on subsea structures using the SPH method / Gustavo Garcia Momm; advisor: Ivan Fabio Mota de Menezes - 2016.

77 f.: il. color.; $30 \mathrm{~cm}$

Dissertação (mestrado) - Pontifícia Universidade Católica do Rio de Janeiro, Departamento de Engenharia Mecânica, 2016

Inclui bibliografia

1. Engenharia Mecânica - Tese. 2. Slamming. 3. Smoothed Particle Hydrodynamics (SPH). 4. Impacto hidrodinâmico. 5. DualSPHysics. 6. Estruturas Submarinas. I. Mota de Menezes, Ivan Fabio. II. Pontifícia Universidade Católica do Rio de Janeiro. Departamento de Engenharia Mecânica. III. Título. 


\section{Acknowledgements}

I am thankful to my family for constant understanding and support.

Special thanks to Prof. Ivan Menezes for providing necessary guidance through the development of this research.

This dissertation was supported by Petróleo Brasileiro S.A - Petrobras, to whom I express here my gratitude. 


\section{Abstract}

Momm, Gustavo Garcia; Mota de Menezes, Ivan Fabio (Advisor); Assessment of slamming loads on subsea structures using the SPH method. Rio de Janeiro, 2016. 77p. MSc. Dissertation - Departmento de Engenharia Mecânica, Pontifícia Universidade Católica do Rio de Janeiro.

Subsea structures employed on offshore oil and gas production systems are commonly designed to be laid on seafloor for decades. For most of these structures the installation is a critical stage and may require costly resources and significant engineering effort. Lowering subsea structures through the wave zone is a complex operation as it involves accelerations of these bodies induced by the vessel motion which, associated to the sea surface displacements, may lead to significant impact loads on these structures during water entry. The initial stage of impact during water entry has been a subject of many researches over the past century since the pioneering work of von Kármán and Wagner on the hydrodynamics of an alighting sea plane. The scenario of impact of the forebody of a ship on the sea surface has also been subject of studies, as it may cause localized and eventually catastrophic damage to the hull. Different numerical methods have been applied to the analysis of this problem. The main contribution of this work is the use of the Smoothed Particle Hydrodynamics (SPH) method to estimate slamming loads on rigid bodies during water entry considering both calm and wavy surfaces. A basic theoretical background on hydrodynamic impact load is firstly introduced, followed by the description of the SPH method. Applications of SPH to simulate water entry of rigid bodies considering both free fall and constant velocity cases are presented and results are compared with experiments and numerical simulations from the literature. The presence of regular waves during constant velocity water entry is also considered. The numerical results obtained here demonstrate the effectiveness of the proposed approach to estimate slamming loads on subsea structures during water entry.

\section{Keywords}

Slamming; Smoothed Particle Hydrodynamics (SPH); Hydrodynamic Impact; DualSPHysics; Subsea Structure. 


\section{Resumo}

Momm, Gustavo Garcia; Mota de Menezes, Ivan Fabio (Orientador); Avaliação das cargas de slamming em estruturas submarinas utilizando o método SPH. Rio de Janeiro, 2016. 77p. Dissertação de Mestrado - Departamento de Engenharia Mecânica, Pontifícia Universidade Católica do Rio de Janeiro.

Estruturas submarinas utilizadas nos sistemas de produção de óleo e gás offshore são normalmente projetadas para permanecerem no leito marinho por décadas. Para a grande maioria dessas estruturas a instalação é uma etapa crítica que pode requerer recursos dispendiosos e significativos esforços de engenharia. A descida de estruturas submarinas em regiões de ondas marinhas é uma operação complexa, uma vez que envolve acelerações desses corpos induzidas pelos movimentos das embarcações que, associados com os deslocamentos da superfície do mar, podem levar a significativas cargas de impacto nessas estruturas durante a entrada na água. O estágio inicial do impacto durante a entrada na água tem sido tema de muita pesquisa no último século, desde os trabalhos pioneiros de von Kármán e Wagner sobre a hidrodinâmica do pouso de hidroaviões. O cenário do impacto da proa de navios na superfície do mar também tem sido objeto de estudo, uma vez que pode levar a danos localizados ou mesmo catastróficos ao casco. Diferentes métodos numéricos têm sido aplicados para análise desse problema. A principal contribuição desse trabalho é a utilização do método numérico Smoothed Particle Hydrodynamics (SPH) para estimar as cargas de slamming em corpos rígidos durante a entrada na água considerando superfícies em repouso e sob o efeito de ondas. Inicialmente é introduzida a fundamentação teórica básica sobre o impacto hidrodinâmico, seguida da descrição do método SPH. Aplicações do SPH para simular a entrada na água de corpos rígidos são apresentadas considerando casos em queda livre e com velocidade constante e os resultados são comparados com experimentos e simulações numéricas obtidos na literatura. A presença de ondas regulares durante a entrada na água com velocidade constante também é considerada. Os resultados numéricos obtidos neste trabalho demonstram a viabilidade da abordagem proposta para estimar as cargas de slamming em estruturas submarinas durante a entrada na água.

\section{Palavras-chave}

Slamming; Smoothed Particle Hydrodynamics (SPH); Impacto hidrodinâmico; DualSPHysics; Estruturas Submarinas. 


\section{Contents}

1 Introduction $\quad 14$

$\begin{array}{lll}1.1 & \text { Motivation } & 14\end{array}$

1.2 Objective and Organization of this Work 17

2 Water Entry Problem $\quad 18$

2.1 Added Mass Definition 18

2.2 Von Kármán's Theory 19

$\begin{array}{ll}2.3 \text { Wagner's Theory } & 21\end{array}$

2.4 Slamming Load 23

2.5 Numerical Approach 24

3 Smoothed Particle Hydrodynamics $\quad 27$

$\begin{array}{lll}3.1 & \text { SPH Method } & 27\end{array}$

3.1.1 Particle Approach 28

3.1.2 Smoothing Kernel $\quad 28$

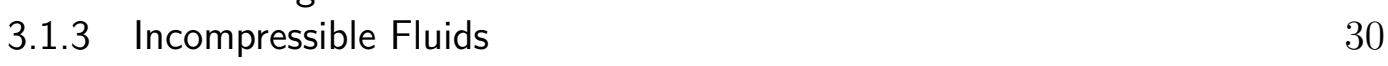

3.1.4 Density 31

3.1.5 Boundaries 31

3.1.6 SPH Algorithm 32

3.2 DualSPHysics Implementation 33

$4 \quad$ Water Entry into Calm Surface $\quad 37$

4.1 Free Fall of Rigid Bodies $\quad 37$

$\begin{array}{lll}4.1 .1 & \text { Cylinder } & 37\end{array}$

4.1.2 Wedge 40

4.2 Constant Velocity Water Entry 43

$5 \quad$ Water Entry into Wavy Surface $\quad 48$

5.1 Wedge on Waves $\quad 49$

5.2 Subsea Manifold on Waves $\quad 51$

6 Conclusions $\quad 59$

$\begin{array}{lll}6.1 & \text { Summary } & 59\end{array}$

6.2 Future Work 60

Bibliography $\quad 62$

$\begin{array}{lll}\text { A Added Mass Tensor } & 68\end{array}$

$\begin{array}{ll}\text { B Case definition file } & \mathbf{7 0}\end{array}$

$\begin{array}{ll}\text { C Script File } & 74\end{array}$

$\begin{array}{ll}\text { D Summary of Simulation Cases } & 76\end{array}$ 


\section{List of figures}

1.1 Overboarding of a Subsea Christmas Tree [2]. 14

$\begin{array}{ll}1.2 & \text { Pendulous installation method [2]. } \\ 1.3 & 15\end{array}$

1.3 Splash zone lifting operation [3]. 16

1.4 Example of wire tension during lowering through the Splash Zone [4]. 16

2.1 Von Karman model. 19

2.2 Increase of added mass with submergence: Blue: water domain, hatched: theoretical added mass and black: rigid body. 20

$\begin{array}{ll}2.3 \text { Wagner model of keeled surfaces [9]. } & 21\end{array}$

3.1 Representation neighboring particles of a referenced particle [44]. 28

3.2 Smoothing kernels poly6, spiky and viscosity: Thick, thin and dotted lines represent kernels, their gradients, and Laplacians, respectively [44].

3.3 Workflow of DualSPHysics. (Adapted from [51]).

4.1 Time versus depth of penetration for a half-buoyant cylinder. 38

4.2 Free surface deformation at time $t=0.33 \mathrm{~s}$ after cylinder released from rest. eft figure shows the results of this work and right figure the shows a picture taken during experiment at same instant [52].

4.3 Time versus depth of penetration for a neutrally-buoyant cylinder.

4.4 Free surface deformation at time $t=0.315 \mathrm{~s}$ after cylinder released from rest. Left figure shows the results of this work and right figure the shows a picture taken during experiment at same instant [52].

4.5 Wedge shaped test set-up [53].

4.6 Vertical velocity (positive downward). Red line with square markers: SPH method; Black solid line: CIP method [34]; Dashed line: Experiment [53].

4.7 Vertical acceleration (positive downward). Red line with square markers: SPH method; Black solid line: CIP method [34]; Dashed line: Experiment [53].

4.8 Vertical hydrodynamic force (positive upward). Red line with square markers: SPH method; Black solid line: CIP method [34]; Dashed line: Experiment [53].

4.9 Test rig for the constant velocity water entry experiment [54]. 43

4.10 Slamming load on $5^{\circ}$ wedge at $0.94 \mathrm{~m} / \mathrm{s}$. 44

4.11 Slamming load on $10^{\circ}$ wedge at $0.94 \mathrm{~m} / \mathrm{s}$. 45

4.12 Slamming load on $15^{\circ}$ wedge at $0.94 \mathrm{~m} / \mathrm{s}$. 45

4.13 Effect of distance between particle ( $5^{\circ}$ wedge at $\left.0.94 \mathrm{~m} / \mathrm{s}\right)$.

4.14 Effect of distance between particles around Case D3. 46

4.15 Effect of kernel function ( $5^{\circ}$ wedge at $0.94 \mathrm{~m} / \mathrm{s}$ ). 47

4.16 Effect of smoothing length ( $5^{\circ}$ wedge at $\left.0.94 \mathrm{~m} / \mathrm{s}\right)$. 47 
5.1 Model of Subsea Structure in two different phases of lowering through the wave zone [56].

5.2 Model of the tank used in simulations with wave. 48

$5.35^{\circ}$ wedge before entering into water before the wave crest. 49

$5.4 \quad 5^{\circ}$ wedge before entering into water after the wave crest. $\quad 49$

5.5 Vertical hydrodynamic force on $5^{\circ}$ wedge in three different situations: Case G1: Calm water, Case G2: wedge entering into water before the wave crest and Case G3: wedge entering into water after the wave crest.

5.6 $5^{\circ}$ wedge reaching the water surface in Case G3. 50

5.7 Representation of Roncador field manifold [57]. 51

5.8 Scaled model developed to simulate the subsea manifold. 52

5.9 Wave components. 52

5.10 Vertical force on model: $H / \lambda=0.05, v_{z}=-0.75 \mathrm{~m} / \mathrm{s}$ in equipment scale.

5.11 Vertical force on the model: $H / \lambda=0.05, v_{z}=-1.5 \mathrm{~m} / \mathrm{s}$ in equipment scale.

5.12 Vertical force on the model: $H / \lambda=0.01, l / \lambda=0.131, v_{z}=-0.1$ $\mathrm{m} / \mathrm{s}$ in equipment scale.

5.13 Vertical force on the model: $H / \lambda=0.01, l / \lambda=0.067, v_{z}=-0.1$ $\mathrm{m} / \mathrm{s}$ in equipment scale.

5.14 Comparison of cases $\mathrm{J}$ and $\mathrm{K}$ when reaching the wave close to crest. 57

5.15 Comparison of cases $\mathrm{J}$ and $\mathrm{K}$ when reaching the wave before the crest.

6.1 Examples of different complex subsea structures in the splash zone [56].

6.2 Numerical (single-phase and two-phase) and experimental results for the peak impact pressure for various wave profiles $(H / \lambda)[60]$. 


\section{List of tables}

4.1 Half buoyant cylinder experiment parameters. 38

4.2 Neutrally-buoyant cylinder experiment parameters. 39

4.3 Wedge experiment parameters. 41

4.4 Constant velocity water entry test program [54]. 44

5.1 Subsea manifold MSGL-RO-02 data [57]. 51 


\section{Notations}

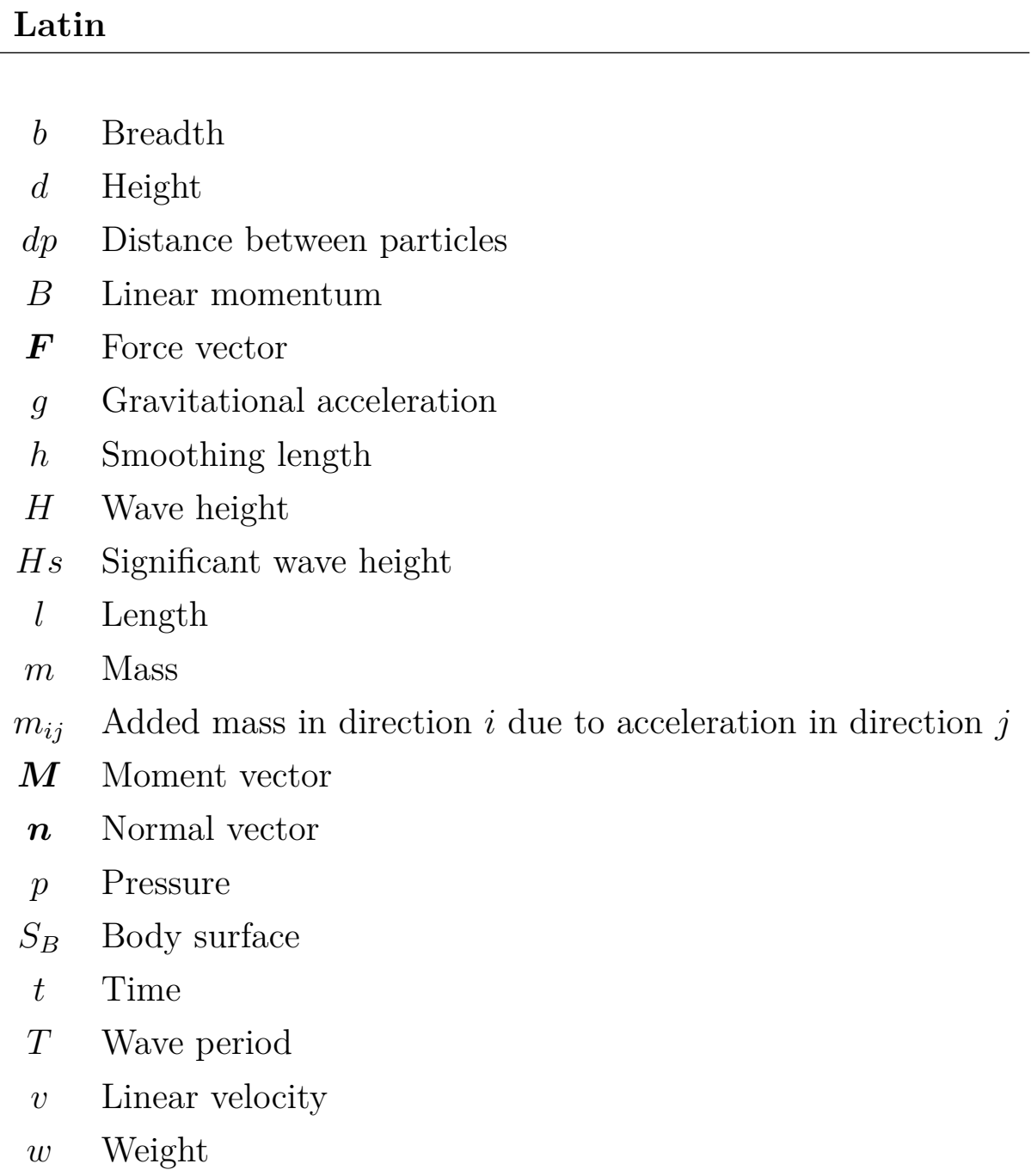

\section{Greek}

$\beta \quad$ Deadrise angle

$\lambda$ Wave length

$\phi \quad$ Velocity potential

$\rho \quad$ Fluid density

$\omega$ Angular velocity 
Acronyms

BEM Boundary Element Method

CFL Courant-Friedrichs-Lewy

CIP Constrained Interpolation Profile

CPU Computer Processing Unit

CUDA Compute Unified Device Architecture

FEM Finite Element Method

GPU Graphical Processing Unit

SPH Smoothed Particles Hydrodynamics

VOF Volume of Fluid 


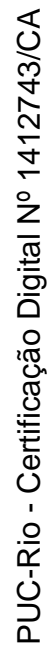

There are no facts, only interpretations.

Friedrich Nietzsche, Nietzsche's Nachlass. 


\section{Introduction}

\section{1}

\section{Motivation}

The exploration and production of offshore Oil and Gas fields in deep water introduced challenges to the industry. One of the most affected areas is the subsea engineering, requiring changes in concepts and paradigms [1].

The deep water scenario imposed design requirements that led to the development of new equipment and technologies. Moreover, the demand for reducing weight on production floating units and the subsea to shore concept, where the production from subsea wells is diverted to onshore plants for processing, contributed for the larger and heavier subsea structures and, in some cases, equipment with sophisticated and fragile components and moving parts, e.g. the subsea boosting systems, requiring special care during installation and several intervention operation during system's life [2]. Figure 1.1 illustrates a modern Subsea Christmas Tree being overboarded for installation.

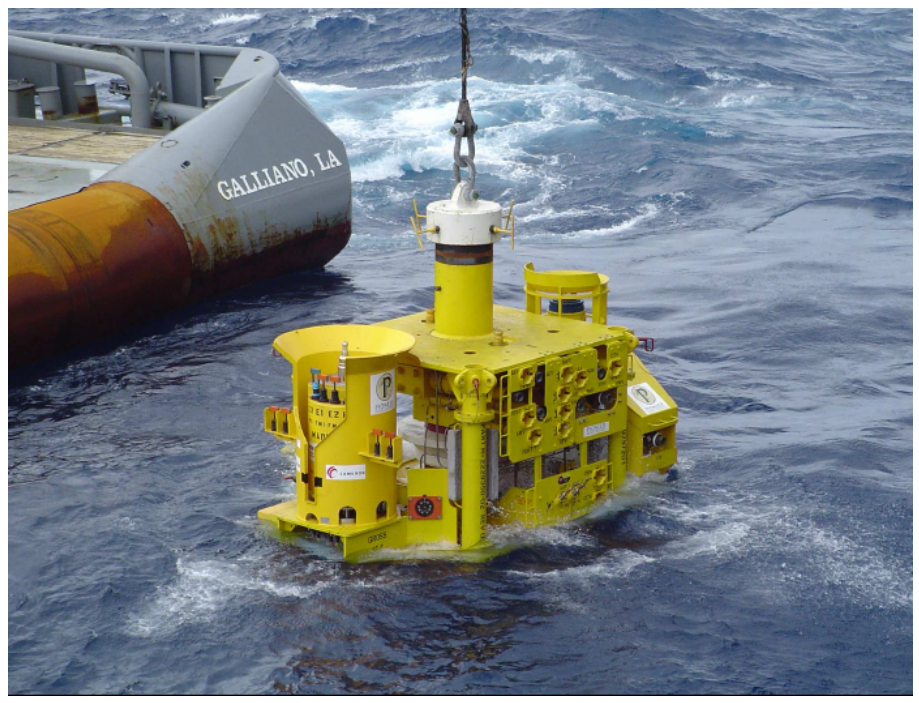

Figure 1.1: Overboarding of a Subsea Christmas Tree [2].

The combination of these factors, associated with low availability and high cost of installation vessels able to perform these operations, instigated the research and development of new concepts and installation methods [2]. 
An example of recent development is the pendulous installation method, that consists of a non-conventional method for installing subsea structures in deepwater areas developed by the company Petrobras in order to install a 280 ton manifold in $1900 \mathrm{~m}$ water depth [3]. In this method the structure is overboarded, lifted through splash zone and lowered to a certain water depth using the first installation vessel while the fiber rope is connected to the winch of the second installation vessel. The vessel are positioned at distance that entire length of deployment line is paid out and then the lifting line of the first vessel is disconnected. Initially the structures performs a free fall movement, followed by the pendulous movement [2]. The installation can be performed with two standard offshore support vessels like e.g. diving support vessels, Remotely operated vehicle support vessels or even dynamic position class anchor handling thugs which are smaller vessels with a lower day rate and a higher availability than the construction vessels or heavy lift vessels [3]. Figure 1.2 illustrates the steps of this method.

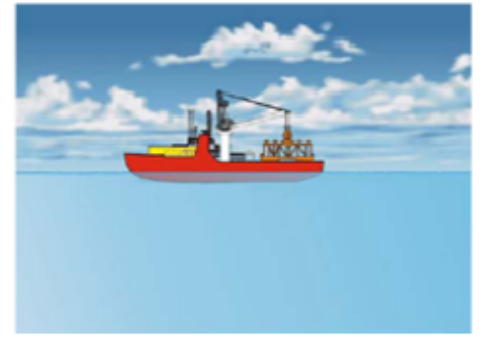

Transportation Vessel

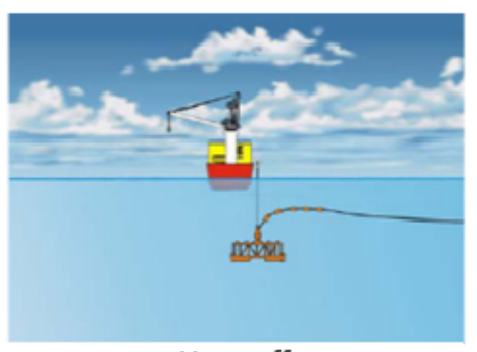

Hangoff

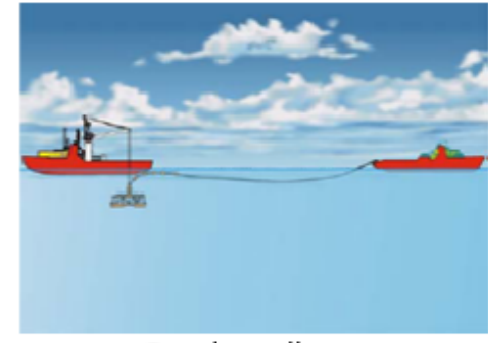

Overboarding

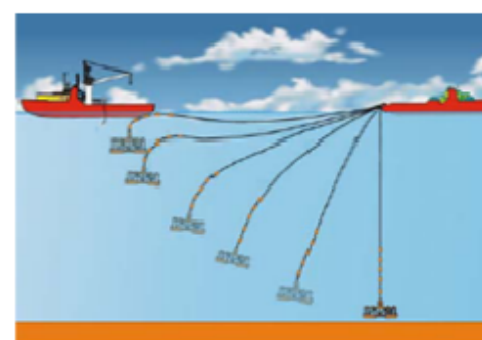

Pendulous Motion

Figure 1.2: Pendulous installation method [2].

This installation of subsea structures are is normally evaluated in four stages [4]: (i) lift off from deck and manoeuvring object clear of transportation vessel, (ii) lowering through the wave zone, (iii) further lowering down to sea bed and (iv) positioning and landing.

Lowering subsea structures through the wave zone is a complex operation [5] as it involves accelerations of these bodies induced by the vessel motion which, associated to the sea surface displacements, may lead to significant 
impact loads on these structures during water entry. Figure 1.3 presents the lowering through wave zone operation.

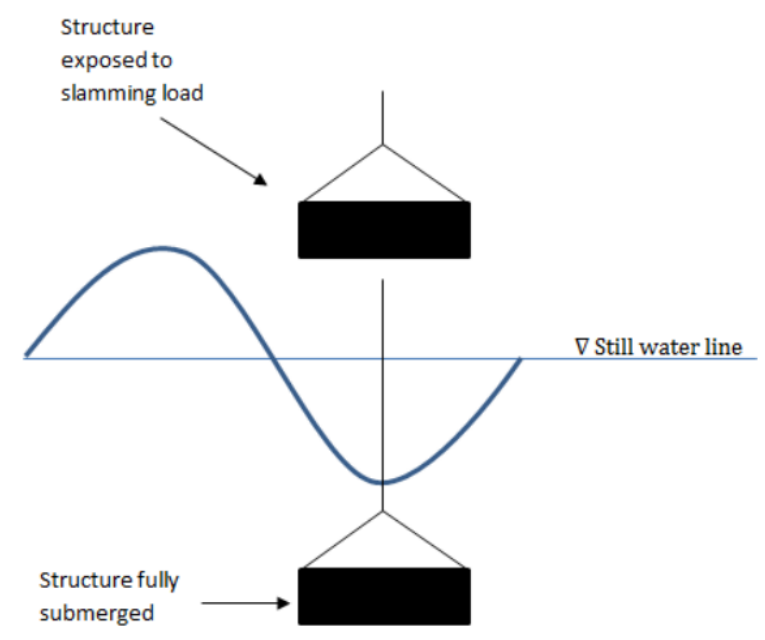

Figure 1.3: Splash zone lifting operation [3].

In many situations in the oil and gas industry the slamming load is in the same magnitude of the structure weight, even with small lowering velocity, which may represent operational risk in case of slack sling or wire. Therefore the operational limits, i.e. lowering velocity, wave high and period and wind velocities, are normally defined to result in slamming loads lower than $90 \%$ of the structure static weight [6]. Figure 1.4 presents an example of lifting wire tension during splash zone transit of a subsea structure.

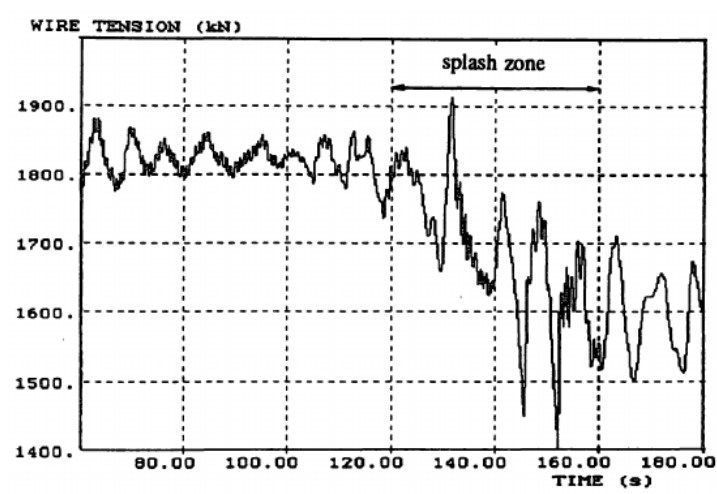

Figure 1.4: Example of wire tension during lowering through the Splash Zone [4].

The calculation of slamming loads and definition of the operational limits is an effortful analysis for subsea strutures when the complex geometries and irregular sea states are taken into consideration. The current practice in the industry [5] is to simplify the problem by using the available information about the hydrodynamic properties, such as added mass, drag coefficient in time 
domain analysis in accordance with the recommendations from DNV-RP-H103 $[6]$.

The DNV-RP-H103 gives guidance for modelling and analysis of marine operations, in particular for lifting operations including lifting through wave zone and lowering of objects in deep water to landing on seabed [6]. This recommended practice includes a simplified method for estimating characteristic forces on objects lowered through the wave zone and provides the basis for time domain analysis [7]. It is generally recognized that this simplified method leads to conservative estimates [7], as it assumes that the horizontal extent of the lifted object (in the wave propagation direction) is relatively small compared to the wave length, i.e. the bottom surface of the structure reaches the water surface all at once, and the object vertical velocity is added by the characteristic vertical water particle velocity.

Conservative estimates of water entry loads lead to higher costs of the subsea structures deployment operation, as consequence of restricted operational limits, that possibly increases the operation time, and/or requirements for more robust installation vessels.

\section{2}

\section{Objective and Organization of this Work}

The main objective of this work is to employ a numerical method, called $\mathrm{SPH}$, to calculate slamming load on rigid bodies during water entry considering both calm and wavy water surfaces. A 2D approach with one degree of freedom is proposed to predict the slamming load on subsea structures during offshore deployment, considering the effect of waves.

The remainder of this document is organized as follow:

In Chapter 2 the basic theories to estimate water entry loads, manly the von Kármán and Wagner theories are introduced. Subsequently the recent numerical methods applied to this problem are discussed.

The SPH method is described in Chapter 3, where the implementation of the method employed in this work, DualSPHysics, is also presented.

The results of simulations using SPH method for free fall and constant velocity water entry of $2 \mathrm{D}$ rigid bodies into flat surface are presented in Chapter 4 , together with a comparison with results from the technical literature.

In Chapter 5, results from the SPH analysis of a subsea structure being lowered through the wavy water surface are presented and discussed.

Finally, conclusions and suggestions of future works are presented in Chapter 6 . 


\section{2}

\section{Water Entry Problem}

The initial stage of impact has been the subject of much research over the past century since the independent and pioneering works of von Kármán [8] and Wagner [9] on the hydrodynamics of an alighting seaplane [10]. Von Kármán developed an analytical expression which allows the estimation of the maximum pressure on seaplane floats during water landing, modelling it as a 2D wedge. Wagner [9] modified the von Kármán solution by taking into account the effect of water splash on the body.

Pressure distribution over a wedge vertically entering water has been of interest in the field of ship building for both structural design and seakeeping properties. This problem is a precursor to the understanding of the problem of slamming of ship hulls in water [11], which can cause localized and eventually catastrophic damage to the hull [10].

The abrupt interaction between the sea surface and the ship, as well as other structures, is called slamming [12]. In this the vertical hydrodynamic loads acting on structures being lowered through the water surface will be referred as slamming load.

In this chapter the added mass definition is presented followed by the von Kármán and Wagner theories. Finally a brief discussion on numerical approach to the water entry problem is presented.

Developments related to the water entry problem are not limited by those referenced in this thesis. In 1965, Moran [13] provided a comprehensive study on water entry and exit theories. Special attention should be paid to recent developments published by Korobkin et al [14], [15], [16] where alternative solutions to Wagner theory, 3D problems and flat plates are proposed, and also finite water depth problem presented by Oliver [10].

\section{1}

\section{Added Mass Definition}

Whenever acceleration is imposed on a fluid flow either by acceleration of a body or by acceleration externally imposed on the fluid, additional fluid forces will act on the surfaces in contact with the fluid [17]. These forces are proportional to the acceleration of the body, in manner analogous to the 
Newton's equation $F=m a$ [18], and coefficient of proportionality is called the added mass. The phenomenon of added mass determines the necessary work done to change the kinetic energy associated with the motion of the fluid [17].

Newman [18] presents the analytical approach to the added mass, as described in Appendix A. It starts with the equations of hydrodynamic pressure forces and moments acting on rigid body surrounded by ideal, irrotational, and incompressible fluid and develop the equations that lead to the definition of added mass tensor as

$$
m_{j i}=\rho \iint_{S b} \phi_{i} \frac{\partial \phi_{j}}{\partial n} d S .
$$

Replacing the Eq. 2-1 in Eqs. A-14 and A-15, the hydrodynamic pressure forces and moments can be calculated using

$$
\begin{gathered}
F_{j}=-\dot{v}_{i} m_{j i}-\varepsilon_{j k l} v_{i} \omega_{k} m_{l i}, \\
M_{j}=-\dot{v}_{i} m_{j+3, i}-\varepsilon_{j k l} v_{i} \omega_{k} m_{l+3, i}-\varepsilon_{j k l} v_{i} v_{k} m_{l i},
\end{gathered}
$$

where the indices $j, k, l$ take on values $1,2,3$ and $i$ denotes the six components of the velocity potential.

Notice that, in Eqs. 2-2 and 2-3 no surface integral is involved, other than those in which define the added mass coefficients, and these quantities depend on body acceleration components and added-mass coefficients $m_{j i}$. The body geometry is taken into account on the added-mass coefficients definition, as shown in Eq. 2-1.

\section{2}

\section{Von Kármán's Theory}

Theodore von Kármán proposed in 1929 [8] a theory to estimate maximum pressure on seaplane floaters during landing. This development was checked against experimental results for different landing velocities. The problem was set as a wedge shaped rigid body landing on calm waters (flat surface), as illustrated in Figure 2.1,

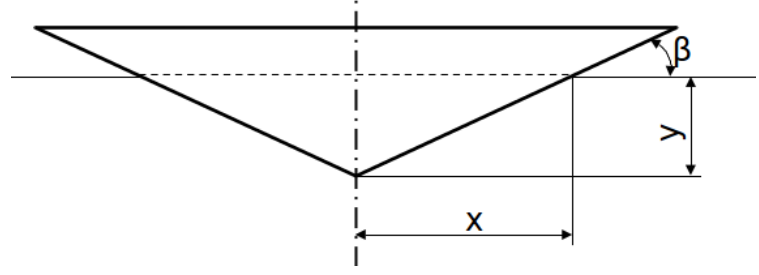

Figure 2.1: Von Karman model. 
where $\beta$ is the inclination angle of under surface with horizontal, $y$ is the vertical distance through which the body travel in time $t$ and $2 x=2 y \cot \beta$ is the width of the body in the water.

The momentum conservation is applied to calculate the force. At time $t$, the momentum before the contact (Eq. 2-4) is distributed between the water and the body (Eq. 2-5)

$$
\begin{gathered}
B_{0}=\frac{w}{g} v_{0} \\
B=\frac{w}{g} v+\frac{1}{2} x^{2} \rho \pi v
\end{gathered}
$$

where $w$ is weight of the body per unit length and $v_{0}$ is the body velocity at the first contact with water.

This theory considers the geometry of the wedge as a continuously growing flat surface, which width is dependent of the submergence $y, x=$ $y \cot \beta$. The added mass, i.e. the mass of fluid accelerated by the flat plate of width $2 x$, is $\frac{1}{2} x^{2} \rho \pi$, where the $\frac{1}{2}$ term results from the consideration that the upper part of the plate is in void. Figure 2.2 represents the increase of added mass (hatched area) with the submergence. The effect of buoyancy is neglected in this theory.

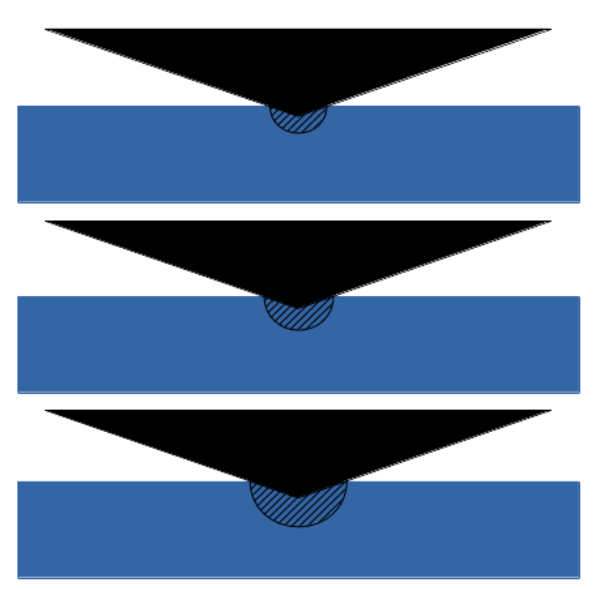

Figure 2.2: Increase of added mass with submergence: Blue: water domain, hatched: theoretical added mass and black: rigid body.

Setting

$$
v=\frac{d y}{d t}=\tan \beta \frac{d x}{d t}
$$

and $\gamma=\rho g$, the relation between sinking velocity and depth can be written

$$
\frac{d x}{d t}=\frac{v_{0} \cot \beta}{1+\frac{\gamma \pi x^{2}}{2 w}}
$$

Deriving the Eq. 2-7, the force of impact $F$ and the average pressure $p$ expressions can be written as 


$$
\begin{aligned}
& F=\frac{v_{0}^{2} \cot ^{2} \beta}{\left(1+\frac{\gamma \pi x^{2}}{2 w}\right)^{3}} \rho \pi x \\
& p=\frac{\rho v_{0}^{2}}{2} \frac{\pi \cot \beta}{\left(1+\frac{\gamma \pi x^{2}}{2 w}\right)^{3}}
\end{aligned}
$$

This theory is cleary limited by the reduction of the inclination angle $\beta$, that would lead to infinite loads if $\beta \rightarrow 0$, requiring different analysis as discussed in $[8]$.

\section{3}

\section{Wagner's Theory}

Herbert Wagner [9] proposed a theory, based on the previous developments of von Kármán [8] and Papst [19], that includes the water elevation on the wedge contact surface. Wagner took advantage of the complex potential theory to estimate the hydrodynamic load on wedges, considering the fluid as irrotational and incompressible. The gravity acceleration is not considered, as it has a negligible effect in the initial phase of water entry of a blunt body [20].

Wagner [9] presented equations for two-dimensional fluid motion with free surface if a center of similitude is present and examples were discussed.

The problem of impact of keeled surfaces is developed considering that initially flat water surface move upward towards the bottom of the body. The velocity of the water $v$ is a function of time: $v=v(t)$. In the impact process, the velocity in the region far from the body is directed vertically $\left(v_{t}=0\right)$. The velocity at the bottom surface drops in the direction of this surface.

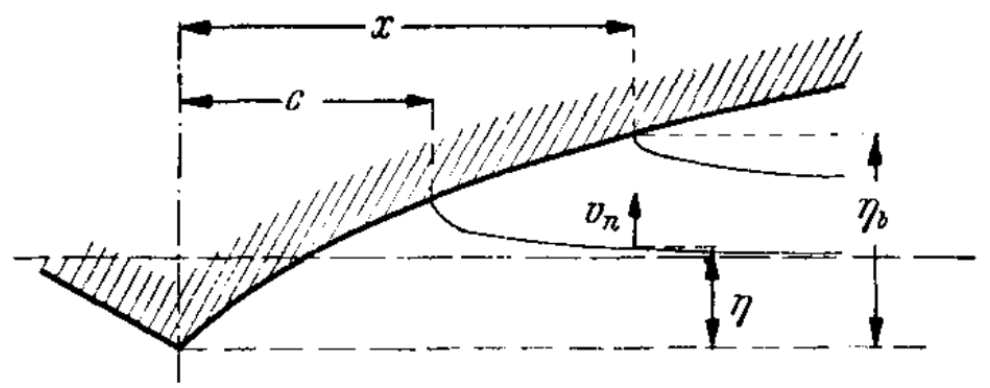

Figure 2.3: Wagner model of keeled surfaces [9].

Wagner employed the method of Schwarz-Christoffel ${ }^{1}[9]$ to solve the problem and present equation for the velocity of water at a position $x>c$,

$$
v_{n}=\frac{v}{\left(1-\frac{c^{2}}{x^{2}}\right)^{1 / 2}} .
$$

\footnotetext{
${ }^{1}$ The use of Schwarz-Christoffel method for solution of wedge water entry problem is detailed by Ghadimi et al. [21]. In the article an analytical solution for slamming load and pressure distribution is presented.
} 
The water elevation $\eta$, can be calculated from the moment of immersion $(t=0)$,

$$
\eta=\int_{0}^{t} v_{n} d t=\int_{0}^{t} \frac{v d t}{\left(1-\frac{c^{2}}{x^{2}}\right)^{1 / 2}} .
$$

The width of the pressure surface $(2 c)$ increases with time $c=c(t)$. Selecting, for the moment, $c$ as an independent variable, hence $t=t(c)$ and $v=v(c)$, one may set

$$
d t=\frac{d t}{d c} d c
$$

Thus

$$
\eta=\int_{c=0}^{c \leq x} \frac{v \frac{d t}{d c}}{\left(1-\frac{c^{2}}{x^{2}}\right)^{1 / 2}} d c=\int_{c=0}^{c \leq x} \frac{u(c)}{\left(1-\frac{c^{2}}{x^{2}}\right)^{1 / 2}} d c
$$

where

$$
u=u(c)=v \frac{d t}{d c}=\frac{v}{v_{t}}
$$

When a water particle at position $x$ reaches the contour of the pressure surface, then $\eta=\eta_{b}$, an therefore

$$
\eta_{b}=\int_{0}^{x} \frac{u(c)}{\left(1-\frac{c^{2}}{x^{2}}\right)^{1 / 2}} d c
$$

Equation 2-15 shall be valid for all $x$ and is to be taken as an integral equation for obtaining $u(c)$. The variable $u$ is a purely geometrical quantity that depends on $\eta_{b}$ only. Wagner [9] presents the result for $u$ considering that it is always possible to represent the given shape of the bottom by power series of the form

$$
\eta_{b}=a_{0} x+a_{1} x^{2}+a_{2} x^{3}+a_{3} x^{4}+\ldots,
$$

where $a_{i}$ are constants to be determined. The solution for Eq. 2-15 is given as

$$
u=u(c)=\frac{2}{\pi} a_{0}+a_{1} c+\frac{4}{\pi} a_{2} c^{2}+\frac{3}{2} a_{3} c^{3}+\ldots
$$

The form of fluid surface may be determined from the Eq. 2-13 and the result for a straight keeled bottom is

$$
\eta=\frac{2}{\pi} \alpha x+\arcsin \frac{c}{x} .
$$

To determine the force $F$ the fluid is assumed to be initially at rest and the body is moving relatively at velocity $v=v(t)$. The momentum equation of the fluid is

$$
B=\frac{\pi}{2} \rho c^{2} v
$$

By differentiation of Eq. 2-19 with respect to $t$ and using Eq. 2-14, the force $F$ can be expressed as

$$
F=\pi \rho c \frac{v^{2}}{u}+\frac{\pi}{2} \rho c^{2} \frac{d v}{d t}
$$

For the special case were the body with mass $m$ touches the water surface with velocity $v_{0}$, the momentum of the fluid, Eq. 2-19 is set as equal to body momentum $\left(v_{0}-v\right)$ and leads to 


$$
v=\frac{v_{0}}{1+\mu}
$$

where

$$
\mu=\frac{\pi \rho c^{2}}{2 m} .
$$

Setting $F=-m \frac{d v}{d t}$ in Eq. 2-20 and using the results from Eqs. 2-21 and 2-22,

$$
F=\frac{\pi \rho c v_{0}^{2}}{(1+\mu)^{3} u} .
$$

Taking a wedge, where the keeled surface is straight, with $\eta_{b}=\beta x$ and $u=\frac{2}{\pi} \beta$, the force $F$ can be expressed as

$$
F=\frac{\pi^{2} \rho c v_{0}^{2}}{2(1+\mu)^{3} \beta} .
$$

\section{4}

\section{Slamming Load}

The vertical hydrodynamic force acting on the body during water entry may be obtained from

$$
F=\int_{-c}^{c} p d x
$$

where $p$ is the pressure and $c$ is presented in Figure 2.3. For $|x|<c$ the potential velocity is $\phi=-v \sqrt{c^{2}-x^{2}}[9]$ and $p$ is given by

$$
\begin{gathered}
p=-\rho\left[\frac{\partial \phi}{\partial t}+\frac{1}{2}\left\{\frac{d \phi}{d x}\right\}^{2}\right] \\
p=\rho\left[\frac{v^{2}}{u} \frac{1}{\sqrt{1-\frac{x^{2}}{c^{2}}}}+\frac{d v}{d t} \sqrt{c^{2}-x^{2}}-\frac{v^{2}}{2\left(\frac{c^{2}}{x^{2}}-1\right)}\right] .
\end{gathered}
$$

Combining Eqs. 2-26 and 2-25 and performing the integration, one obtains

$$
F=\rho \pi c \frac{v^{2}}{u}+\frac{1}{2} \rho \pi c^{2} \frac{d v}{d t} .
$$

Equation 2-27 leads to an interpretation of the vertical hydrodynamic load, or slamming load, in terms of added mass and its rate of change. Taking the heave added mass $\left(m_{33}=\right.$ added mass in vertical direction due to vertical acceleration) of a flat plate of width $2 c$ and unitary length, $m_{33}=\frac{\pi \rho c^{2}}{2}$, its time derivative is

$$
\frac{d m_{33}}{d t}=\rho \pi c \frac{d c}{d t} .
$$

Replacing Eq. 2-14 into Eq. 2-28 and using the chain rule on the first term, Eq. 2-27 can be rewritten as

$$
F=\frac{d m_{33}}{d y} v^{2}+m_{33} \frac{d v}{d t}=\frac{d\left(m_{33} v\right)}{d t} .
$$

Equation 2-29 is relevant for the context of this work as it allows the conclusion that, for a constant velocity water entry, the slamming load depends only on 
the change of added mass with the submergence of the body.

In many practical applications the non-dimensional slamming coefficient $C_{s}$ is employed on the calculation of slamming loads, using

$$
C_{s}=\frac{2 F}{\rho \pi A v^{2}} .
$$

The coefficient $C_{s}$ is dependent on the rate of change of the added mass with the submergence Eq. 2-29, thus dependent on the body geometry as shown in Eq. A-18. This aspect makes the determination of this coefficient for complex geometry bodies very difficult and, therefore, values from the literature are commonly assumed [5], as well as for non-flat or moving water surface.

\section{5}

\section{Numerical Approach}

In addition to analytical theories, numerical methods have been investigated to deal with non-linearities of the water entry problem and the complexities associated to the free surface and different geometries. Moran [13], in 1965, highlighted the limitations of the analytical theories available at that time and recommended effort in the development of numerical methods for solving water-entry and -exit problems.

Several numerical methods to solve partial differential equations have been developed in the last decades. The water entry problem requires a multidomain analysis, typical from fluid-structure interaction process in which the free surface mapping is essential. Croce [22] presents in his thesis the historical development of numerical methods for simulation of the free surface and the characteristics of each method. In general the methods can be divided in two classes: Tracking methods, that are inherently Lagrangian techniques, such as Moving Mesh Methods, Front Tracking Processes (Marker and Cell), Boundary Element Method and Particle Methods (Particle in Cell and Smoothed Particle Hydrodynamics). The second class is the Capturing methods, that are inherently Eulerian techniques, such as in Continuum Advection Method, Volume Capturing Methods (Volume of Fluid), Phase Field Methods and Level Set Method.

The water entry problem has been addressed numerically using methods listed by Croce [22] and relevant developments to this work are referenced below:

\section{i. Boundary Element Method (BEM)}

- Zhao et al. [23] proposed a numerical model based on nonlinear boundary element method (BEM) for the simulation of water entry 
of wedges and other arbitrary cross-section 2D bodies;

- Battistin et al. [24] further developed the method proposed in [23] adding a model for the jet flow;

- Wu et al. [25] employed BEM to simulate water entry through free fall motion of $2 \mathrm{D}$ wedge;

- Tassin et al. [26] extended BEM application to 3D cases of elliptic paraboloid, wedge-cone and square pyramid.

\section{ii. Volume of Fluid (VOF)}

- Shen et al. [27] studied the sphere water entry problem using VOF associated with Dynamic Mesh method;

- Ghadimi et al. [28] simulated water entry process with different bow sections using VOF;

- Constantinescu et al. [29] applied the VOF to 3D simulations water entry of simple geometries and compared with experiments.

- Mukha [30] used VOF method to simulate a subsea equipment being lowered through the splash zone in order to estimate forces applied to the structure.

- Jia et al. [5] performed similar simulations as [30], focusing on the tension on the components of the sling that suspends the structure;

- Damblans et al. [31] simulated flat plates and perforated flat plates during water entry using VOF and results were compared with experiments;

\section{iii. Finite Element Method (FEM)}

- Roe [32] developed a model based on the finite element method to solve the water-entry problem of a torpedo like body. In this model the body is discretized in panels where hydrodynamic loads are applied;

- Wang [33] used a commercial software based on the finite element method to assess slamming loads on various deadrise angles wedges and ship sections;

\section{iv. Constrained Interpolation Profile (CIP)}

- Zhu [34] employed the Constrained Interpolation Profile (CIP) method to simulate water entry of $2 \mathrm{D}$ ship sections with different heel angles.

\section{v. Smoothed Particle Hydrodynamics (SPH)}


- Vandamme et al. [35] reproduced water entry and exit experiments of simple geometries using $\mathrm{SPH}$;

- Liu et al. [36] simulated high velocity water entry of wedge using $\mathrm{SPH}$;

- Oger et al. [36] compared the results obtained with SPH method with both experimental data and VOF simulations. In [35] asymmetric water entry case was studied using SPH method;

- Farsi et al. [39] used SPH in conjunction with turbulence model and density filter to simulated water entry of wedges.

The SPH method was selected to be used in this work due to its ability to handle different geometries and free surface, as well as its computational performance [35]. 


\section{3}

\section{Smoothed Particle Hydrodynamics}

Smoothed Particle Hydrodynamics (SPH) is a Lagrangian meshless method that is increasingly used for an extensive range of applications within the field of Computational Fluid Dynamics [40]. The technique discretizes a continuum using a set of material points or particles. When used for the simulation of fluid dynamics, the discretized Navier-Stokes equations are locally integrated at the location of each of these particles, according to the physical properties of the surrounding particles.

In this chapter, the main characteristics of SPH are described and the DualSPHysics [40] implementation is presented.

\section{1}

\section{SPH Method}

First introduced by Gingold et al. [41] and Lucy [42], the Smoothed Particle Hydrodynamics, SPH, is a numerical method developed for simulation of astrophysical problems. Since the early stages of development it has been employed for simulation of a variety of problems, such as hydrodynamics and solid mechanics [43].

The SPH method uses the concept of integral representation of a function $f(\boldsymbol{x})$ as the convolution [43]

$$
f(\boldsymbol{x})=\int_{\Omega} f\left(\boldsymbol{x}^{\prime}\right) \delta\left(\boldsymbol{x}-\boldsymbol{x}^{\prime}\right) d \boldsymbol{x}^{\prime}
$$

where $\Omega$ is the domain, $d \boldsymbol{x}^{\prime}$ is the differential volume element and $\delta\left(\boldsymbol{x}-\boldsymbol{x}^{\prime}\right)$ is the Dirac delta function. Replacing the Dirac delta by a smoothing kernel function $W$ with support radius (smoothing length) $h$, the integral representation of $f(\boldsymbol{x})$ is given by [44]

$$
f(\boldsymbol{x})=\int_{\Omega} f\left(\boldsymbol{x}^{\prime}\right) W^{h}\left(\boldsymbol{x}-\boldsymbol{x}^{\prime}\right) d \boldsymbol{x}^{\prime} .
$$

Equation 3-2 represents the fundamental concept of the SPH method. Figure 3.1 illustrates the neighboring particles of a referenced particle, the smoothing length $h$ and the kernel (weighted) function $W$. 


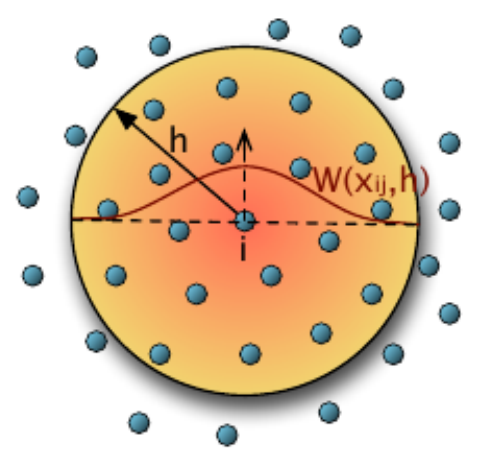

Figure 3.1: Representation neighboring particles of a referenced particle [44].

\subsection{1}

\section{Particle Approach}

The particle approach of the SPH method allows the representation of the function $f$ replacing the integral in the domain $\Omega$ by a sum on the finite set of particles representing the domain, see Eq.3-2. Using the compact condition, the integration on the domain $\Omega$ is reduced to a sum on the particles in the non-zero area of the smoothing function [43]. The approximation of Eq. 3-2 for the particle $i[45]$ is given as

$$
f^{h}(\boldsymbol{x})=\sum_{j} f\left(\boldsymbol{x}_{j}\right) \frac{m_{j}}{\rho_{j}} W^{h}\left(\boldsymbol{x}-\boldsymbol{x}_{j}\right),
$$

where the differential volume element $d \boldsymbol{x}^{\prime}$ in Eq. 3-2 is replaced by the volume $V_{j}$ which is the mass $m_{j}$ divided by its density $\rho_{j}$.

The gradient and Laplacian operators can be calculated based on the first and second derivative of the kernel, respectively

$$
\begin{aligned}
\nabla f^{h}(\boldsymbol{x}) & =\sum_{j} f\left(\boldsymbol{x}_{j}\right) \frac{m_{j}}{\rho_{j}} \nabla_{j} W^{h}\left(\boldsymbol{x}-\boldsymbol{x}_{j}\right) \\
\nabla^{2} f^{h}(\boldsymbol{x}) & =\sum_{j} f\left(\boldsymbol{x}_{j}\right) \frac{m_{j}}{\rho_{j}} \nabla^{2} W^{h}\left(\boldsymbol{x}-\boldsymbol{x}_{j}\right)
\end{aligned}
$$

Equations 3-4 and 3-5 are the basic forms to express the operators. Monaghan [46] discuss other forms to expand terms of these functions to increase accuracy and stability. A comprehensive analysis of these functions is presented by Paiva et al. [43].

\subsection{2}

\section{Smoothing Kernel}

The choice of kernel function $W^{h}$ rules the function approximation accuracy, defines the support dimension [43] and affects the stability [47]. The kernel function typically satisfies the following set of conditions [44] [45]: 
1. The kernel has to be normalized

$$
\int_{\mathbb{R}^{n}} W^{h}\left(\boldsymbol{x}-\boldsymbol{x}^{\prime}\right) d \boldsymbol{x}^{\prime}=1
$$

2. The Dirac delta function property has to be satisfied

$$
\lim _{h \rightarrow 0} W^{h}\left(\boldsymbol{x}-\boldsymbol{x}^{\prime}\right)=\delta\left(\boldsymbol{x}-\boldsymbol{x}^{\prime}\right)
$$

3. The compact condition should define the non-zero area of the smoothing function

$$
W^{h}\left(\boldsymbol{x}-\boldsymbol{x}^{\prime}\right)=0 \quad \text { when } \quad\left\|\boldsymbol{x}-\boldsymbol{x}^{\prime}\right\|>h
$$

4. The kernel has to be positive, symmetric and a decreasing function.

Several smoothing kernels have been proposed in the literature. Monaghan et al. [41] recommended use of Gaussian function [43]

$$
W^{h}\left(\boldsymbol{x}-\boldsymbol{x}^{\prime}\right)=\left(\frac{1}{\pi h^{2}}\right)^{3 / 2} e^{\frac{-r^{2}}{h^{2}}}
$$

where $r=\left\|\boldsymbol{x}-\boldsymbol{x}^{\prime}\right\|$. Gaussian function has no compact support, requiring large evaluation domain in order to have values of this function close to zero [43]. A cubic spline is presented by Monaghan [48] as a commonly used kernel, i.e.

$$
W^{h}\left(\boldsymbol{x}-\boldsymbol{x}^{\prime}\right)=\alpha_{D} \begin{cases}1-\frac{3}{2} q^{2}+\frac{3}{4} q^{3} & 0 \leq q \leq 1 \\ \frac{1}{4}(2-q)^{3} & 1 \leq q \leq 2, \\ 0 & q \geq 2,\end{cases}
$$

where $q=\frac{r}{h}$ and $\alpha_{D}$ is equal to $\frac{10}{7 \pi h^{2}}$ in $2 \mathrm{D}$ and $\frac{1}{\pi h^{3}}$ in 3D. Wendland [49] presents the Quintic function as an alternative kernel

$$
W^{h}\left(\boldsymbol{x}-\boldsymbol{x}^{\prime}\right)=\alpha_{D}\left(1-\frac{q}{2}\right)^{4}(2 q+1) \quad 0 \leq q \leq 2,
$$

where $\alpha_{D}$ is equal to $\frac{7}{4 \pi h^{2}}$ in $2 \mathrm{D}$ and $\frac{21}{16 \pi h^{3}}$ in $3 \mathrm{D}$.

Müller et al.[47] presented three other possible kernels highlighting their characteristics. The first kernel, named poly6 is given as,

$$
W_{\text {poly } 6}^{h}\left(\boldsymbol{x}-\boldsymbol{x}^{\prime}\right)=\frac{315}{64 \pi h^{9}} \begin{cases}\left(h^{2}-r^{2}\right)^{3} & 0 \leq r \leq h \\ 0 & \text { otherwise }\end{cases}
$$

As pointed out by the authors and represented in the Figure 3.2 if this kernel is used to compute pressure forces, particles tend to build clusters under high pressure, as gradient approaches zero when particles get close. The spiky kernel is proposed to address this issue 


$$
W_{\text {spiky }}^{h}\left(\boldsymbol{x}-\boldsymbol{x}^{\prime}\right)=\frac{15}{\pi h^{6}} \begin{cases}(h-r)^{3} & 0 \leq r \leq h \\ 0 & \text { otherwise }\end{cases}
$$
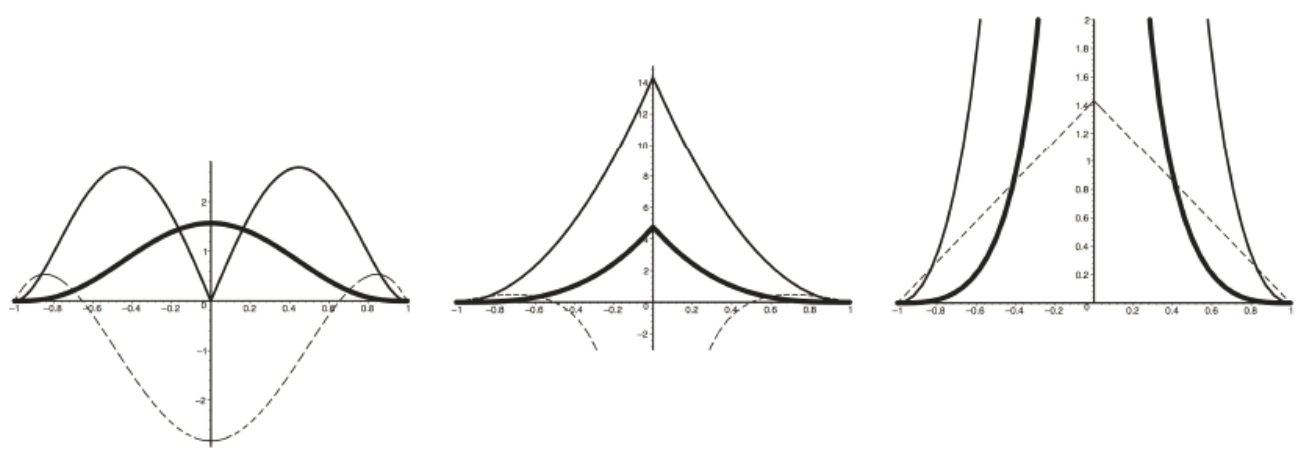

Figure 3.2: Smoothing kernels poly6, spiky and viscosity: Thick, thin and dotted lines represent kernels, their gradients, and Laplacians, respectively [44].

The aim of the third kernel presented was to support better calculation of viscosity forces

$$
W_{\text {viscosity }}^{h}\left(\boldsymbol{x}-\boldsymbol{x}^{\prime}\right)=\frac{15}{2 \pi h^{3}} \begin{cases}-\frac{r^{3}}{2 h^{3}}+\frac{r^{2}}{h^{2}}+\frac{h}{2 r}-1 & 0 \leq r \leq h \\ 0 & \text { otherwise }\end{cases}
$$

which increases stability by leading to positive Laplacian everywhere.

\subsection{3}

\section{Incompressible Fluids}

The SPH method when simulating incompressible fluids typically treats them as an artificial fluid which is slightly compressible [44] and relates the density and the pressure using the Tait equation of state

$$
p_{i}=B\left[\left(\frac{\rho_{i}}{\rho_{0}}\right)^{\gamma}-1\right]
$$

where $\gamma=7$ and $\rho_{0}$ is the reference density. Parameter $B=c_{s}^{2} \rho_{0} / \gamma$ is related to density fluctuations.

The weakly compressible SPH (WCSPH) method uses such a large value for the speed of sound $c_{s}$ to keep density fluctuations $\frac{|\delta \rho|}{\rho_{0}}$ small, where $\delta \rho$ corresponds to the deviation from the rest density $\rho_{0}$ [44]. According to Moanghan [48]

$$
\frac{|\delta \rho|}{\rho_{0}} \sim \frac{v^{2}}{c_{s}^{2}},
$$

where $v$ is the maximum speed of the fluid and $c_{s}$ is the speed of sound. Thus, to keep the pressure fluctuations in the magnitude of $1 \%$, the selected speed of sound has to be greater than 10 times the maximum speed of the 
fluid. Approximating the fluid as a quasi-incompressible is one of the main techniques employed [43]. Solenthaler [44] presented two other techniques, the incompressible SPH and the predictive corrective incompressible SPH.

\subsection{4}

Density

The approximation of the density of particle $i$ can be computed directly using the standard density summation [44],

$$
\rho_{i}=\sum_{j \in V_{i}} m_{j} W_{i j}
$$

As density is calculated before other parameters, extra computation cicle is required [43].

Alternatively, the density can be computed from the continuity formulation [44]. With this formulation, particle densities are initially set and evolved during the simulation by computing the rate of change of the density of each particle $i$ by means of

$$
\frac{d \rho_{i}}{d t}=\sum_{j i}\left(v_{i}-v_{j}\right) \cdot \nabla m_{i j} W_{i j} .
$$

The density of particle $i$ can be obtained with the time integration of Eq. 3-15 [43].

\subsection{5}

\section{Boundaries}

Most problems related to liquids also involve boundaries which may be fixed or moving or they might represent the surfaces of rigid bodies, wholly or partially, within the fluid [48]. The SPH method requires the evaluation of integrals of the type Eq. 3-2, defined over a region of radius $2 h$. When such a evaluation is performed for a particle at a distance less than $2 h$ from the boundary this requires careful enforcement of boundary conditions [50].

One of the methods proposed in the literature for the enforcement of the no penetration velocity boundary condition consists of modelling the boundary with so-called boundary particles that exert a repulsive force on the $\mathrm{SPH}$ particles in order to prevent penetration of the boundary by the fluid [50]. This procedure is exemplified by Monaghan [48].

Another method used consists of extending the domain, adding particles outside of the boundaries, the so-called ghost particles [43]. In this case the evaluation of integrals is similar to those within the domain, but the ghost particles are not allowed to move or have prescribed movement. Properties 
and location of these particles have to be correctly defined in order to ensure SPH approximation close to boundaries.

\subsection{6}

\section{SPH Algorithm}

The SPH algorithm starts by finding the neighboring particles, that usually can be performed through scanning of particles in a defined region around the reference particle or using optimized adaptive methods [43].

After having determined the neighbors of each particle, pressure can be computed using equation 3-12 and density using Eq. 3-15.

The acceleration of particle $i$ is calculated using Newton's second law, where forces acting on particle $i$ (pressure, viscous and body forces) are determined using SPH approximation

$$
\frac{D \boldsymbol{v}_{i}}{D t}=-\sum_{j \in V_{i}} m_{j}\left(\frac{p_{i}}{\rho_{i}^{2}}+\frac{p_{j}}{\rho_{j}^{2}}\right) \nabla_{i} W_{i j}+\frac{2 \mu}{\rho_{i}} \sum_{j \in V_{i}} \frac{m_{j}}{\rho_{j}} \boldsymbol{v}_{i j} \frac{\boldsymbol{x}_{i j} \cdot \nabla_{i} W_{i j}}{r_{i j}^{2}}+\boldsymbol{g} .
$$

Then, the accelerations are used to integrate the velocities and positions forward in time, and the new particle positions are checked for collisions with the domain boundary. The time integration can be performed using explicit methods such as Euler or Leap-Frog [43]. The time step size can be determined by the CFL condition, detailed by Paiva et al.[43], that ensures that an information which propagates with velocity $v$ does not leave out some grid points in a grid with cell size $\Delta x$, giving the condition $\frac{v \Delta t}{\Delta x} \leq 1$ [44].

Algorithm 1 shows the basic steps of the SPH method, adapted from [43]. 


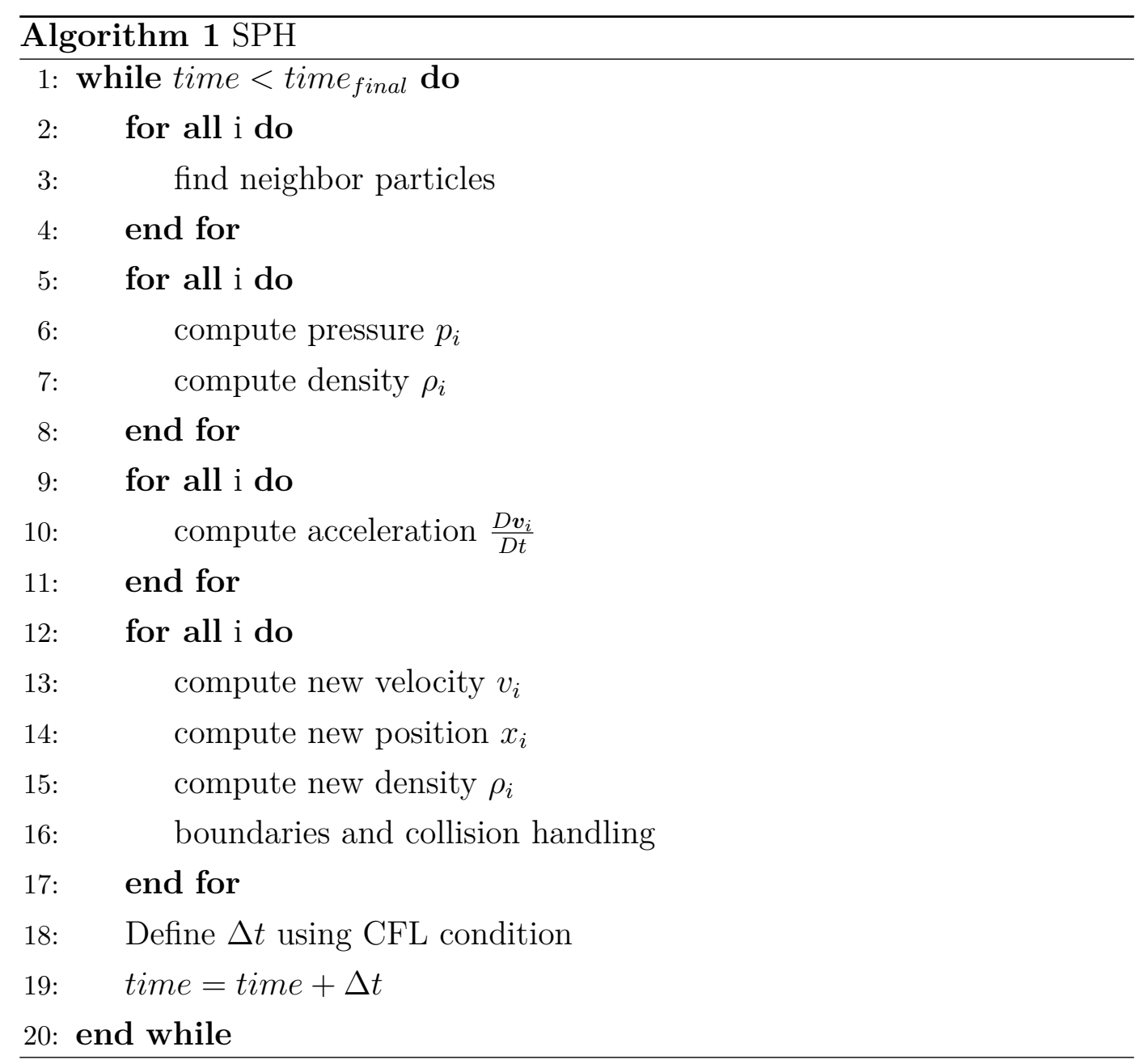

\section{2}

\section{DualSPHysics Implementation}

DualSPHysics is a hardware accelerated Smoothed Particle Hydrodynamics code developed to solve free surface flow problems [40]. The code DualSPHysics has been developed by starting from the FORTRAN SPH formulation implemented in SPHysics, an open-source SPH model developed by researchers at the Johns Hopkins University (US), the University of Vigo (Spain), the University of Manchester (UK) and the University of Rome, La Sapienza [40].

DualSPHysics is an open-source code developed and redistributed under the terms of the GNU General Public License as published by the Free Software Foundation. The code is implemented in $\mathrm{C}++$ and CUDA [40] and is designed to launch simulations either on multiple CPUs using OpenMP or on a GPU. The validation of DualSPHysics on GPUs include applications to compute forces exerted by large waves on the urban furniture of a realistic promenade, to study the run-up on a real armour block coastal breakwater and to simulate large waves generated by land slide events [40]. 
The choice of two smoothing kernels is available in DualSPHysics, the cubic spline Eq. 3-7 and the quintic (or Wendland) Eq. 3-7.

The DualSPHysics offers two options to compute the dissipative term $\boldsymbol{\Gamma}$ that appears in the momentum conservation equation

$$
\frac{d \boldsymbol{v}}{d t}=-\frac{1}{\rho} \nabla P+\boldsymbol{g}+\boldsymbol{\Gamma},
$$

artificial viscosity [46] and the combination of laminar viscosity with SubParticle Scale turbulence [40].

The fluid in DualSPHysics is treated as weakly compressible, and the equation of state Eq. 3-12 is applied. The continuity equation

$$
\frac{d \rho_{a}}{d t}=\sum_{b} m_{b} \boldsymbol{v}_{a b} \cdot \nabla_{a} W_{a b}
$$

may be modified to introduce a diffusive term to reduce density fluctuations, i.e.

$$
\frac{d \rho_{a}}{d t}=\sum_{b} m_{b} \boldsymbol{v}_{a b} \cdot \nabla_{a} W_{a b}+2 \delta h \sum_{b} m_{b} \overline{c_{a b}} \times\left(\frac{\rho_{a}}{\rho_{b}}\right) \frac{1}{\boldsymbol{r}_{a b}^{2}+\eta^{2}} \nabla_{a} W_{a b},
$$

where $\overline{c_{a b}}=0.5\left(c_{a}+c_{b}\right), \eta^{2}=0.01 h^{2}$ and $\delta$ is the delta-SPH coefficient [40]. This technique is designed to filter relatively large wave numbers from the density field while solving for the mass conservation of each particle, therefore reducing noise throughout the system of particles. In order to correct the density field, the Shepard filter may be applied every $M$ time steps [40], according to

$$
\rho_{a}^{\text {new }}=\sum_{b} m_{b} \tilde{W}_{a} b
$$

where the kernel has been corrected using zeroth-order correction, i.e.

$$
\tilde{W}_{a} b=\frac{W_{a b}}{\sum_{b} W_{a b} \frac{m_{b}}{\rho_{b}}} .
$$

DualSPHysics includes two numerical integration schemes, Verlet scheme and Symplectic scheme [40], associated with variable time steps, dependent on the CFL condition.

In DualSPHysics, the boundary is described by a set of particles that are considered as a separate set from the fluid particles. The Dynamic Boundary Condition (DBC) is the default method provided by DualSPHysics [40]. This method sees boundary particles that satisfy the same equations as fluid particles, however they do not move according to the forces acting on them. Instead, they remain either fixed in position or move according to an imposed/prescribed motion function (i.e. moving objects such as gates or wave-makers). When a fluid particle approaches a boundary and the distance 
between its particles and the fluid particle becomes smaller than twice the smoothing length $h$, the density of the affected boundary particles increases, which results in a pressure increase. This results in a repulsive force being exerted on the fluid particle due to the pressure term in the momentum equation.

The DualSPHysics workflow consists on three steps: (i) Pre-processing, (ii) Processing and (iii) Post-Processing, as illustrated in Figure 3.3.

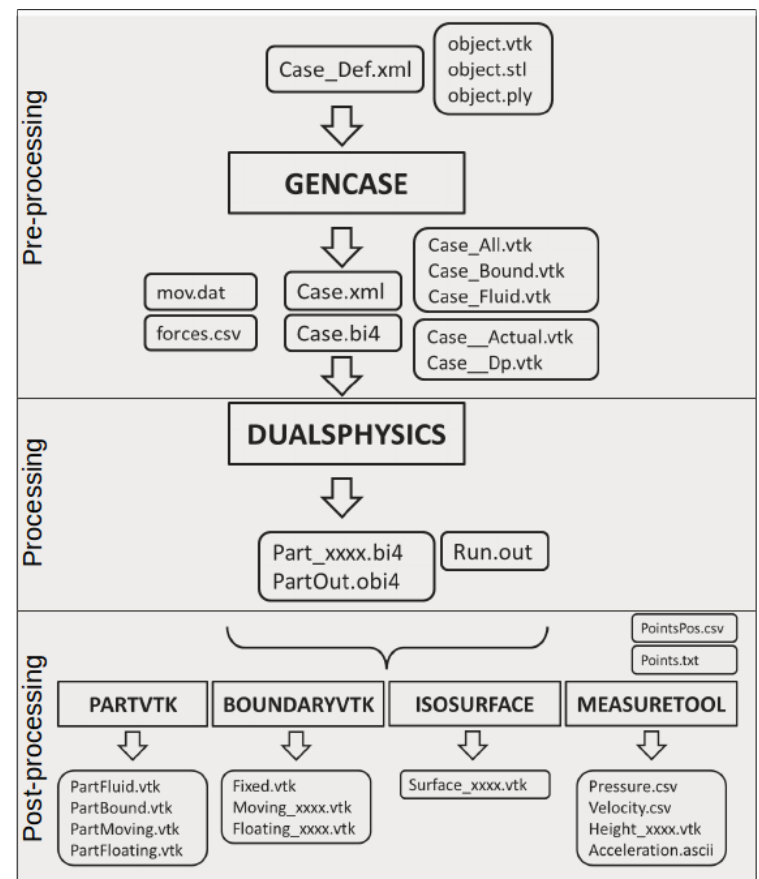

Figure 3.3: Workflow of DualSPHysics. (Adapted from [51]).

The pre-processing step is made by the GenCase program, that reads the case definition file and generates support files to configure the simulation. In DualSPHysics cases are defined in $x m l$ files, where domains, geometries, motions and all other parameters for simulation are listed. If required, external files with geometries may be imported and processed by the GenCase program. An example of $x m l$ is presented in Appendix B.

The DualSPHysics program processes the support files generated by GenCase and run the SPH algorithm. The output is a set of binary files with particle information at different instants of the simulation.

The particles information may be visualized and/or analysed using the PartVTK program, which generates output files in .vtk, .csv and ASCII formats. The variables to be included in these files are configurable. Postprocessing programs for analysis of boundaries particles, surface representation, analysis of numerical measurements, computing on boundaries and analysis of floating objects forces are available [51]. 
For each case a script file was developed to run pre-processing, processing and post-processing programs and an example of the script file (bash file) is presented in Appendix C.

The simulations developed in this work are summarized in Appendix D. The simulations were performed with DualSPHysics version 4.0 (released in April 2016), running on a single GeForce GTX 750 Ti 2GB GPU, supported by AMD A10-7850K Radeon R7 CPU with 8GB RAM memory. The linux version of the code was used on Ubuntu 14.04LTS. 


\section{4}

\section{Water Entry into Calm Surface}

Water entry into calm water is a common subject of theory and experimental developments. In this chapter the method and the implementation described in Chapter 3 are employed to reproduce basic experiments. Initially three cases of free fall of rigid bodies on the water calm surface are studied and compared with results from the technical literature.

The second section is dedicated to the interesting case of a constant velocity water entry of a wedge, where a downward velocity is imposed and forces during water entry are computed. This is complemented by a convergence study.

\section{1}

\section{Free Fall of Rigid Bodies}

The free fall of rigid bodies on water surface process is widely studied and the literature is rich in experimental, algebric and numerical developments. In this work the free fall of a cylinder and a wedge is reproduced using SPH.

In all cases the body is considered as rigid and released from rest above the water surface. The air domain is considered as void and the body is accelerated by gravity force.

\subsection{1}

\section{Cylinder}

Greenhow et al. [52] conducted two-dimensional tests of free fall of halfbuoyant and neutrally buoyant cylinders into calm water, where the position of the cylinder was recorded at different instants. These experiments were reproduced by Zhu [34] using CIP method and by Vandamme et al. [35] using SPH method.

In the experiment a half-buoyant cylinder (density $=500 \mathrm{~kg} / \mathrm{m}^{3}$ ) was released half meter above the water surface and the submergence of the lowest point of this cylinder was recorded [52]. The main experiment parameters are presented in Table 4.1 
Table 4.1: Half buoyant cylinder experiment parameters.

\begin{tabular}{cc}
\hline Parameter & Value \\
\hline Cylinder Radius & $0.055 \mathrm{~m}$ \\
Density & $500 \mathrm{~kg} / \mathrm{m}^{3}$ \\
Free fall height & $0.5 \mathrm{~m}$ \\
Fluid Density & $1,000 \mathrm{~kg} / \mathrm{m}^{3}$ \\
\hline
\end{tabular}

Results from SPH method (Case A1) employed in this work are illustrated in Figure 4.1 together with experiment [52] and CIP method [34]. In this experiment $t=0 s$ is the time when the lowest point of the cylinder touches the water surface.

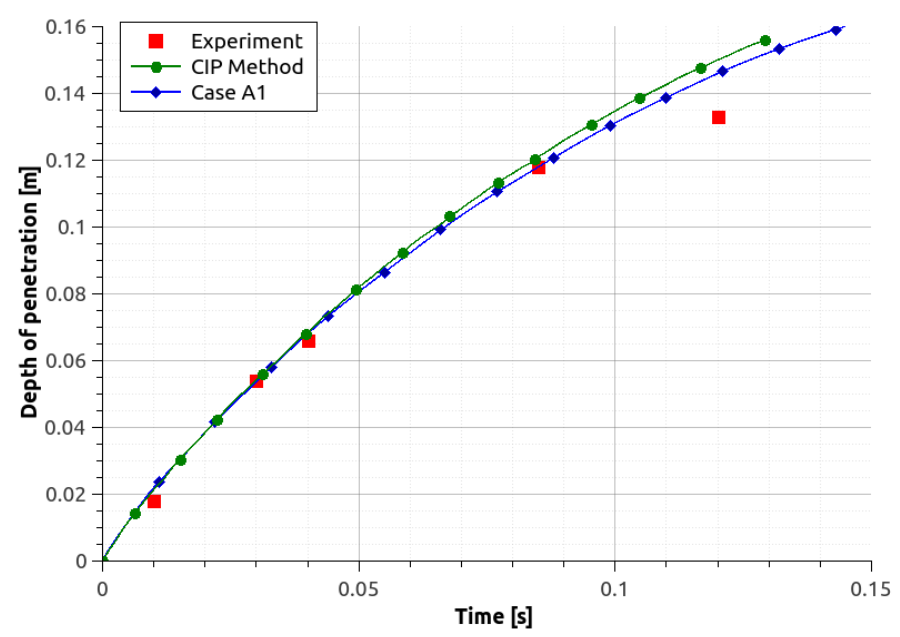

Figure 4.1: Time versus depth of penetration for a half-buoyant cylinder.

The results obtained here demonstrate adherence to both experimental data and CIP method results. The free surface deformation is comparable to both experiment and simulation, as shown in Figure 4.2. 

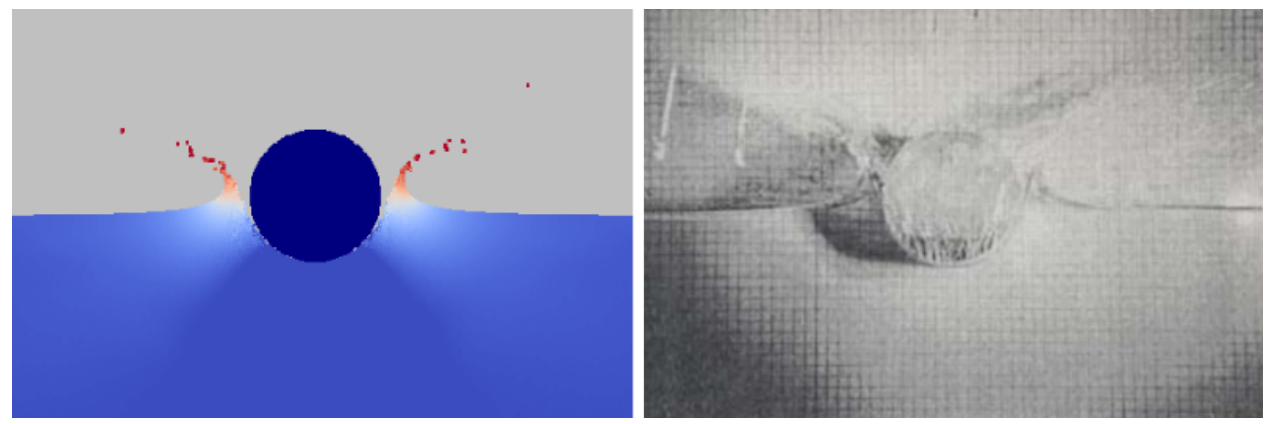

Figure 4.2: Free surface deformation at time $t=0.33 \mathrm{~s}$ after cylinder released from rest. eft figure shows the results of this work and right figure the shows a picture taken during experiment at same instant [52].

Similar experiment (Case A2) was conducted with neutrally-buoyant (density $=1,000 \mathrm{~kg} / \mathrm{m}^{3}$ ) cylinder [52] and main experiment parameters are given in Table 4.2

Table 4.2: Neutrally-buoyant cylinder experiment parameters.

\begin{tabular}{cc}
\hline Parameter & Value \\
\hline Cylinder Radius & $0.055 \mathrm{~m}$ \\
Density & $1,000 \mathrm{~kg} / \mathrm{m}^{3}$ \\
Free fall height & $0.5 \mathrm{~m}$ \\
Fluid Density & $1,000 \mathrm{~kg} / \mathrm{m}^{3}$ \\
\hline
\end{tabular}

Figure 4.3 shows the results of experiment and simulations. At $t=0 \mathrm{~s}$ the lowest point of the cylinder touches the water surface and at depth $0.3 \mathrm{~m}$ this point reaches the bottom of the water domain.

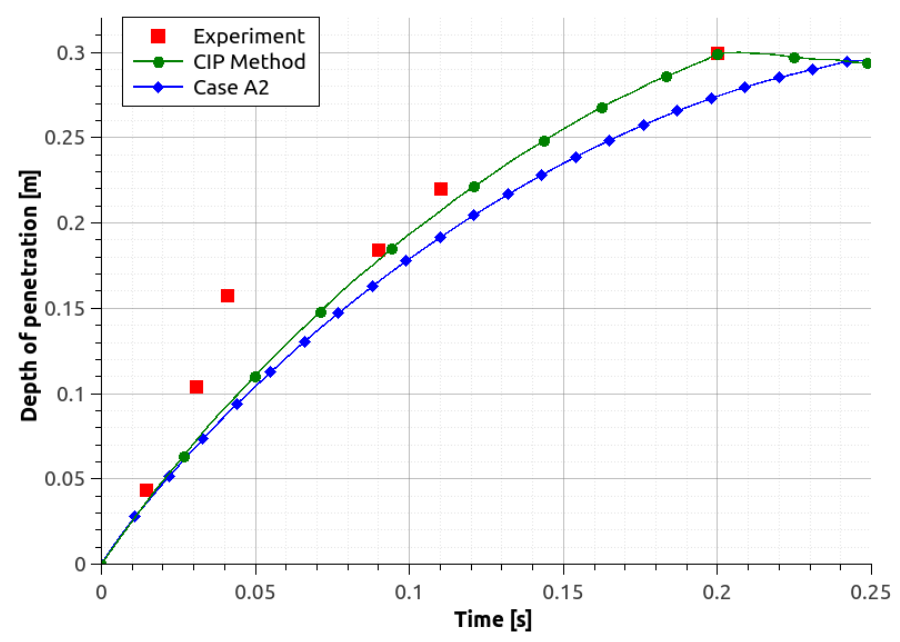

Figure 4.3: Time versus depth of penetration for a neutrally-buoyant cylinder. 
The discrepancy in results observed with the increase of the depth of penetration may be cause by the viscosity effects. Vandamme et al. [35] reproduced this simulation using SPH and results adherent to experiment and CIP method were obtained.

The free surface deformation at instant $t=0.315 \mathrm{~s}$ is shown in Figure 4.4
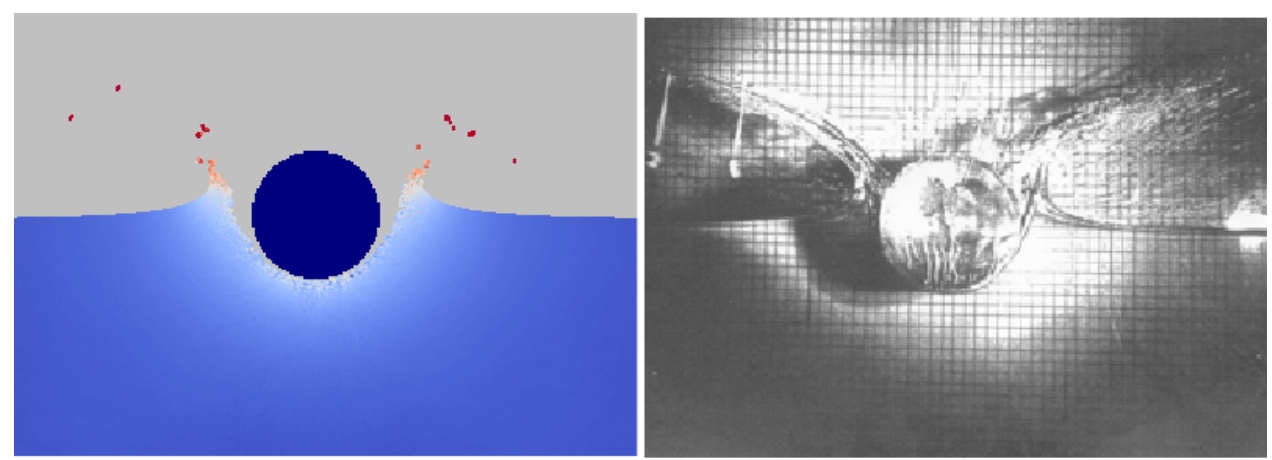

Figure 4.4: Free surface deformation at time $t=0.315 \mathrm{~s}$ after cylinder released from rest. Left figure shows the results of this work and right figure the shows a picture taken during experiment at same instant [52].

\subsection{2 Wedge}

Wedge shaped and bow-flare ship sections were used in free fall tests conducted by Aarsnes [53]. The geometry used in the wedge shaped test setup is shown in Figure 4.5. and the main test data are given in Table 4.3.

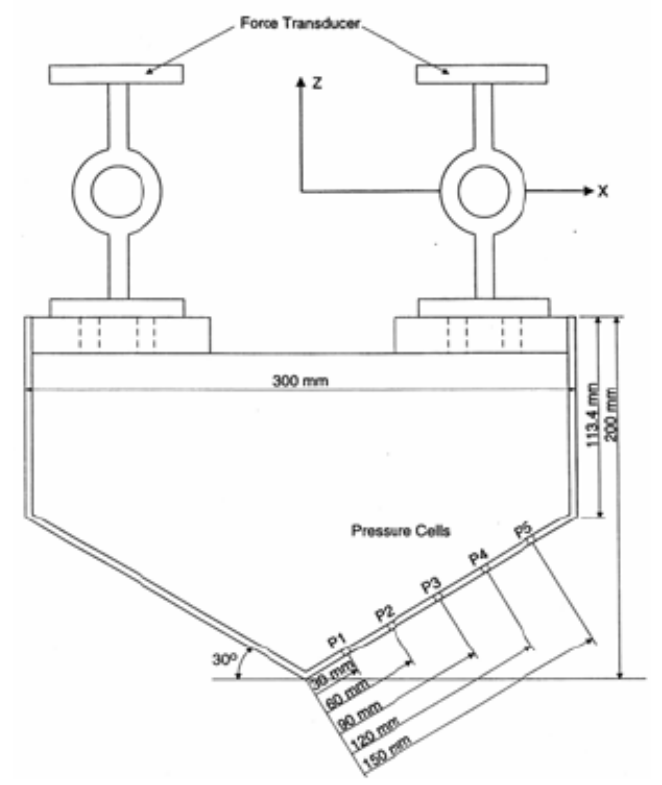

Figure 4.5: Wedge shaped test set-up [53]. 
Different tests were performed using this test set-up, however the free fall from $0.5 \mathrm{~m}$ above the water level case is reproduced (Case B) in this work and results are compared with those obtained by Zhu [34] using CIP method. Main test data are given in Table 4.3

Table 4.3: Wedge experiment parameters.

\begin{tabular}{cc}
\hline Parameter & Value \\
\hline Breadth & $0.3 \mathrm{~m}$ \\
Length & $0.1 \mathrm{~m}$ \\
Free fall height & $0.5 \mathrm{~m}$ \\
Weight & $288.0 \mathrm{~kg}$ \\
Fluid Density & $1,000 \mathrm{~kg} / \mathrm{m}^{3}$ \\
\hline
\end{tabular}

The results for the velocity behaviour are illustrated in Figure 4.6 and it is important to note that, although the landing velocity is similar for both $\mathrm{SPH}$ and CIP, the peak velocity is smaller in the SPH method.

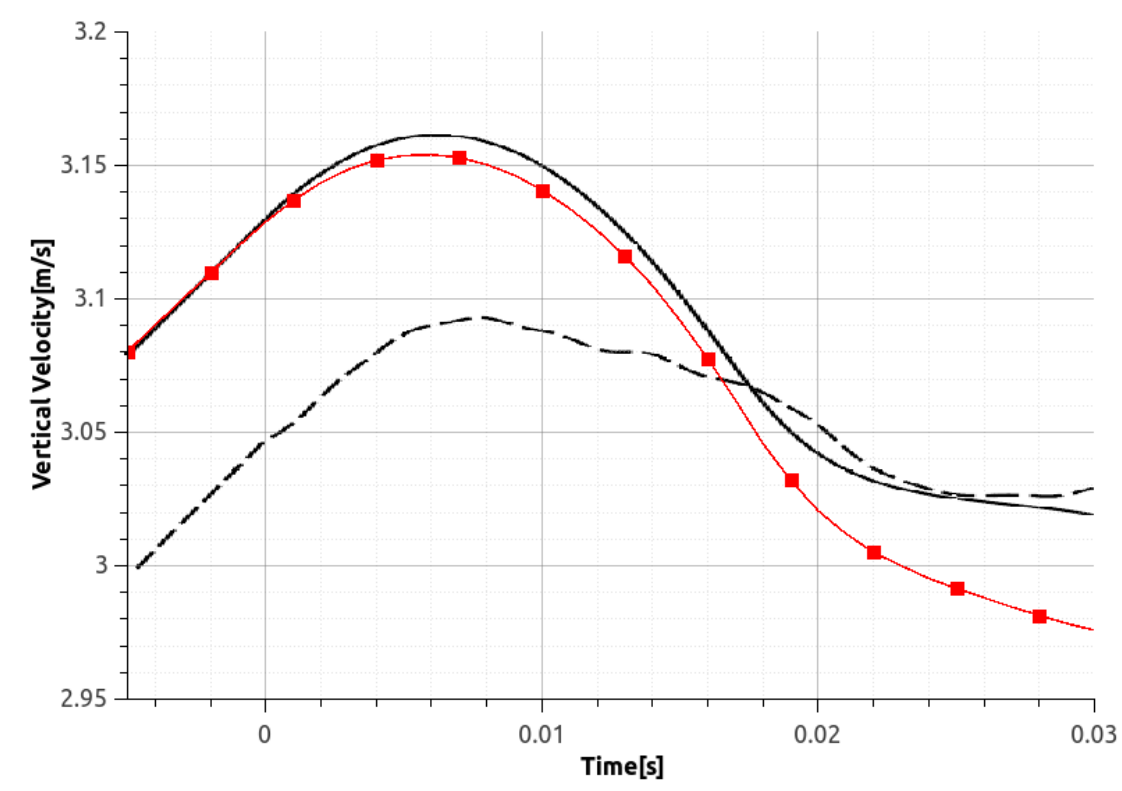

Figure 4.6: Vertical velocity (positive downward). Red line with square markers: SPH method; Black solid line: CIP method [34]; Dashed line: Experiment [53].

The difference in peak velocities implies into higher deceleration, as shown in Figure 4.7. Acceleration presented for SPH method were obtained by means of time differentiation of the velocity data. 


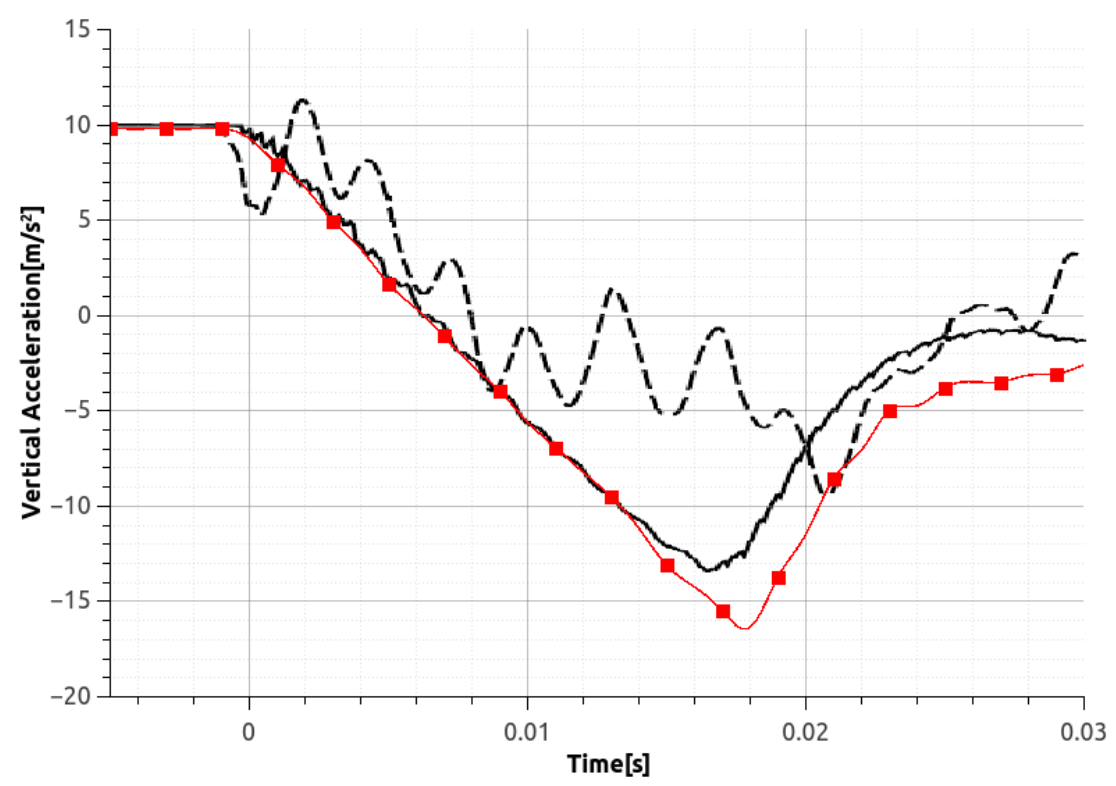

Figure 4.7: Vertical acceleration (positive downward). Red line with square markers: SPH method; Black solid line: CIP method [34]; Dashed line: Experiment [53].

Using Newton's second law the hydrodynamic force acting on the wedge during water entry can by calculated. The results obtained here, presented in Figure 4.8, are adherent to CIP method. The results differ from experiment as the wedge velocity at the time of first contact are not the same, as noted in Figure 4.6. 


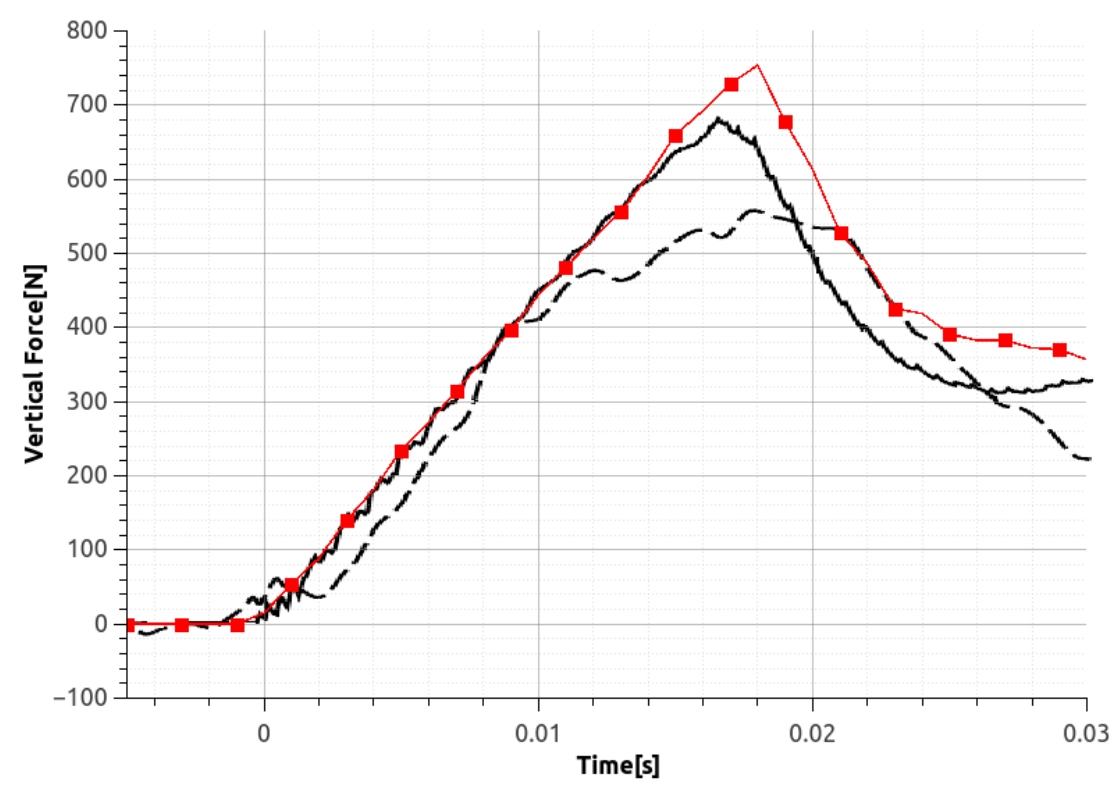

Figure 4.8: Vertical hydrodynamic force (positive upward). Red line with square markers: SPH method; Black solid line: CIP method [34]; Dashed line: Experiment [53].

\section{2}

\section{Constant Velocity Water Entry}

The constant velocity water entry of wedge-shaped sections is important as an aid to understanding two main phenomena: slamming and planing [54]. Tveitnes [55] showed, in his Thesis, a series of experiments with wedges entering the water with constant velocity. The test rig was equipped with drive system to impose downward velocity to the model, as represented in Figure 4.9, and force was recorded using load sensors at the model carrier.

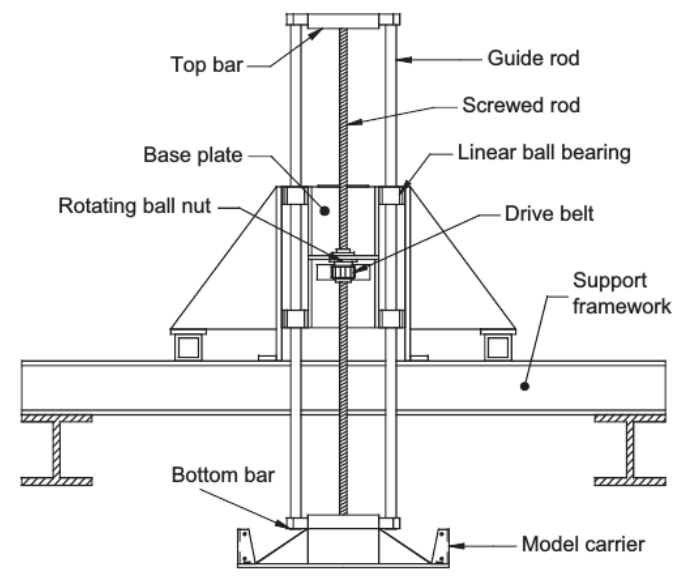

Figure 4.9: Test rig for the constant velocity water entry experiment [54]. 
A water entry test program was established following the velocities and deadrise angles as per Table 4.4.

Table 4.4: Constant velocity water entry test program [54].

\begin{tabular}{lccccc}
\hline & \multicolumn{5}{c}{ Deadrise Angle } \\
& $5^{\circ}$ & $10^{\circ}$ & $15^{\circ}$ & $30^{\circ}$ & $45^{\circ}$ \\
\hline Velocity $(\mathrm{m} / \mathrm{s})$ & 0.24 & 0.48 & 0.48 & & \\
Velocity $(\mathrm{m} / \mathrm{s})$ & 0.48 & 0.72 & 0.72 & 0.72 & \\
Velocity $(\mathrm{m} / \mathrm{s})$ & $\mathbf{0 . 9 4}$ & $\mathbf{0 . 9 4}$ & $\mathbf{0 . 9 4}$ & 0.94 & 1.19 \\
\hline
\end{tabular}

From the results presented in [55] the peak of water entry force is clear noticed in experiments with higher velocities and smaller deadrise angles, therefore those experiments were subject of study in this work and the results corresponding to cases highlighted in bold in Table 4.4 are presented in Figures 4.10, 4.11 and 4.12. Results demonstrate adherence to experimental data for peak load. After the peak, buoyancy force and wall effect start to play considerable role and differences between density of the body in this work and in the experiment, as well as differences in water domain dimensions may explain the discrepancy in results.

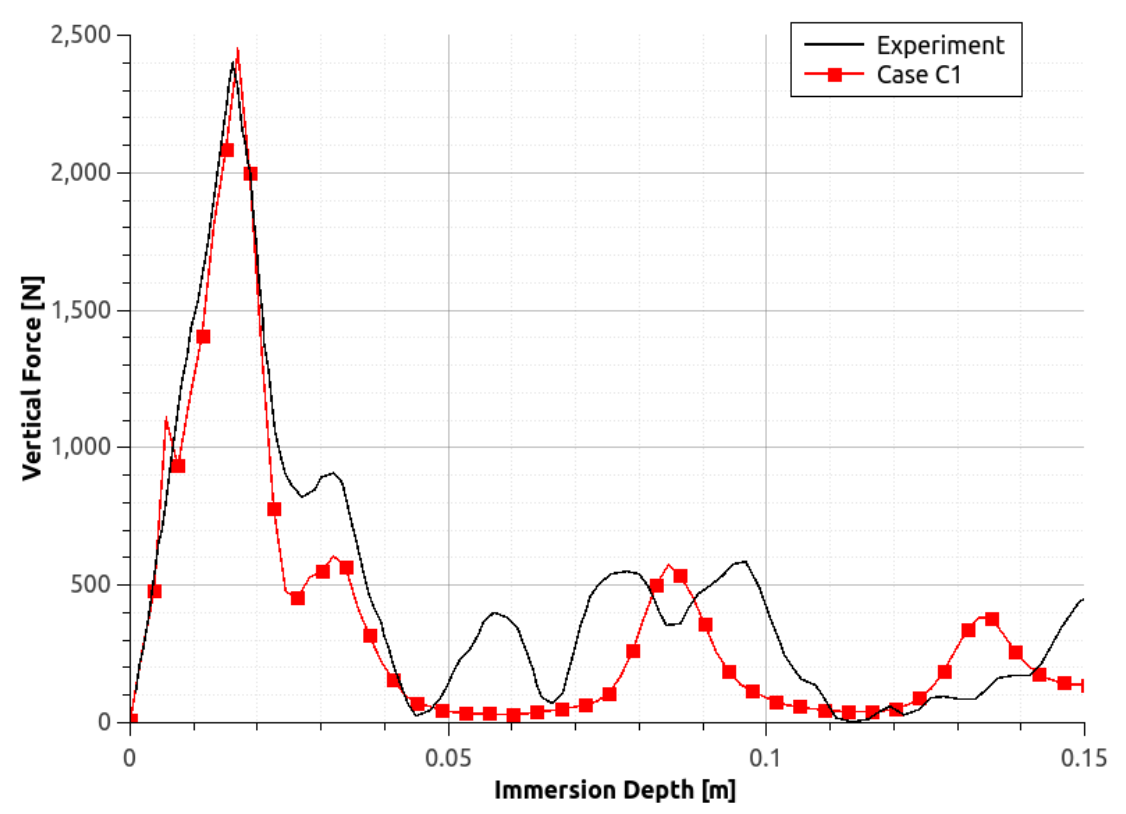

Figure 4.10: Slamming load on $5^{\circ}$ wedge at $0.94 \mathrm{~m} / \mathrm{s}$. 


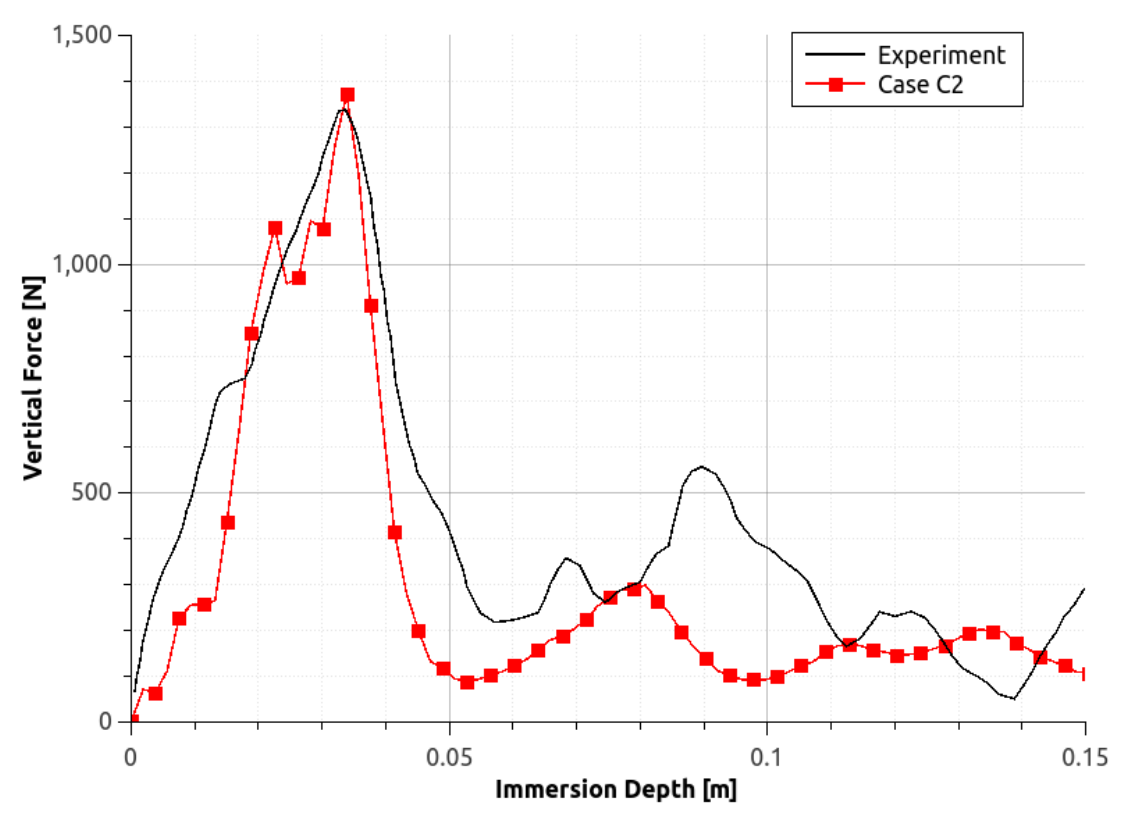

Figure 4.11: Slamming load on $10^{\circ}$ wedge at $0.94 \mathrm{~m} / \mathrm{s}$.

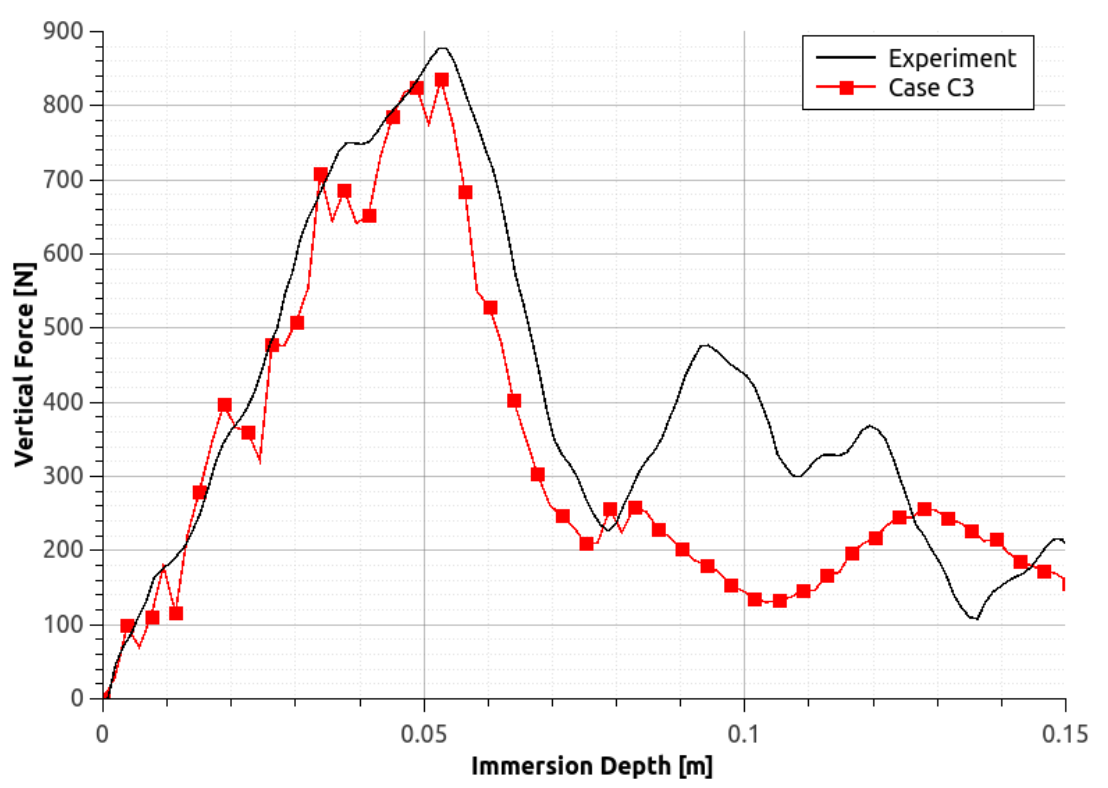

Figure 4.12: Slamming load on $15^{\circ}$ wedge at $0.94 \mathrm{~m} / \mathrm{s}$.

Three simulation variables are studied in the sequence using the $5^{\circ}$ wedge at $0.94 \mathrm{~m} / \mathrm{s}$, Figure 4.10, as the reference.

The results obtained with SPH method are heavily dependent on the density of particles, or the distance between particles $(d p)$. Figure 4.13 shows results for a series of $d p$. 

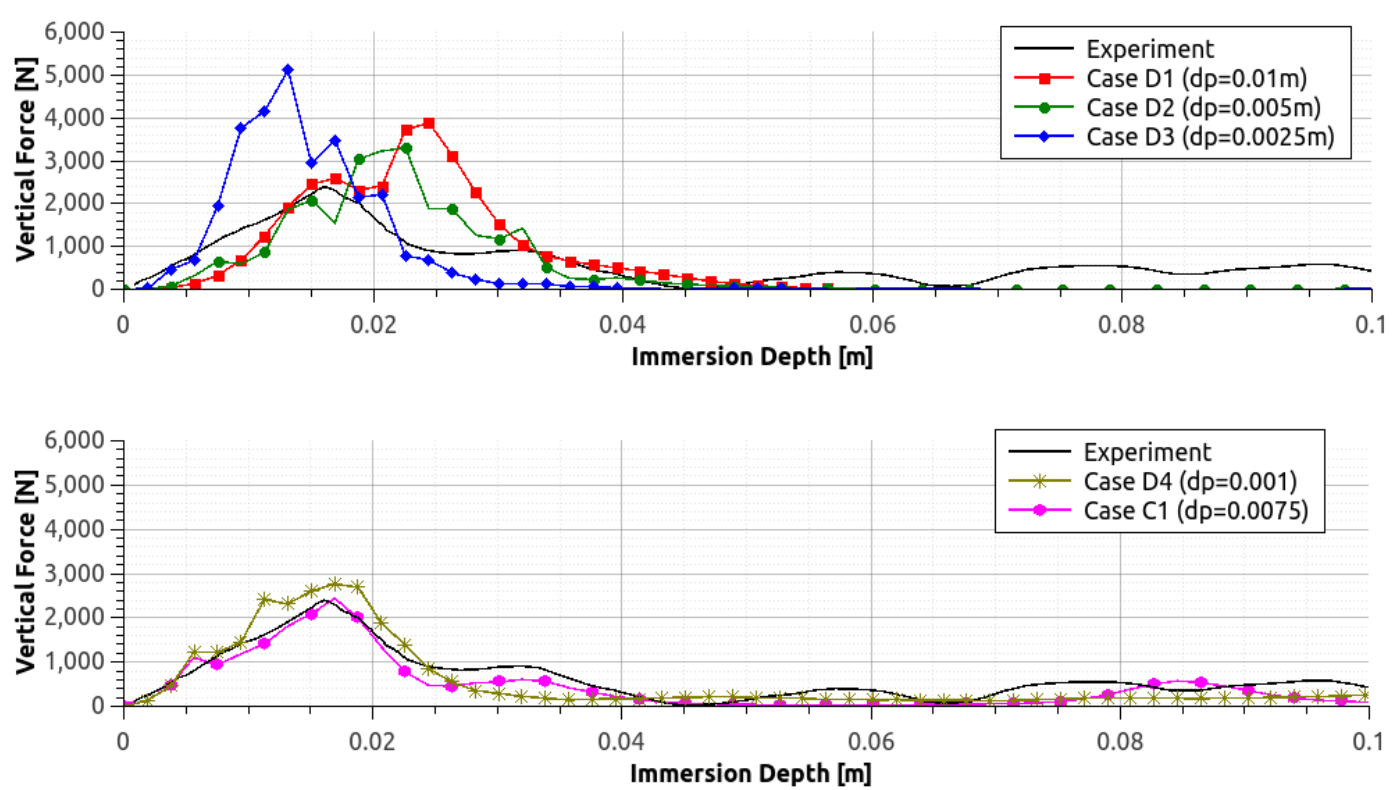

Figure 4.13: Effect of distance between particle $\left(5^{\circ}\right.$ wedge at $\left.0.94 \mathrm{~m} / \mathrm{s}\right)$.

Results from case D3 $(d p=0.0025 \mathrm{~m})$ differ from the tendency towards experiment data and two additional cases with similar $d p$ are presented in Figure 4.14: case D5 $(d p=0.0020 \mathrm{~m})$ and D6 $(d p=0.0030 \mathrm{~m})$. These two additional cases confirm the singularity around the $(d p=0.0025 \mathrm{~m})$.

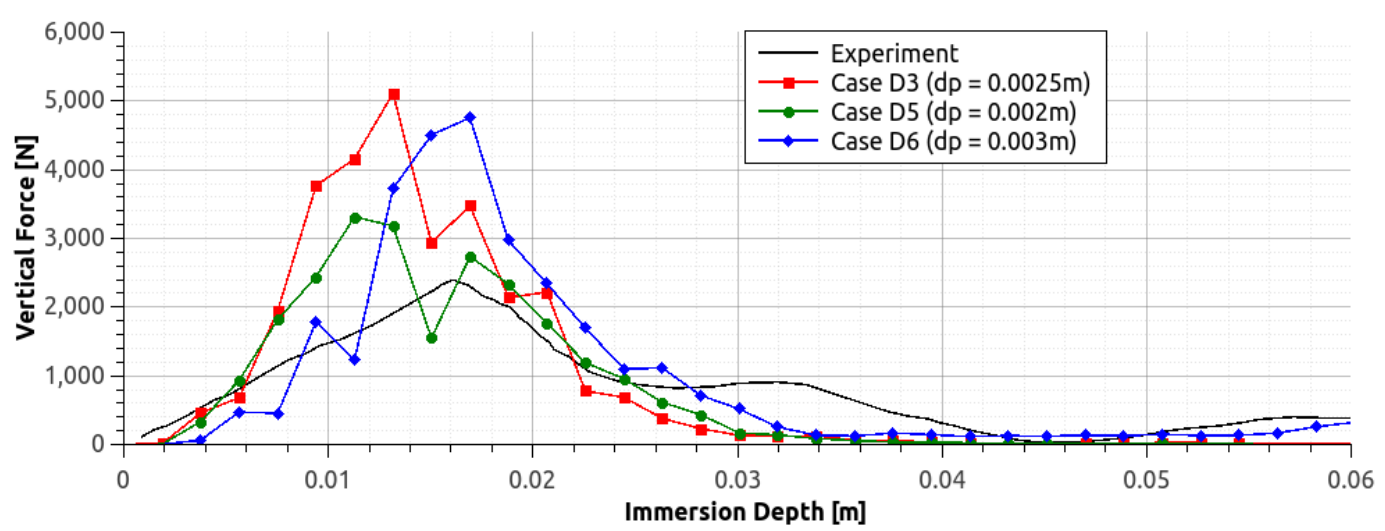

Figure 4.14: Effect of distance between particles around Case D3.

The DualSPHysics implementation allows the use of two different kernels, Cubic and Wendland, as described in Section 3.2 and the impact of kernel choice is illustrated in Figure 4.15. 

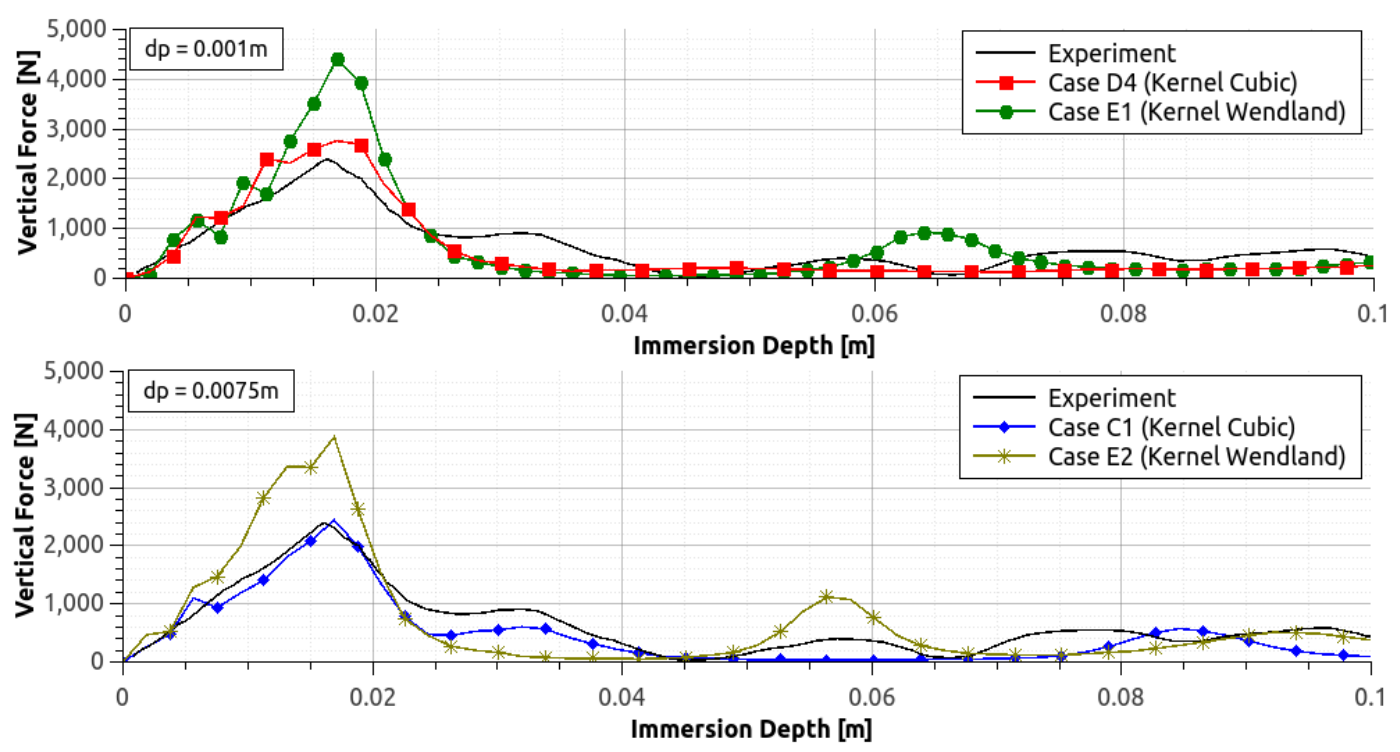

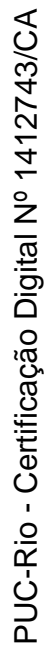

Figure 4.15: Effect of kernel function ( $5^{\circ}$ wedge at $\left.0.94 \mathrm{~m} / \mathrm{s}\right)$.

Another parameter that influences the results in $\mathrm{SPH}$ simulations is the smoothing length $(h)$. In DualSPHysics the smoothing length is calculated using a coefficient coef $h$, where $h=\operatorname{coe} f h \sqrt{2 d p^{2}}$ for 2D cases. The influence of the smoothing length is presented in Figure 4.16, where the distance between neighbouring particles is constant for all cases, i.e. $d p=0.0025 \mathrm{~m}$.
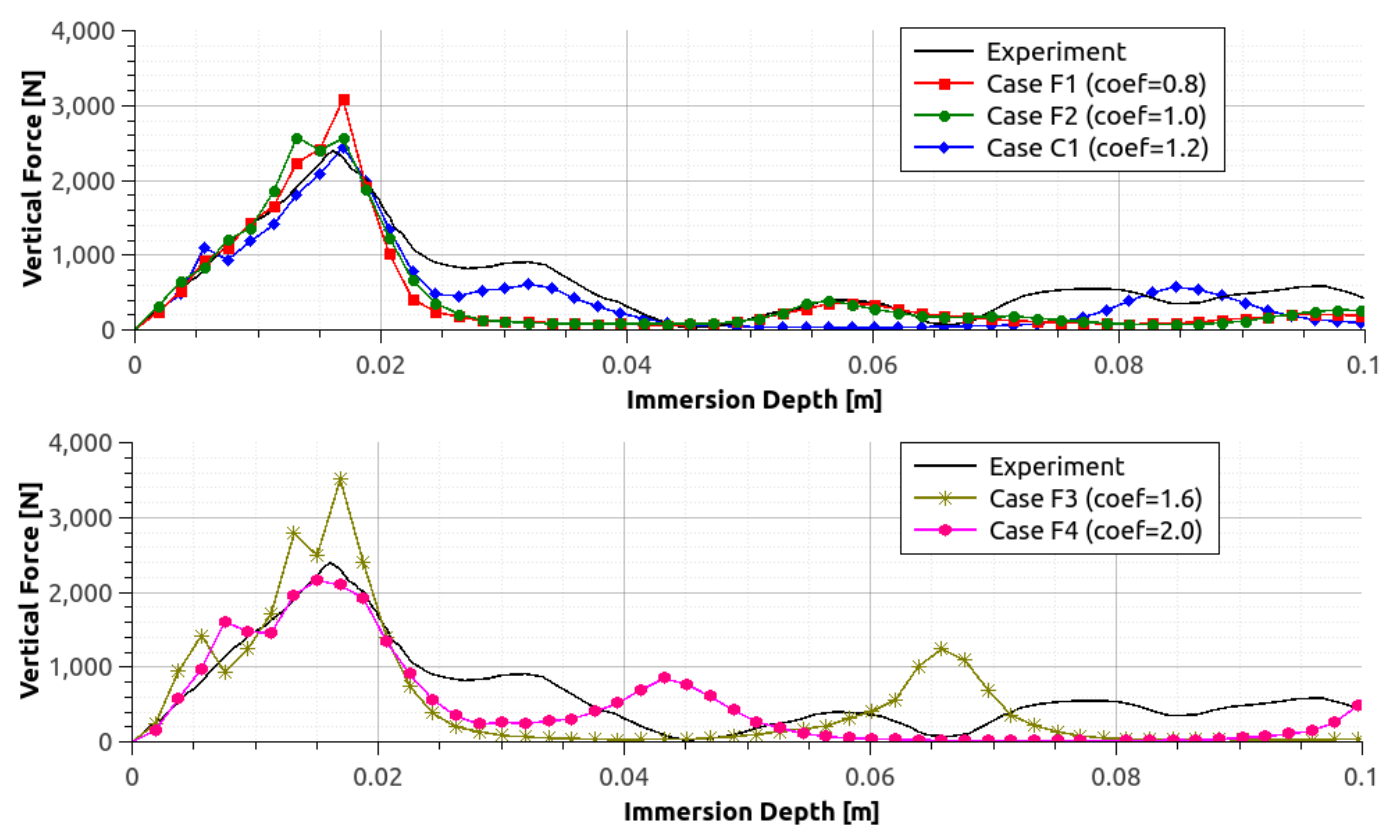

Figure 4.16: Effect of smoothing length $\left(5^{\circ}\right.$ wedge at $\left.0.94 \mathrm{~m} / \mathrm{s}\right)$. 


\section{5}

\section{Water Entry into Wavy Surface}

In offshore operations the sea surface is normally not flat and, when lowering a subsea structure through the wave zone, the bottom face of the body touches the water gradually, as illustrated in Figure 5.1. Due to the effect of wave velocities, each part of the equipment ingresses in water with different relative velocities.
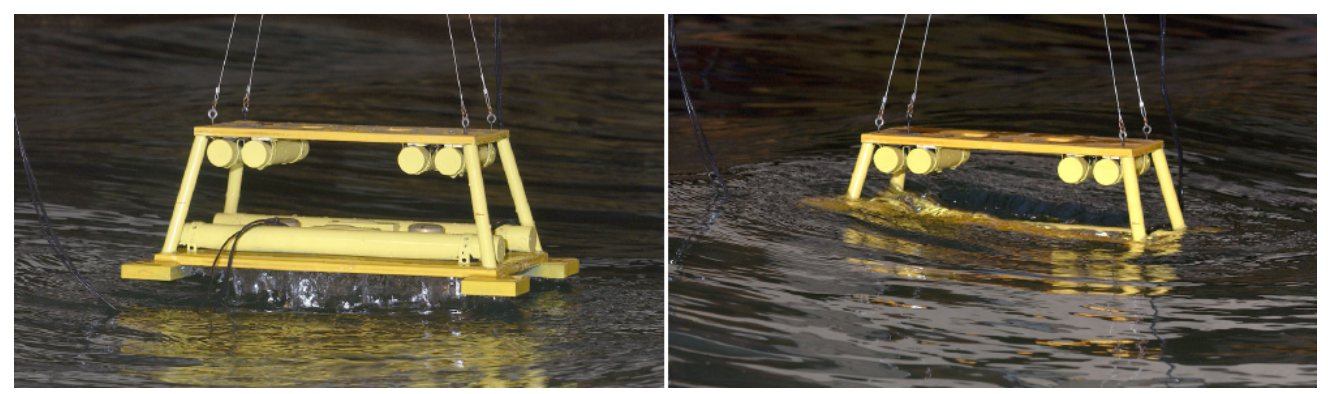

Figure 5.1: Model of Subsea Structure in two different phases of lowering through the wave zone [56].

In this chapter the one degree of freedom constant velocity water entry into wavy surface is simulated considering deep water regular waves theory. The problem is set as: the water domain is defined as a flat bottom 2D tank where in one side a paddle generates waves that are dissipated in a 1:3 beach on the other side, as illustrated in Figure 5.2. A constant downward velocity is imposed to the body until it is fully submerged. The only degree of freedom of this body is the vertical movement and the vertical component of the hydrodynamic force is computed. The depth of the tank is defined in order to comply with deep water waves theory.

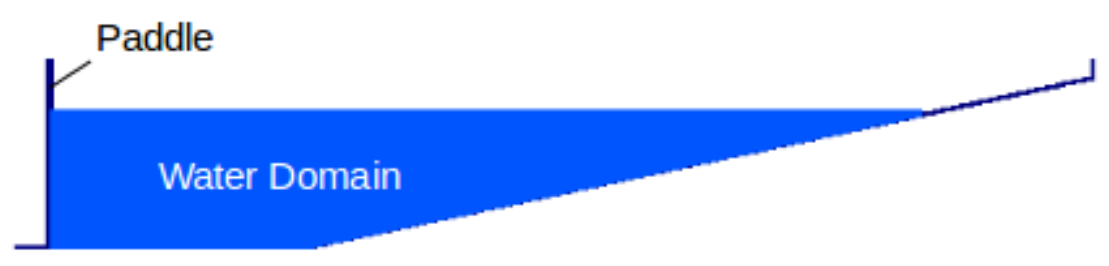

Figure 5.2: Model of the tank used in simulations with wave. 


\section{1}

\section{Wedge on Waves}

The experiment reproduced in Section 4.2 is simulated here in two different cases. In the first case, the wedge enters into water at a moment where particles subjected to wave have upward vertical velocities, Figure 5.3, and in the second case the wedge enters in a different moment, when particles subjected to wave have downward vertical velocities, according to Figure 5.4.

The wave steepness $H / \lambda$ ( $H$ is the wave height and $\lambda$ is the wave length) used in the simulation is 0.05 and the ratio between the wedge breadth $(b)$ and wave length $(\lambda)$ is 0.2 . The downward velocity of the wedge is set as $0.2 \mathrm{~m} / \mathrm{s}$, in the same order of magnitude as the wave vertical velocities.

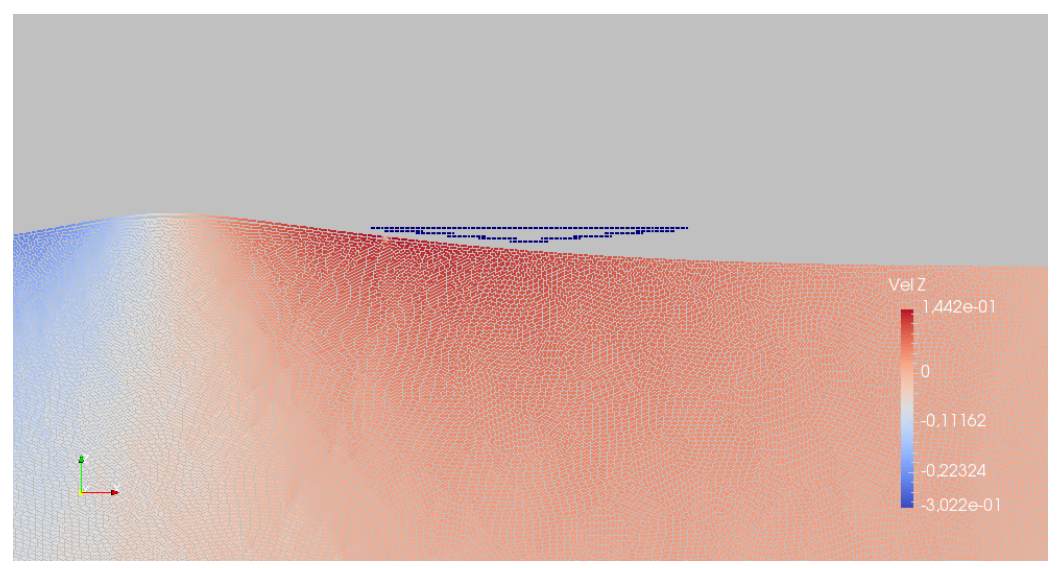

Figure 5.3: $5^{\circ}$ wedge before entering into water before the wave crest.

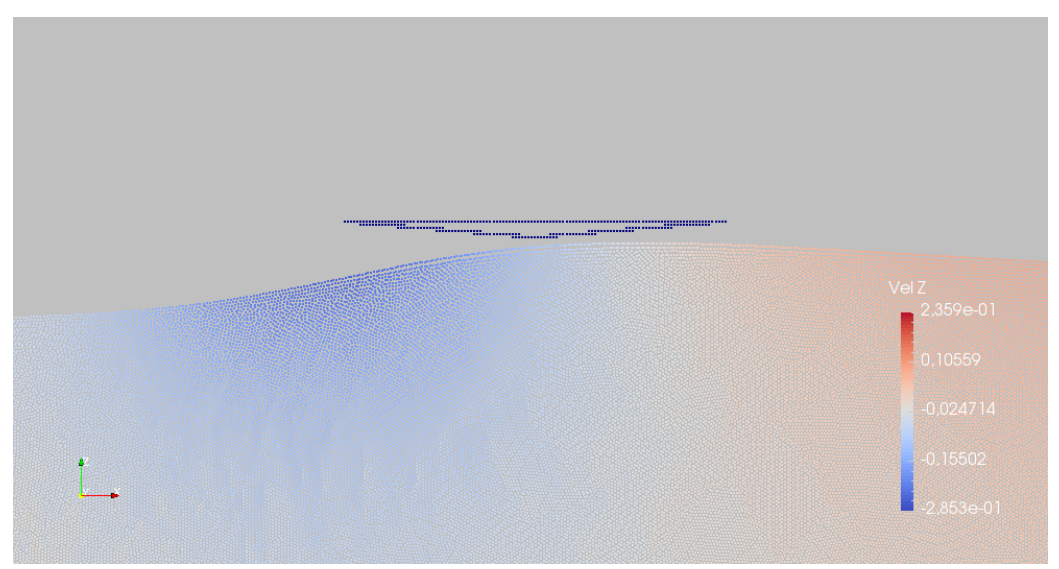

Figure 5.4: $5^{\circ}$ wedge before entering into water after the wave crest.

The vertical hydrodynamic force applied on the wedge depends on the moment the wedge reaches the water surface, as shown in Figure 5.5, where the immersion depth is related to calm water level. 


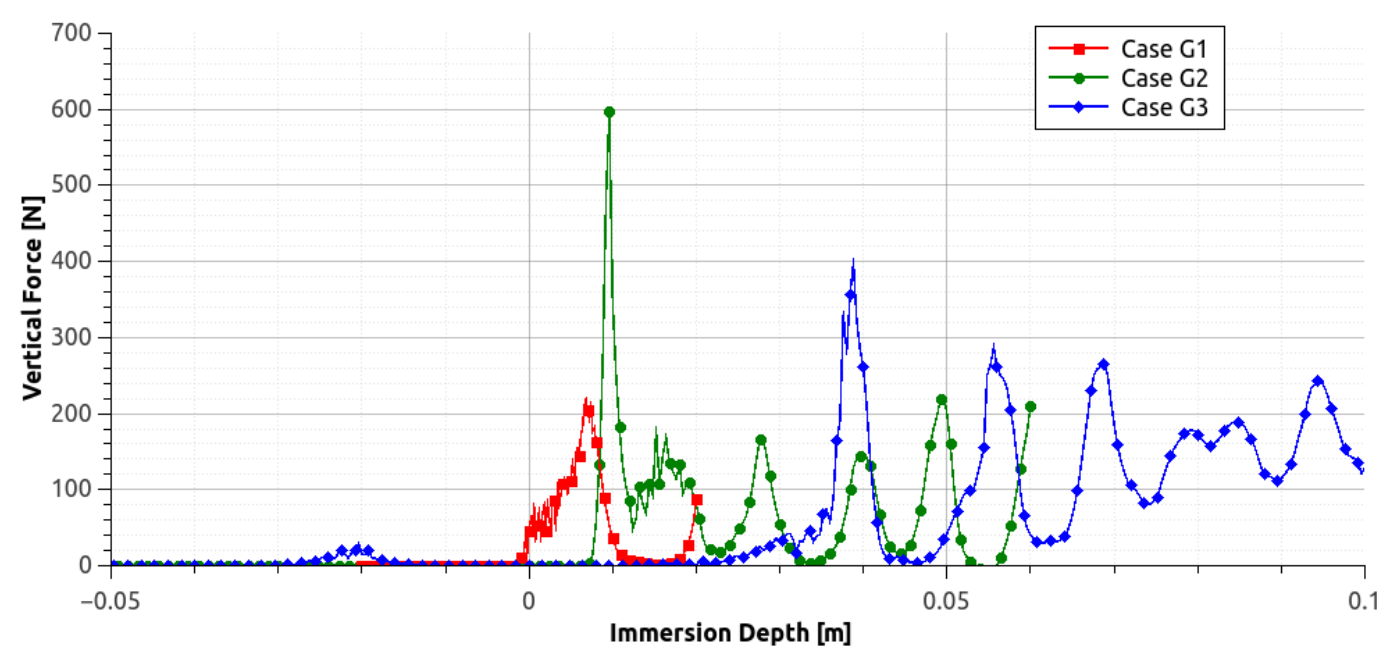

Figure 5.5: Vertical hydrodynamic force on $5^{\circ}$ wedge in three different situations: Case G1: Calm water, Case G2: wedge entering into water before the wave crest and Case G3: wedge entering into water after the wave crest.

In Case G3 the force still presents a peak higher then the calm case because the wedge low downward velocity causes the wedge to fully reach the water surface when the particles of this surface start to be accelerated upwards, as shown in Figure 5.6.

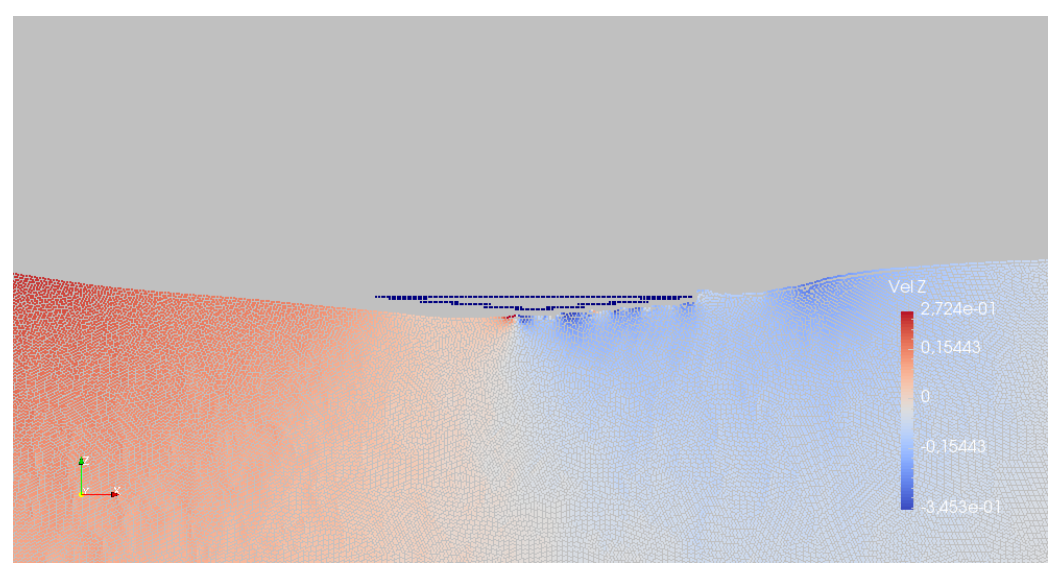

Figure 5.6: $5^{\circ}$ wedge reaching the water surface in Case G3.

These simulations demonstrate the influence of the waves on the slamming load and the two main effects could be observed: the bottom surface is gradually wetted and the wedge vertical velocity is added to the wave particles vertical velocities.

Figure 5.5 illustrates the increase of vertical force with the submergence in case G3. This increase is due to the gravity force, as the wedge has the 
same density of the fluid. This effect is not expected to be so evident in real operations due to high density of subsea structures when compared with water density. Tveitnes et al [54] presented the results of gravity force (buoyancy) together with the hydrodynamic force for cases presented in Section 4.2.

\section{2}

\section{Subsea Manifold on Waves}

Subsea Manifolds are equipment commonly used on offshore oil \& gas fields. Owing to dimensions and weight of these equipment the installation offshore may be critical and detailed analyses are normally required.

A sensitive analysis on size of equipment versus wave length and wave phase is presented in this section. The equipment of this analysis is a subsea manifold (MSGL-RO-02) installed in Roncador field, Brazil [57], illustrated in Figure 5.7 and the main data of the manifold are listed in Table 5.1.

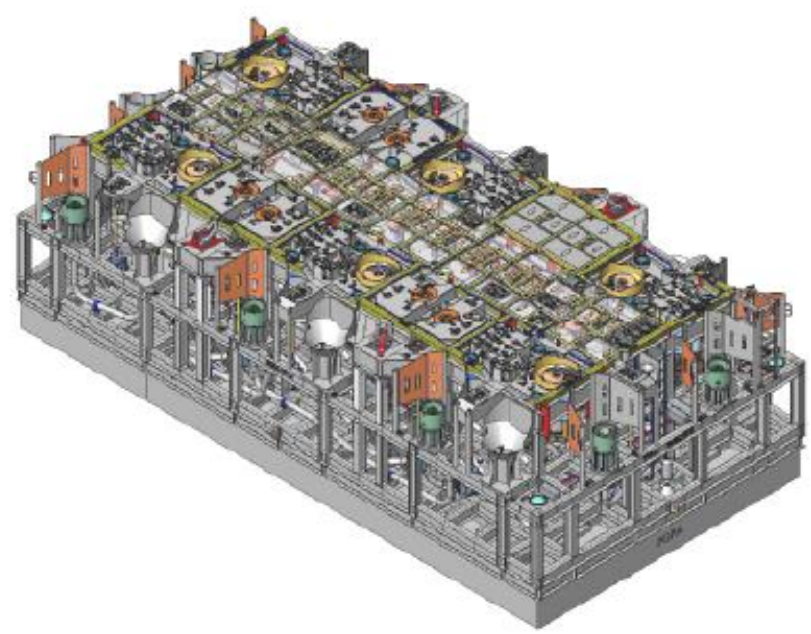

Figure 5.7: Representation of Roncador field manifold [57].

Table 5.1: Subsea manifold MSGL-RO-02 data [57].

\begin{tabular}{ccc}
\hline Parameter & Equipment & Model \\
\hline Breadth $(b)$ & $8.5 \mathrm{~m}$ & $0.170 \mathrm{~m}$ \\
Length $(l)$ & $16.5 \mathrm{~m}$ & $0.330 \mathrm{~m}$ \\
Height $(d)$ & $5.2 \mathrm{~m}$ & $0.104 \mathrm{~m}$ \\
Weight $(w)$ & $280 \mathrm{ton}$ & $2.24 \mathrm{~kg}$ \\
\hline
\end{tabular}

The equipment dimensions are in higher order of magnitude of previous simulations and the Froude's similitude law [58] is applied with $1 / 50^{\text {th }}$ scale. 
The use of scaled model is a common practice as presented by Bunnik et al. [56] and the scale proposed is suitable for application in experiments.

The equipment is modelled as a box, as shown in Figure 5.8.

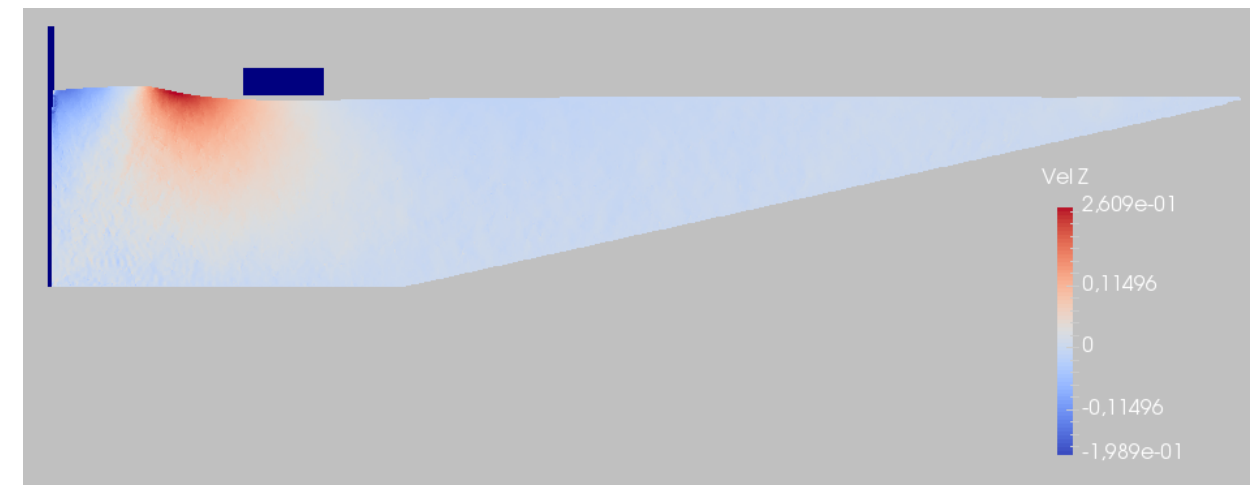

Figure 5.8: Scaled model developed to simulate the subsea manifold.

An important aspect for the estimation of slamming load observed in simulations presented in Section 5.1 is the moment that the bottom surface of the body first reaches the water surface. A delay of rule for the starting of movement of the model is employed in order to capture the influence of the wave phase. Figure 5.9 presents the wave components here considered. Four water entry moments were applied:

1. The model reaches the water surface at a point approximately half way between trough and crest;

2. The model movement is delayed in $1 / 4$ of the wave period, in respect of the first case;

3. The model movement is delayed in $2 / 4$ of the wave period, in respect of the first case;

4. The model movement is delayed in $3 / 4$ of the wave period, in respect of the first case.

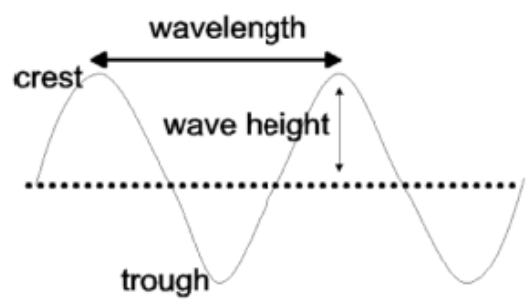

Figure 5.9: Wave components. 
The first simulation is performed considering a single regular wave with steepness $H / \lambda=0.05$ and $l / \lambda=0.216$ using linear wave theory, where $\lambda=1.56 T^{2}$ for deep water $($ depth $>\lambda / 2)[59]$.

The equipment is lowered with vertical velocity of $0.75 \mathrm{~m} / \mathrm{s}$ in equipment scale. Four cases are presented in Figure 5.10 (H1, H2, H3, H4), where delay rule previously described is applied. The immersion depth is related to the calm water surface and results are presented in Figure 5.10.
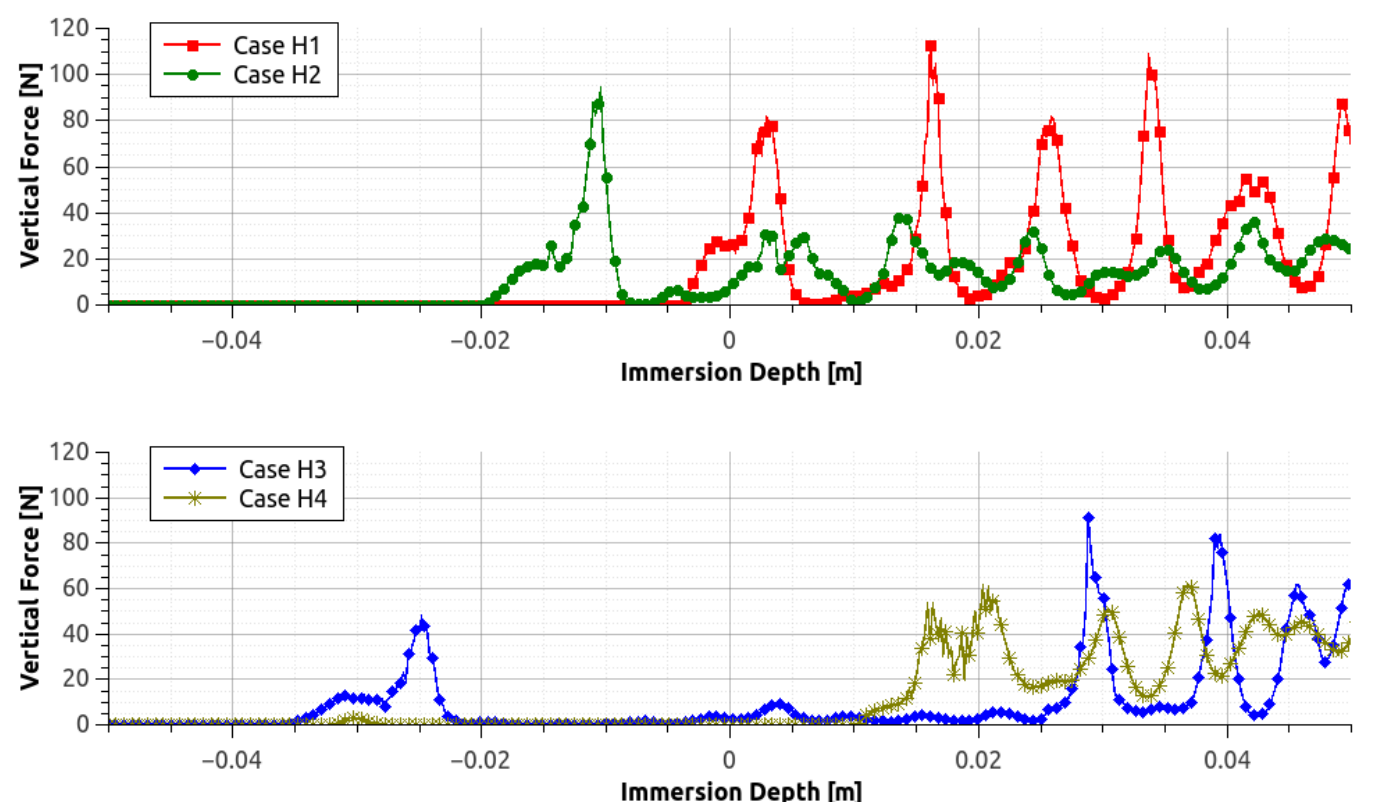

Figure 5.10: Vertical force on model: $H / \lambda=0.05, v_{z}=-0.75 \mathrm{~m} / \mathrm{s}$ in equipment scale.

The second simulation is set up similarly to the previous one, with same delay rule, considering however a higher downward velocity of $1.5 \mathrm{~m} / \mathrm{s}$ (in equipment scale) and four cases (I1, I2, I3, I4) are shown in Figure 5.11. 

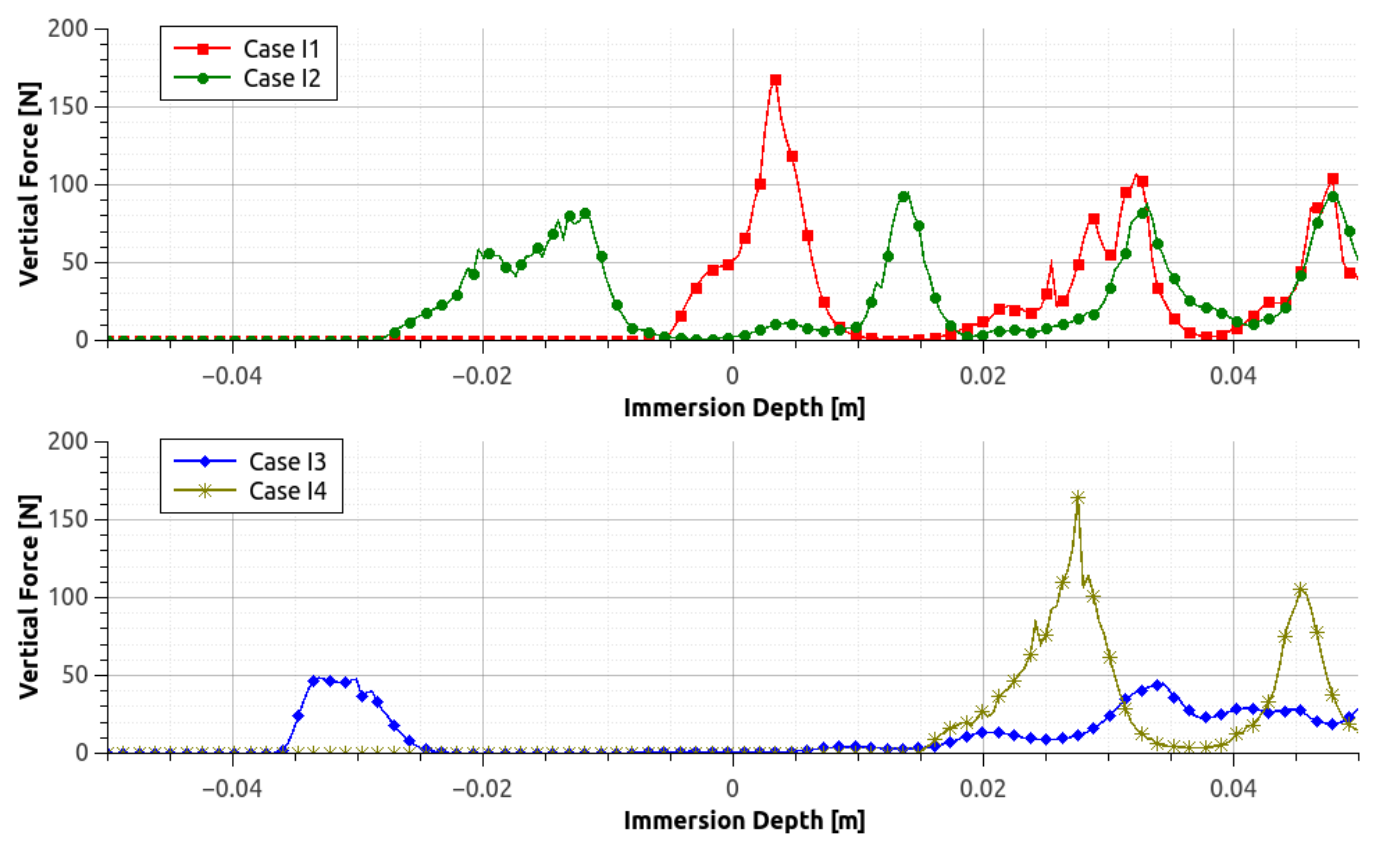

Figure 5.11: Vertical force on the model: $H / \lambda=0.05, v_{z}=-1.5 \mathrm{~m} / \mathrm{s}$ in equipment scale.

The forces observed in these first two simulations are significantly greater than the model weight. This is due to the high velocities of the equipment and the wave steepness employed.

The following simulation is performed with moderate wave $(H / \lambda=0.01$ and $l / \lambda=0.131)$ and lower equipment downward velocity $(0.1 \mathrm{~m} / \mathrm{s}$ in equipment scale). Results are shown in Figure 5.12. 

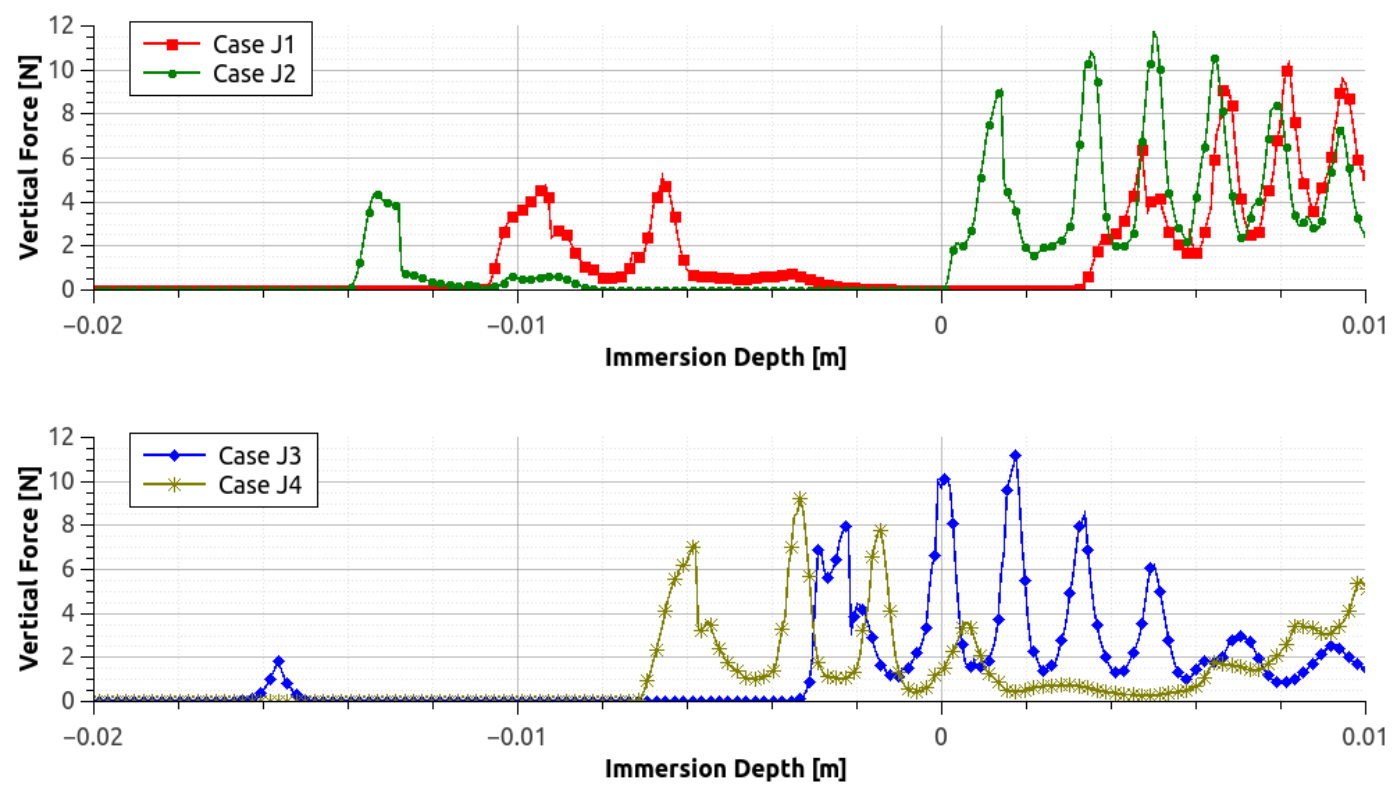

Figure 5.12: Vertical force on the model: $H / \lambda=0.01, l / \lambda=0.131, v_{z}=-0.1$ $\mathrm{m} / \mathrm{s}$ in equipment scale.

The peaks observed with the submergence of the body are originated by the action of wave reflections in different parts of the bottom surface of the model.

In order to check the influence of the relation $H / \lambda$, the following simulation is set with the model rotated in $90^{\circ}$, i.e. the longer dimension orthogonal to the wave direction. Figure 5.13 presents the results for $l / \lambda=$ 0.067 . 

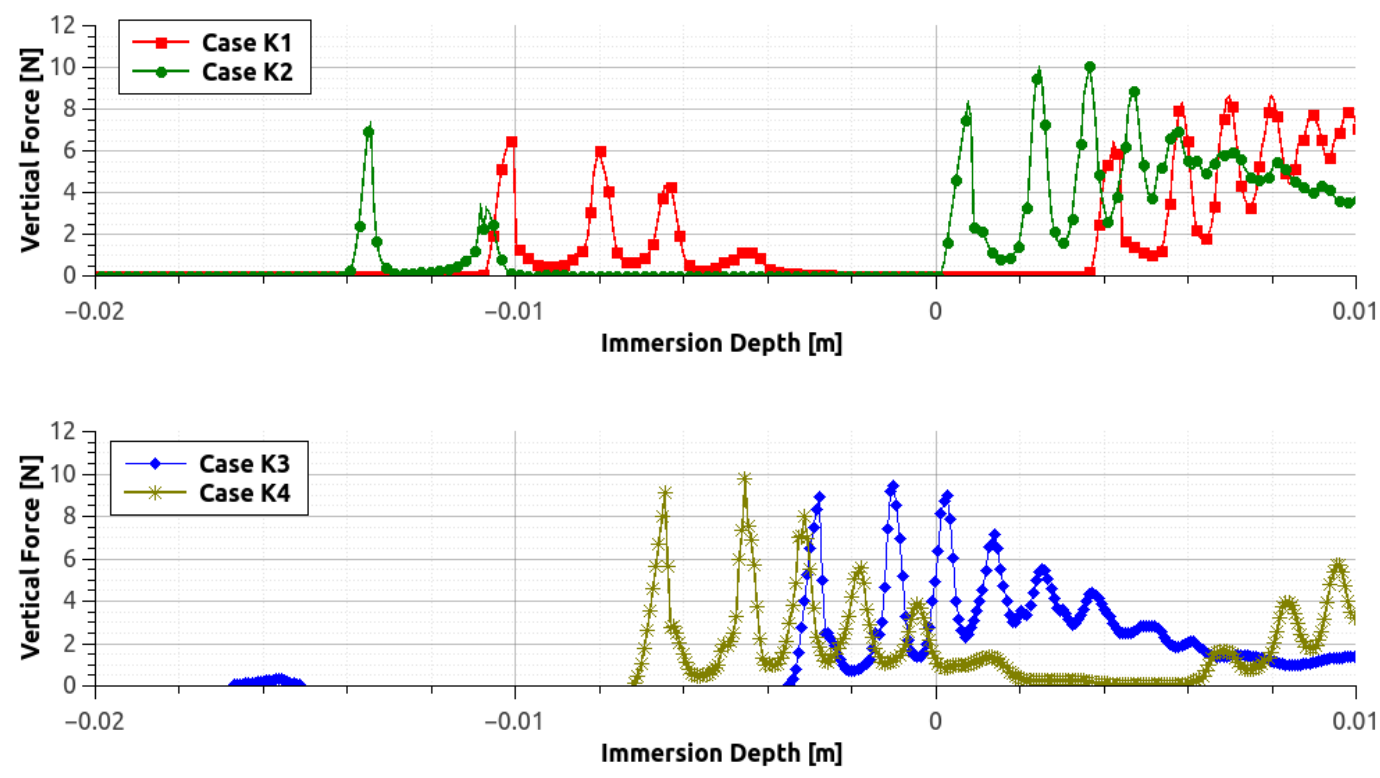

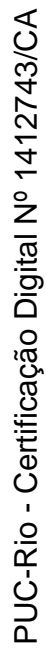

Figure 5.13: Vertical force on the model: $H / \lambda=0.01, l / \lambda=0.067, v_{z}=-0.1$ $\mathrm{m} / \mathrm{s}$ in equipment scale.

The influence of the equipment alignment is noticed when results shown in Figure 5.12 are compared with those presented in Figure 5.13. For higher $l / \lambda$ the peak force is reduced when the equipment reaches the wave close to the crest, as the bottom surface gradually enters into water, as shown in Figure 5.14 . 


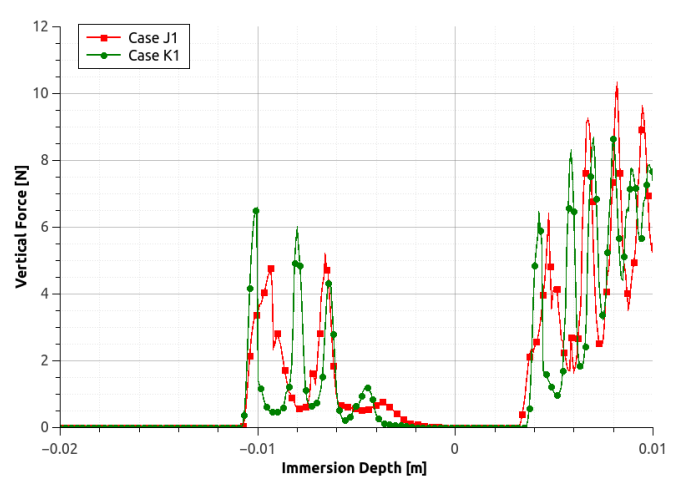

5.14(a): Vertical force (J1, K1)

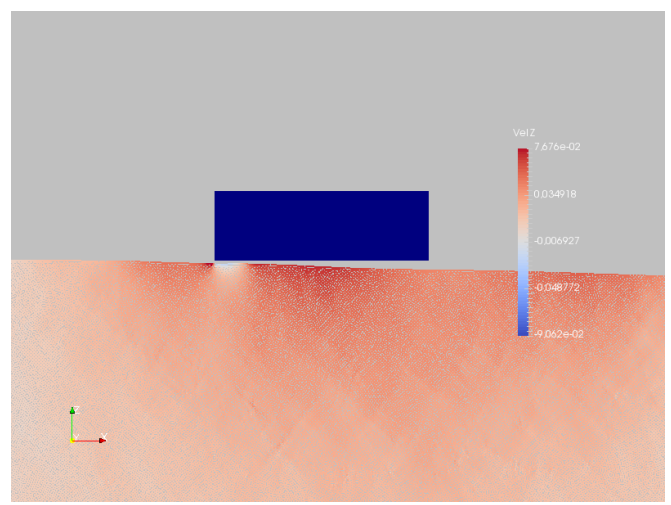

5.14(c): Case J1

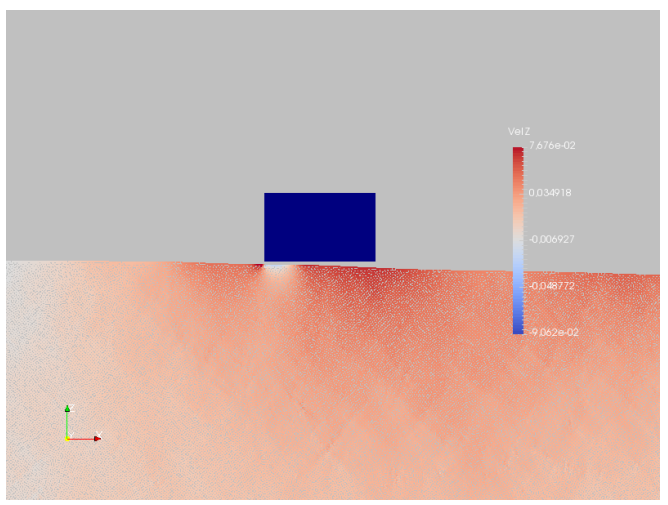

5.14(e): Case K1

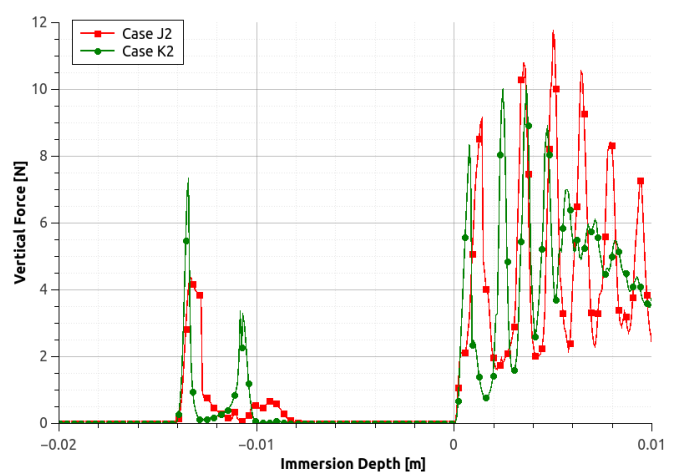

5.14(b): Vertical force (J2, K2)

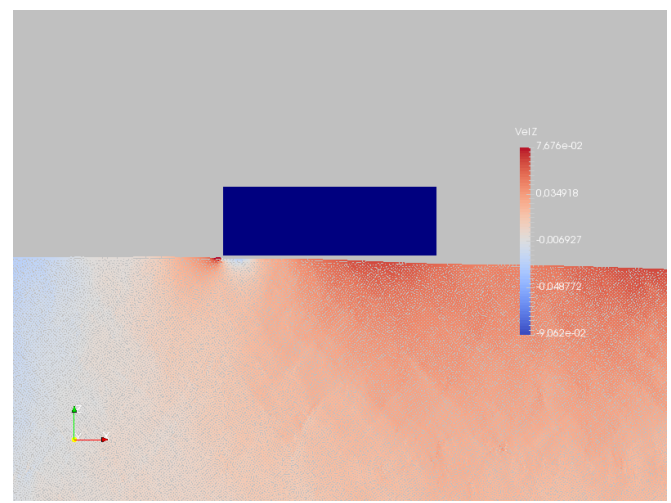

5.14(d): Case J2

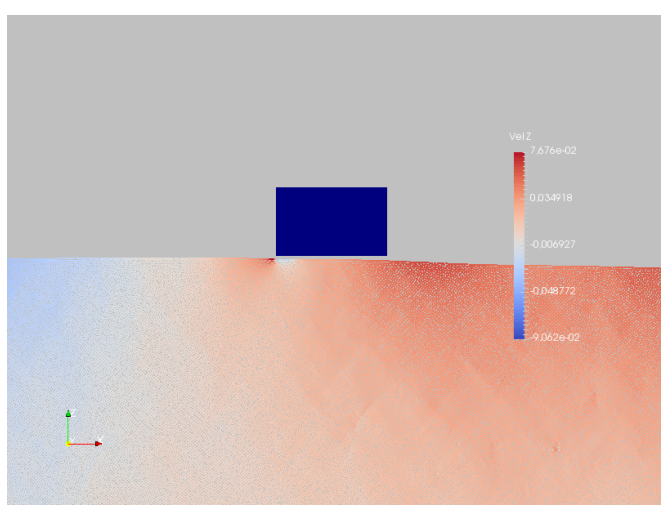

5.14(f): Case K2

Figure 5.14: Comparison of cases $\mathrm{J}$ and $\mathrm{K}$ when reaching the wave close to crest.

The difference in vertical force highlighted above is not so evident if the equipment reaches the wave before the crest, as illustrated in Figure 5.15. The bottom surface enters in water faster for both $l / \lambda$ since higher vertical velocities are observed. 


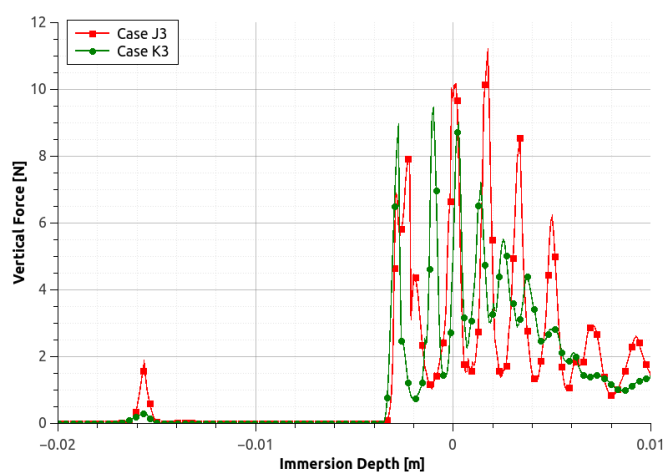

5.15(a): Vertical force (J3, K3)

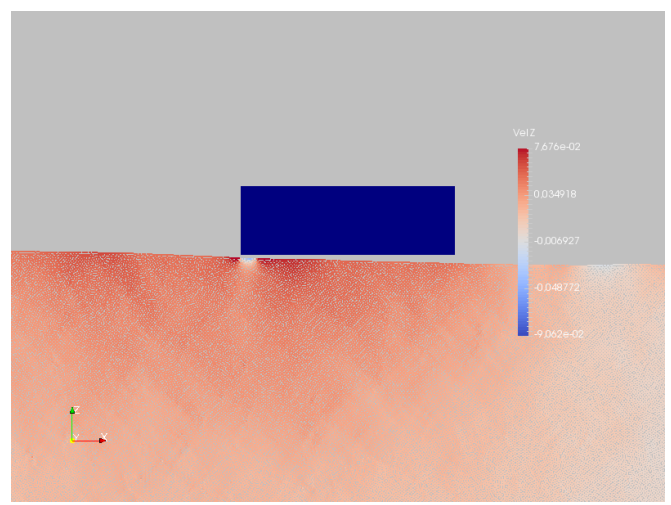

5.15(c): Case J3

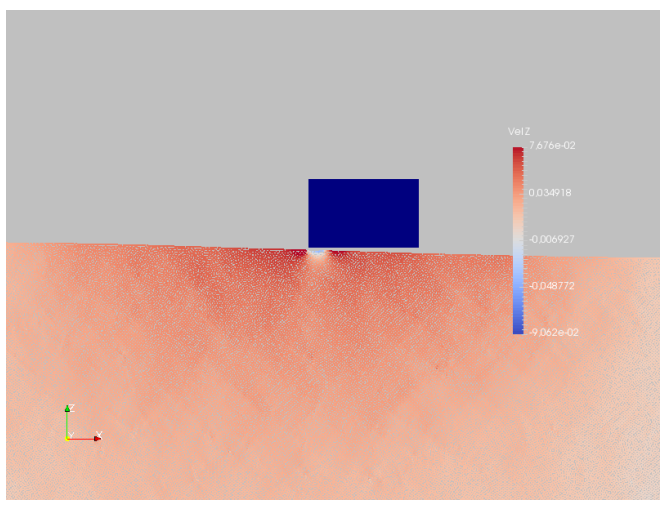

5.15(e): Case K3

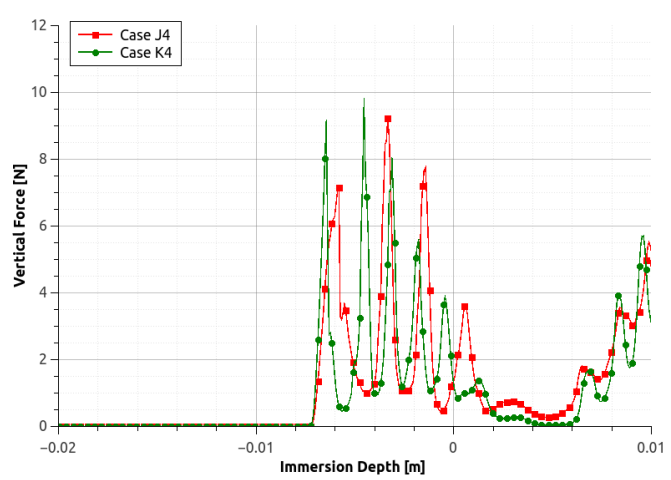

5.15(b): Vertical force (J4, K4)

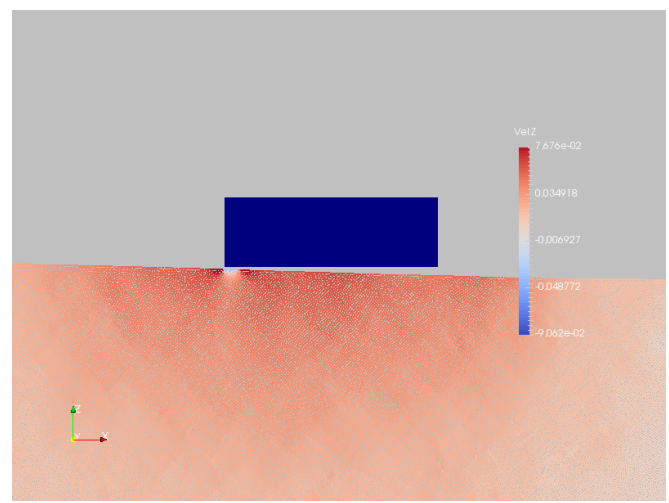

5.15(d): Case J4

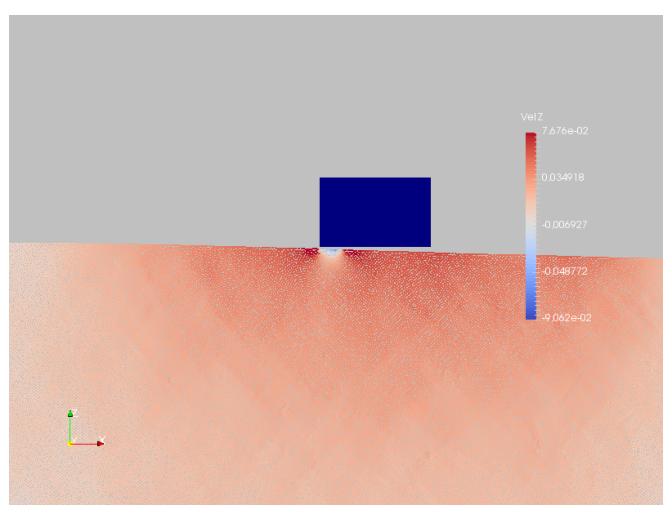

5.15(f): Case K4

Figure 5.15: Comparison of cases $\mathrm{J}$ and $\mathrm{K}$ when reaching the wave before the crest. 


\section{Conclusions}

\section{1 \\ Summary}

This work dealt with the water entry of rigid body into both calm and wavy water. The fundamental theory was reviewed and relevant numerical developments in this field were presented. The numerical method SPH was employed to estimate slamming load during water entry on simple geometries.

The approach presented in this work aimed at the estimation of slamming load considering the effect of waves. A 2D one degree of freedom model using the SPH method was develop for this assessment. In the simulations a constant downward velocity was imposed to the model during water entry, where, in presence of waves, the bottom surface of the body is gradually wetted and the velocity of the wave particles are combined with the rigid body vertical velocity.

In this work these two phenomena were observed: the simulation of a $5^{\circ}$ wedge water entry into wavy surface clearly demonstrated the consequence of the wave particles velocities on the slamming load, as discussed in Section 5.1. The simulation of water entry of bodies with flat bottom surface indicated the influence of the relation between the body length and wave length $(l / \lambda)$ in the slamming load, where higher $l / \lambda$ was translated into smaller $\left(d m_{33} / d y\right)$, thus reducing the slamming load.

Smoothed Particle Hydrodynamics and the DualSPHysics implementation demonstrated the ability to handle free surface and fluid solid interaction. Experiments with water entry of rigid bodies were reproduced using SPH and results were compared with technical literature data. These simulations covered the water entry, from the free fall, of cylinders and wedges, as well as, the constant velocity water entry of wedges.

The DualSPHysics feature to generate waves and the post-processing tool to compute force on boundaries were important to the model proposed in this work, furthermore the simulation configuration file accommodated the necessary elements to develop the different simulation cases presented here.

The simulations were performed on GPU, reducing significantly the 
processing time. As an example, the Case C1 presented in Appendix B consumed 2.9 hours for processing when running on GPU, it is considerable efficient when compared with the same case running on CPU described in Section 3.2, that consumed approximately 85 hours. A shortcoming of the DualSPHysics is the size of the post-processing files, where for each case they can reach dozens of gigabytes.

\section{2}

\section{Future Work}

The model developed in this work may be enhanced with the incorporation of the following improvements:

- The 2D, one degree-of-freedom model can be expanded to a 2D three degree-of-freedom model where the $x$ displacement and the $y$ rotation would be combined with the $z$ displacement. This new model would better reproduce offshore operation and would allow the estimation of the loads on slings, as presented in [5];

- The imposed constant velocity water entry was applied in order to produce comparable results. However, to adhere with the real operation, the harmonic displacement of hoisting point could be applied to the model proposed in the previous paragraph. Similarly, irregular waves could be considered;

- The results presented in Chapter 5 can be validated with model tests carried out in tanks in presence of waves;

- A comparative study can be developed with the results presented in Chapter 5 and the formulation proposed in DNV-RP-H103 [6];

- The overall simulation time could be reduced if the post-processing routines were implemented for GPU;

- The multiphase approach for the water entry problem is an important field of research and thus recommended to be a focus of future developments. In offshore operations, as shown in Figure 6.1, it is possible to observe that air is dragged with the equipment into water, resulting in multiphase cushion surrounding the water-equipment interface. The air cushion trapped plays an important role on slamming on small deadrise angles wedges and flat surfaces, as discussed by Lind et al. [60]. In their work a multiphase model is employed to simulate the water entry of a flat plate into waves with different steepness. In the model the air domain was considered in a multiphase SPH implementation. Relevant results 
are presented in Figure 6.2, where the multiphase model is compared with the single phase and experiment.

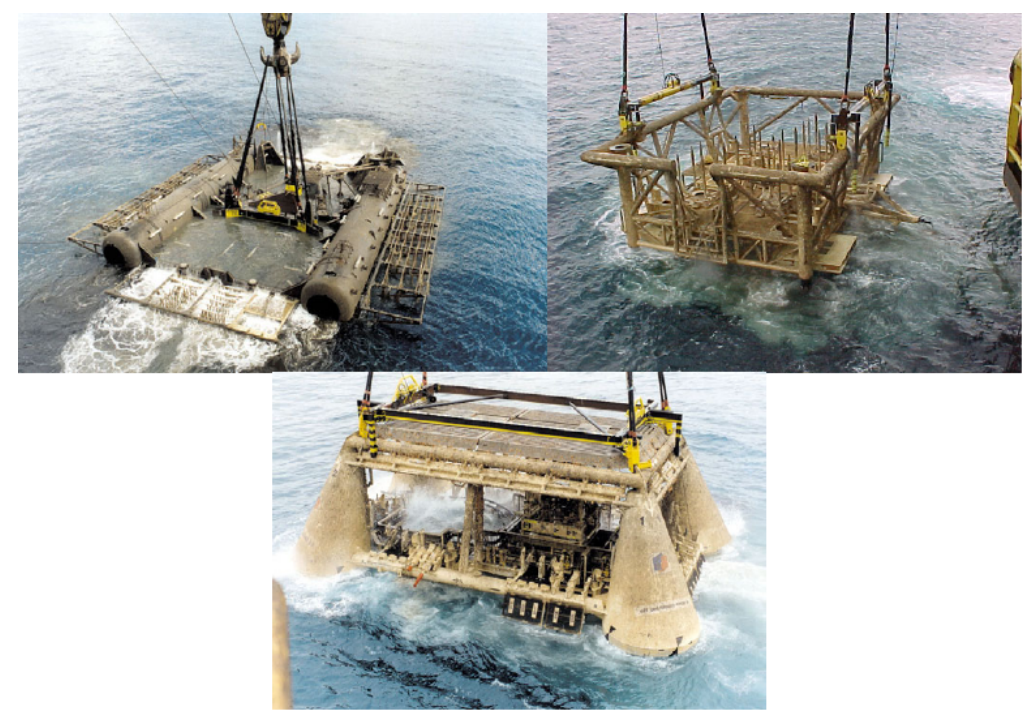

Figure 6.1: Examples of different complex subsea structures in the splash zone

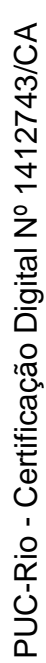
$[56]$.

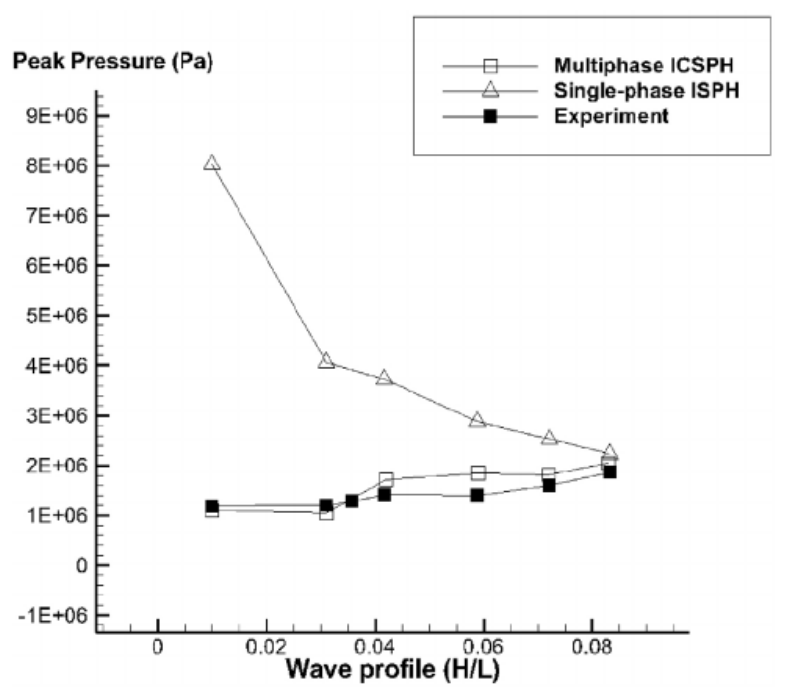

Figure 6.2: Numerical (single-phase and two-phase) and experimental results for the peak impact pressure for various wave profiles $(H / \lambda)[60]$. 


\section{Bibliography}

[1] ORLOWSKI, R. T. C.. Dispositivo com rigidez não-linear na instalação de módulos submarinos em águas profundas. Master's thesis, Universidade Federal do Rio de Janeiro, 2007.

[2] SOUZA, C. E. M. D.. Ferramenta submarina para compensação ativa de movimentos verticais na instalação de equipamentos. Master's thesis, Universidade Federal do Rio de Janeiro, 2009.

[3] THORGERSEN, S.. Comparison study of deepwater installation methods. Master's thesis, University of Stavanger, Norway, 2014.

[4] KOPSOV, I.; SANDVIK, P.. Analysis of subsea structure installation. The Fifth International Offshore and Polar Engineering Conference, 1995.

[5] JIA, D.; AGRAWAL, M.. Fluid-structure interaction: lowering subsea structure/equipment in splash zone during installation. Offshore Technology Conference, 2014.

[6] DNV-RP-H103: Modelling and analysis of marine operations, 2014.

[7] GORDON, R. B.; GRYTØYR, G. ; DHAIGUDE, M.. Modeling suction pile lowering through the splash zone. ASME 2013 32nd International Conference on Ocean, Offshore and Arctic Engineering, 2013.

[8] VON KARMAN, T.. The impact on seaplane floats during landing. National Advisory Committee on Aeronautics, 1929.

[9] WAGNER, H.. Über stoß-und gleitvorgänge an der oberfläche von flüssigkeiten. ZAMM-Journal of Applied Mathematics and Mechanics/Zeitschrift für Angewandte Mathematik und Mechanik, 1932.

[10] OLIVER, J. M.. Water entry and related problems. PhD thesis, University of Oxford, United Kingdom, 2002.

[11] TRUONG, T.; REPAlle, N.; PISTANI, F. ; THIAGARAJAN, K.. An experimental study of slamming impact during forced water entry. 17th Australasian fluid mechanics conference, Auckland, New Zealand, 2010. 
[12] SANTOS, F. M. D.. Impacto hidrodinâmico vertical de corpos axissimétricos através de uma abordagem variacional. $\mathrm{PhD}$ thesis, Universidade de São Paulo, Brazil, 2013.

[13] MORAN, J. P.. On the hydrodynamic theory of water-exit and -entry. Technical report, Fluid dynamics Branch - Office of Naval Research, USA, 1965.

[14] KOROBKIN, A.; PUKHNACHOV, V.. Initial stage of water impact. Annual review of fluid mechanics, USA, 1988.

[15] KOROBKIN, A.. Three-dimensional nonlinear theory of water impact. 18th International Congress of Mechanical Engineering (COBEM), Brazil, 2005.

[16] KOROBKIN, A.; IAFRATI, A.. Hydrodynamic loads on flat plate entering water. Proceedings of the 21st Int. Workshop on Water Waves and Floating Bodies, United Kingdom, 2006.

[17] BRENNEN, C.. A review of added mass and fluid inertial forces. Technical report, Naval Civil Engineering Laboratory, Department of the Navy, USA, 1982.

[18] NEWMAN, J. N.. Marine hydrodynamics. MIT press, 1977.

[19] PAPST, W.. Theory of the landing impact of seaplanes. Zeitschrift für Flugtechnik und Motorluftschiffahrt, 1930.

[20] ZHAO, R.; FALTINSEN, O. ; AARSNES, J.. Water entry of arbitrary two-dimensional sections with and without flow separation. Proceedings of the 21st symposium on naval hydrodynamics, USA, 1996.

[21] GHADIMI, P.; SAADATKHAH, A. ; DASHTIMANESH, A.. Analytical solution of wedge water entry by using schwartz-christoffel conformal mapping. International Journal of Modeling, Simulation, and Scientific Computing, 2(03):337-354, 2011.

[22] CROCE, R.. Numerische Simulation der Interaktion von inkompressiblen Zweiphasenstromungen mit Starrkorpern in drei Raumdimensionen. PhD thesis, Rheinischen Friedrich-WilhelmsUniversität Bonn, Germany, 2010.

[23] ZHAO, R.; FALTINSEN, O.. Water entry of two-dimensional bodies. Journal of Fluid Mechanics, Cambridge Univ Press, 1993. 
[24] BATTISTIN, D.; IAFRATI, A.. Hydrodynamic loads during water entry of two-dimensional and axisymmetric bodies. Journal of fluids and structures, Elsevier, 2003.

[25] WU, G.; SUN, H. ; HE, Y.. Numerical simulation and experimental study of water entry of a wedge in free fall motion. Journal of Fluids and Structures, Elsevier, 2004.

[26] TASSIN, A.; JACQUES, N.; EL MALKI ALAOUI, A.; NÊME, A. ; LEBLÉ, $B$.. Assessment and comparison of several analytical models of water impact. The International Journal of Multiphysics, Multi Science Publishing, 2010.

[27] SHEN, Z.; WAN, D.. Numerical Simulation of Sphere Water Entry Problem Based on VOF and Dynamic Mesh Methods. Proceedings of the Twenty-first International Offshore and Polar Engineering Conference, 2011.

[28] GHADIMI, P.; CHEKAB, M. A. F. ; DASHTIMANESH, A.. Numerical simulation of water entry of different arbitrary bow sections. Journal of Naval Architecture and Marine Engineering, Bangladesh, 2014.

[29] Constantinescu, A.; Alaoul, A. E. M.; Neme, A. ; RigO, P.. Numerical and Experimental Studies of Simple Geometries in Slamming. Proceedings of the Nineteenth International Offshore and Polar Engineering Conference, 2009.

[30] MUKHA, T.. Modeling Large Equipment Behavior in the Sea Splash-Zone Using Methods of Computational Fluid Dynamics. Master's thesis, Chalmers Univertity of Technology, Gothenburg, Sweden, 2012.

[31] DAMBlanS, G.; Berhault, C.; MARCER, R.; CINEllo, A. ; PÉTRIÉ, F.. CFD and Experimental Investigations of Slamming Load Prediction on Subsea Structures in Splash Zone. The Twentysecond International Offshore and Polar Engineering Conference, 2012.

[32] ROE, S. M.. Numerical and experimental analysis of initial water impact of an air-dropped REMUS AUV. Master's thesis, Massachusetts Institute of Technology, USA, 2005.

[33] WANG, S.. Assessment of slam induced loads on two dimensional wedges and ship sections. Master Thesis, Universidade Técnica de Lisboa, Portugal, 2011. 
[34] ZHU, X.. Application of the CIP Method to Strongly Nonlinear Wave-Body Interaction Problems. PhD thesis, NTNU, Norway, 2006.

[35] VANDAMME, J.; ZOU, Q. ; REEVE, D. E.. Modeling Floating Object Entry and Exit Using Smoothed Particle Hydrodynamics. Journal of Waterway, Port, Coastal, and Ocean Engineering, 2011.

[35] OGER, G.; DORING, M.; ALESSANDRINI, B. ; FERRANT, P.. Twodimensional SPH simulations of wedge water entries. Journal of Computational Physics, Elsevier, 2005.

[36] LIU, H.; WANG, B. ; GONG, K.. Numerical Simulation of Violent Evolution of Free Surface during Water Entry of Wedge. The Tenth ISOPE Pacific/Asia Offshore Mechanics Symposium, 2012.

[36] OGER, G.; DORING, M.; LEROYER, A.; ALESSANDRINI, B. ; VISONNEAU, M.. SPH and finite volume simulations of a wedge water entry. The Fourteenth International Offshore and Polar Engineering Conference, 2004.

[39] FARSI, M.; GHADIMI, P.; ZAMANIAN, R. ; DASHTIMANESH, A.. Simulation of wedge water entry using smoothed particle hydrodynamics method. International Journal of Scientific World, 2013.

[40] CRESPO, A. J. C.; DOMINGUEZ, J. M.; ROGERS, B. D.; GOMEZGESTEIRA, M.; LONGSHAW, S.; CANELAS, R.; VACONDIO, R.; BARREIRO, A. ; GARCIA-FEAL, O.. DualSPHysics: Open-source parallel CFD solver based on Smoothed Particle Hydrodynamics (SPH). Computer Physics Communications, Elsevier, 2015.

[41] GINGOLD, R. A.; MONAGHAN, J. J.. Smoothed particle hydrodynamics: theory and application to non-spherical stars. Monthly notices of the royal astronomical society, Oxford University Press, 1977.

[42] LUCY, L. B.. A numerical approach to the testing of the fission hypothesis. The astronomical journal, European Southern Observatory, 1977.

[43] PAiva, A.; PetronetTO, F.; TAVARES, G. ; LEWINER, T.. Simulação de fluidos sem malha: uma introdução ao método SPH. $27^{\circ}$ Colóquio Brasileiro de Matemática, Rio de Janeiro, Brazil, 2009.

[44] SOLENTHALER, B.. Incompressible fluid simulation and advanced surface handling with SPH. PhD thesis, ETH, Switzerland, 2010. 
[45] NAKAMURA, F. I.. Animação interativa de fluido baseada em partícula pelo método sph. Master Thesis, Pontifícia Universidade Católica do Rio de Janeiro, Brazil, 2007.

[46] MONAGHAN, J. J.. Smoothed particle hydrodynamics. Annual review of astronomy and astrophysics, 1992.

[47] MÜLleR, M.; CHARYPAR, D. ; GROSS, M.. Particle-based fluid simulation for interactive applications. Proceedings of the 2003 ACM SIGGRAPH/Eurographics symposium on Computer animation, 2003.

[48] MONAGHAN, J. J.. Smoothed particle hydrodynamics. Reports on Progress in Physics, IOP Publishing, 2005.

[49] WENDLAND, H.. Piecewise polynomial, positive definite and compactly supported radial functions of minimal degree. Advances in computational Mathematics, Springer, 1995.

[50] NOUTCHEUWA, R. K.; OWENS, R. G.. A new incompressible smoothed particle hydrodynamics-immersed boundary method. Int. J. Numer. Anal. Model, 2012.

[51] DUALSPHYSICS. User Guide for DualSPHysics code, 042016.

[52] GREENHOW, M.; LIN, W.-M.. Nonlinear free surface effects: experiments and theory. Technical report, DTIC Document, 1983.

[53] AARSNES, J.. Drop test with ship sections-effect of roll angle. Technical report, Norway, 1996.

[54] TVEITNES, T.; FAIRLIE-CLARKE, A. ; VARYANI, K.. An experimental investigation into the constant velocity water entry of wedgeshaped sections. Ocean Engineering, Elsevier, 2008.

[55] TVEITNES, T.. Application of added mass theory in planing. PhD thesis, University of Glasgow, 2001.

[56] BUNNIK, T.; BUCHNER, B.. Numerical prediction of wave loads on subsea structures in the splash zone. The Fourteenth International Offshore and Polar Engineering Conference, 2004.

[57] RIBEIRO, M. L.. Concepção de manifolds submarinos para lançamento pendular em águas ultra profundas. $\mathrm{PhD}$ thesis, Universidade Federal do Rio de Janeiro, 2008. 
[58] WOLOWICZ, C. H.; BROWN JR, J. ; GILBERT, W. P.. Similitude requirements and scaling relationships as applied to model testing. Technical report, NASA, 1979.

[59] DNV-RP-C205: Environmental conditions and environmental loads, 2010.

[60] LIND, S.; STANSBY, P.; ROGERS, B. ; LLOYD, P.. Numerical predictions of water-air wave slam using incompressible-compressible smoothed particle hydrodynamics. Applied Ocean Research, Elsevier, 2015. 


\section{Added Mass Tensor}

The hydrodynamic pressure forces acting on rigid body surrounded by ideal, irrotational, and incompressible fluid are represented by the integrals of the pressure over the body surface

$$
\boldsymbol{F}=\iint_{S_{B}} p \boldsymbol{n} d S .
$$

The normal vector $\boldsymbol{n}$ is taken to be positive when pointing out of the fluid volume and hence into the body. The moment vector is represented as

$$
\boldsymbol{M}=\iint_{S_{B}} p(\boldsymbol{r} \times \boldsymbol{n}) d S .
$$

Considering the velocity potential $\phi$ and substituting $p$ in Eqs. A-1 and A-2 for the dynamic pressure from the Bernoulli's equation, one obtains,

$$
\begin{gathered}
\boldsymbol{F}=-\rho \iint_{S_{B}}\left[\frac{\partial \phi}{\partial t}+\frac{1}{2} \nabla \phi . \nabla \phi\right] \boldsymbol{n} d S, \\
\boldsymbol{M}=-\rho \iint_{S_{B}}\left[\frac{\partial \phi}{\partial t}+\frac{1}{2} \nabla \phi . \nabla \phi\right](\boldsymbol{r} \times \boldsymbol{n}) d S .
\end{gathered}
$$

Recasting these equations using Gauss' and Reynolds transport theorems and introduced the fixed control surface $S_{C}$, exterior to the body surface $S_{B}$, to obtain the force and moment equations

$$
\begin{gathered}
\boldsymbol{F}=-\rho \frac{d}{d t} \iint_{S_{B}} \phi \boldsymbol{n} d S-\rho \iint_{S_{C}}\left[\frac{\partial \phi}{\partial n} \nabla \phi-\boldsymbol{n} \frac{1}{2} \nabla \phi . \nabla \phi\right] d S, \\
\boldsymbol{M}=-\rho \frac{d}{d t} \iint_{S_{B}} \phi(\boldsymbol{r} \times \boldsymbol{n}) d S-\rho \iint_{S_{C}} \boldsymbol{r} \times\left[\frac{\partial \phi}{\partial n} \nabla \phi-\frac{1}{2} \nabla \phi . \nabla \phi \boldsymbol{n}\right] d S .
\end{gathered}
$$

The artifice of the surface $S_{C}$ simplifies the calculation of the pressure forces as the integrals over $S_{C}$ may be evaluated with this control surface moved to the far field, where the details of the flow past the body are not relevant.

Considering the hydrodynamic forces and moments acting on a rigid body, which moves in an unbounded fluid with translational velocity $\boldsymbol{v}(t)$ and angular velocity $\boldsymbol{\omega}(t)$ about an origin fixed to the body, the potential velocity must satisfy the boundary condition 


$$
\frac{\partial \phi}{\partial n}=\boldsymbol{v} \cdot \boldsymbol{n}+\boldsymbol{\omega} \cdot\left(\boldsymbol{r}^{\prime} \times \boldsymbol{n}\right)
$$

where $\boldsymbol{r}^{\prime}$ is the radius vector from the center of rotation. Let $v_{i}$ represent the six velocity components, where

$$
\begin{gathered}
\boldsymbol{v}=\left(v_{1}, v_{2}, v_{3}\right), \\
\boldsymbol{\omega}=\left(\omega_{1}, \omega_{2}, \omega_{3}\right) \equiv\left(v_{4}, v_{5}, v_{6}\right),
\end{gathered}
$$

the total potential is given as the sum

$$
\phi=v_{i} \phi_{i}
$$

which satisfies the boundary condition Eq. A-7, with $i=1,2, \ldots, 6$. Physically, each $\phi_{i}$ represents the velocity potential due to a body motion with unit velocity in the $i$ th mode. Provided each component $\phi_{i}$ satisfies the corresponding condition

$$
\begin{gathered}
\frac{\partial \phi_{i}}{\partial n}=n_{i}, \quad i=1,2,3, \\
\frac{\partial \phi_{i}}{\partial n}=\left(\boldsymbol{r}^{\prime} \times \boldsymbol{n}\right)_{i-3}, \quad i=4,5,6 .
\end{gathered}
$$

Equations A-5 and A-6 can be expanded using, from the vector analysis, the time derivative of the vector $\boldsymbol{n}$

$$
\frac{d \boldsymbol{n}}{d t}=\boldsymbol{\omega} \times \boldsymbol{n},
$$

and the results from Eq. A-10. The integrals over $S_{C}$ are neglected and the cross-product is written in indicial notation

$$
F_{j}=-\rho \dot{v}_{i} \iint_{S_{B}} \phi_{i} n_{j} d S-\rho \varepsilon_{j k l} v_{i} \omega_{k} \iint_{S_{B}} \phi_{i} n_{l} d S,
$$

$M_{j}=-\rho \dot{v}_{i} \iint_{S_{B}} \phi_{i}\left(\boldsymbol{r}^{\prime} \times \boldsymbol{n}\right)_{j} d S-\rho \varepsilon_{j k l} v_{i} \omega_{k} \iint_{S_{B}} \phi_{i}\left(\boldsymbol{r}^{\prime} \times \boldsymbol{n}\right)_{l} d S-\rho \varepsilon_{j k l} v_{i} v_{k} \iint_{S_{B}} \phi_{i} n_{l} d S$.

The boundary conditions Eqs. A-11 and A-12 allow one to rewrite some above integrals as

$$
\begin{gathered}
\iint_{S_{B}} \phi_{i} n_{j} d S=\iint_{S_{B}} \phi_{i} \frac{\partial \phi_{j}}{\partial n} d S \\
\iint_{S_{B}} \phi_{i}\left(\boldsymbol{r}^{\prime} \times \boldsymbol{n}\right)_{j} d S=\iint_{S_{B}} \phi_{i} \frac{\partial \phi_{j+3}}{\partial n} d S
\end{gathered}
$$

Inspecting Eqs. A-14 and A-15 in light of the integrals Eqs. A-16 and A-17, the added-mass tensor may be defined as

$$
m_{j i}=\rho \iint_{S b} \phi_{i} \frac{\partial \phi_{j}}{\partial n} d S .
$$


B

\section{Case definition file}

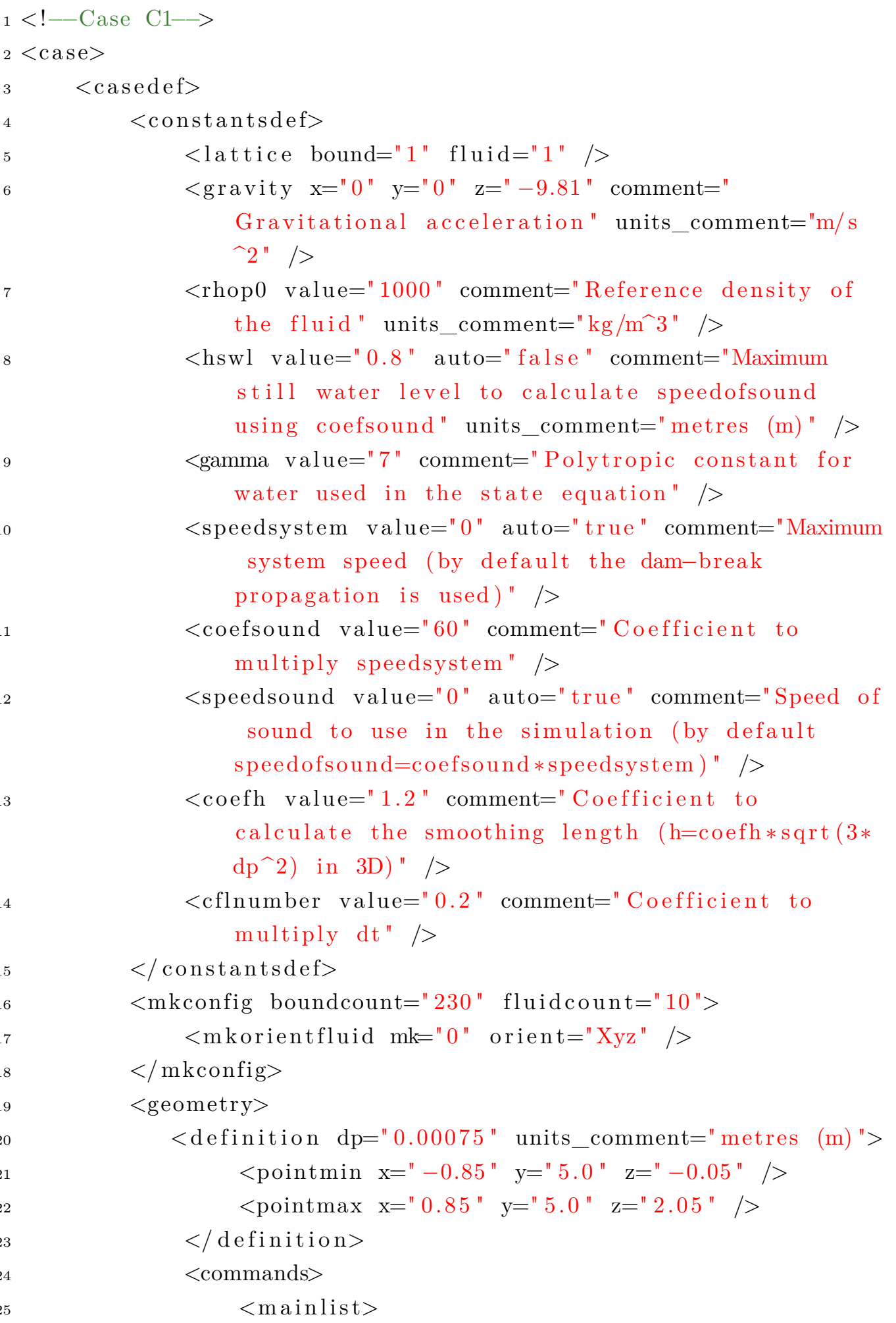


$</$ commands $>$

$</$ geometry $>$

$<$ initials $>$

$</$ initials $>$

$<$ motion $>$

$<$ setshapemode $>$ dp | real | bound $<$ / setshapemode $>$ $<$ setdrawmode mode="full " /> $<$ setmkfluid mk=" $0 " \quad />$

$<$ drawbox $>$ $<$ boxfill $>$ solid $<$ boxfill $>$

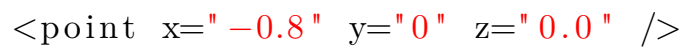
$<\operatorname{size} x=" 1.6 " \quad y=" 10 " \quad z=" 0.5 " \quad />$

$</$ drawbox $>$

$<$ setdrawmode mode $=$ "face" $/>$ $<$ setmkbound mk=" $20 " \quad />$

$<$ drawbox $>$

$<$ boxfill $>$ bottom $</$ boxfill $>$

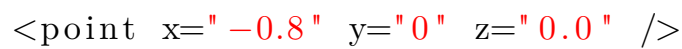

$<\operatorname{size} \quad \mathrm{x}=" 1.6 " \mathrm{y}=" 10.0 " \mathrm{z}=" 0.40 " \quad />$

$</$ drawbox $>$

$<$ shapeout file $=$ "Boundary" $/>$

$<$ setdrawmode mode="full " / >

$<$ setmkbound $\mathrm{B}=$ "0" $\mathrm{G}=$ " 0 " $\mathrm{R}=$ " 0 " mk=" 51 " name= "prism " />

$<$ drawprism mask $=" 0 ">$

$<$ point $\mathrm{x}=$ " $0.0 " \mathrm{y}=" 4.5 " \mathrm{z}=" 0.60 " />$

$<$ point $\mathrm{x}=$ " 0.15 " $\mathrm{y}=$ " 4.5 " $\mathrm{z}=$ " 0.6131233 " $/>$

$<$ point $\mathrm{x}=$ " -0.15 " $\mathrm{y}=$ " 4.5 " $\quad \mathrm{z}=$ " $0.6131233 " /$

$>$

$<$ point $\mathrm{x}=$ " $0.0 " \mathrm{y}=" 5.5$ " $\mathrm{z}=$ " $0.6 " />$

$<$ point $\mathrm{x}=$ " 0.15 " $\mathrm{y}=" 5.5$ " $\mathrm{z}=" 0.6131233 " />$

$<$ point $\quad x="-0.15^{\prime \prime} \quad \mathrm{y}=" 5.5^{\prime \prime} \quad \mathrm{z}=" 0.6131233^{\prime \prime} /$

$</$ drawprism $>$

$<$ shapeout file $="$ prism " $/>$

$</$ mainlist $>$

$<$ velocity mkfluid="0" $\quad \mathrm{x}=$ "0.0" $\quad \mathrm{y}=$ "0.0" $\quad \mathrm{z}=$ " $0.0 " \quad />$

$$
\begin{aligned}
& <\text { objreal ref=" } 51 "> \\
& \quad<\text { begin mov=" } 1 " \text { start }=" 0 " /> \\
& <\text { mvrect } \mathrm{id}=" 1 " \text { duration }=" 0.25 "> \\
& \quad<\text { vel } \mathrm{x}=" 0 " \mathrm{y}=" 0 " \mathrm{z}="-0.94 " /> \\
& \quad<\text { mvrect }> \\
& <\text { / objreal }> \\
& <\text { motion }>
\end{aligned}
$$




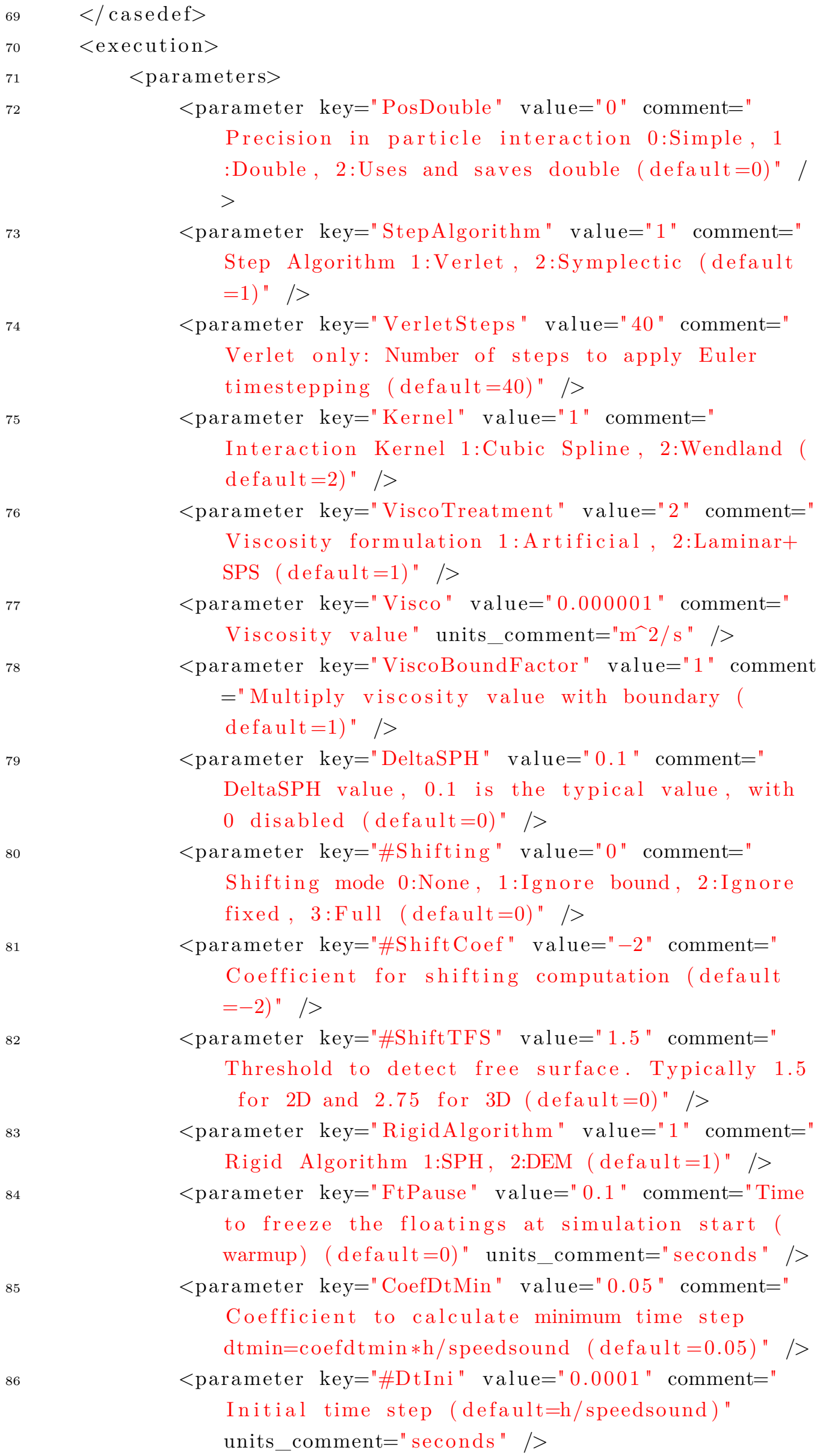


87

88

89

91

92

93

94

95

97

98

$99</$ case $>$

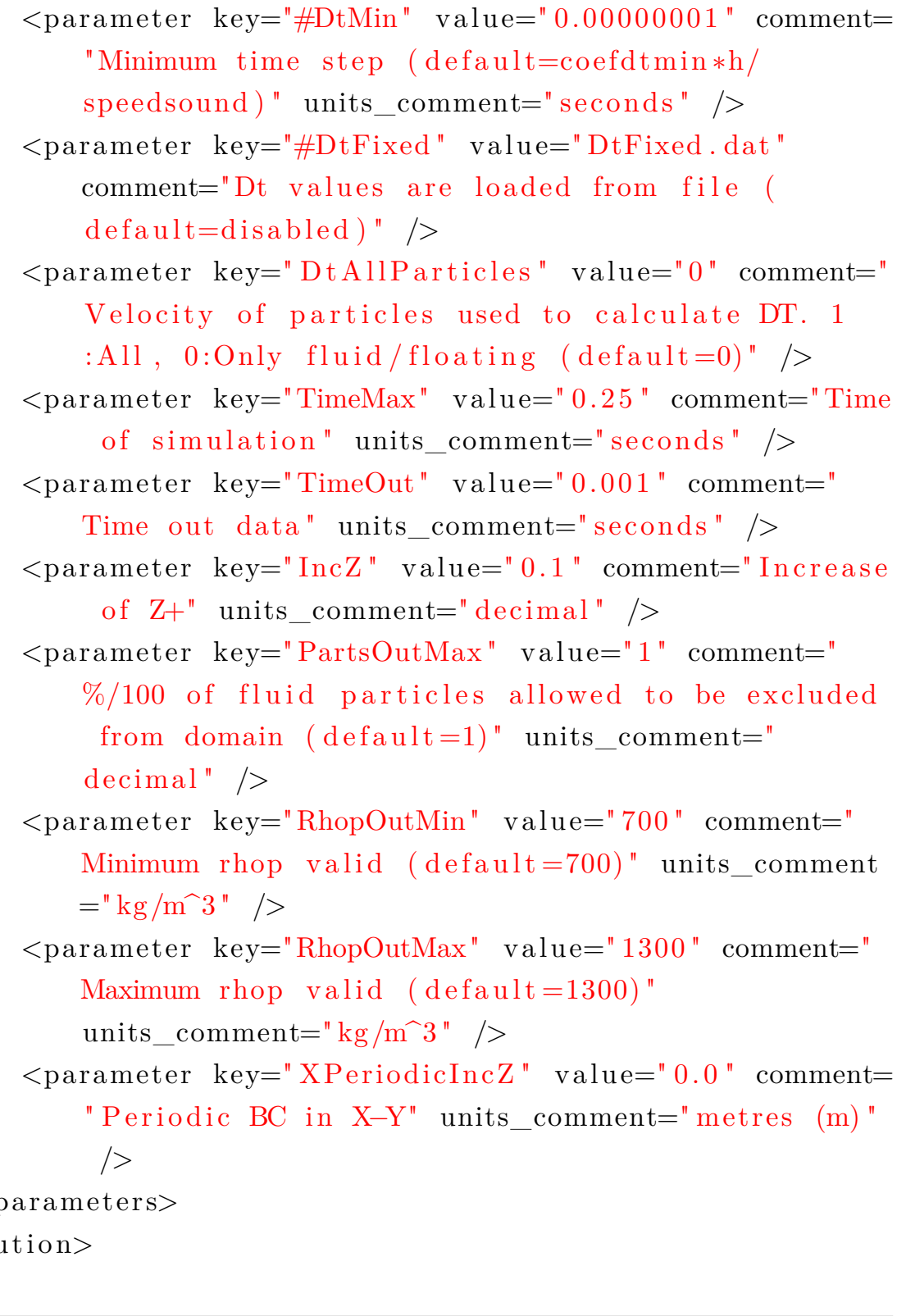




\section{Script File}

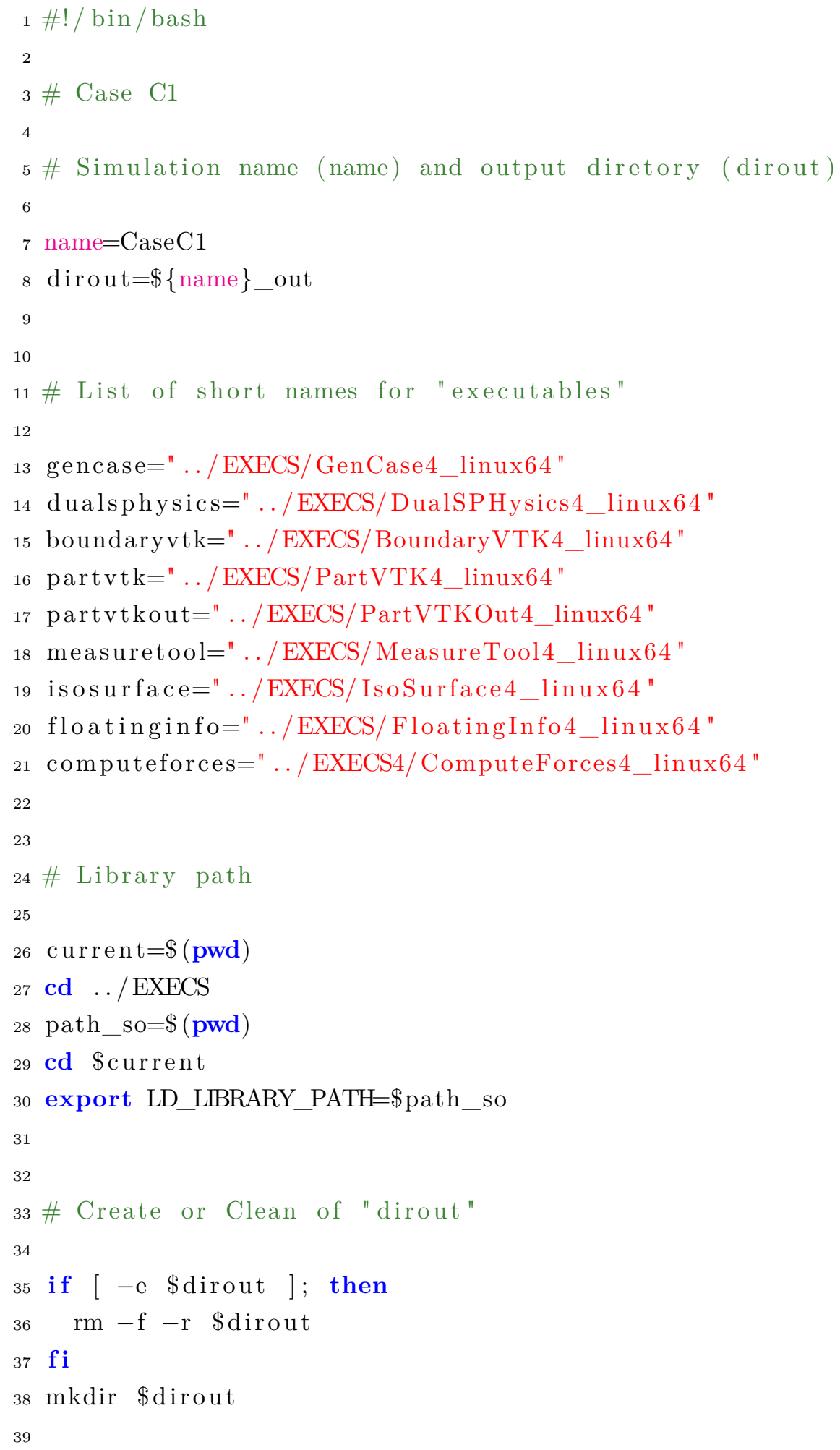




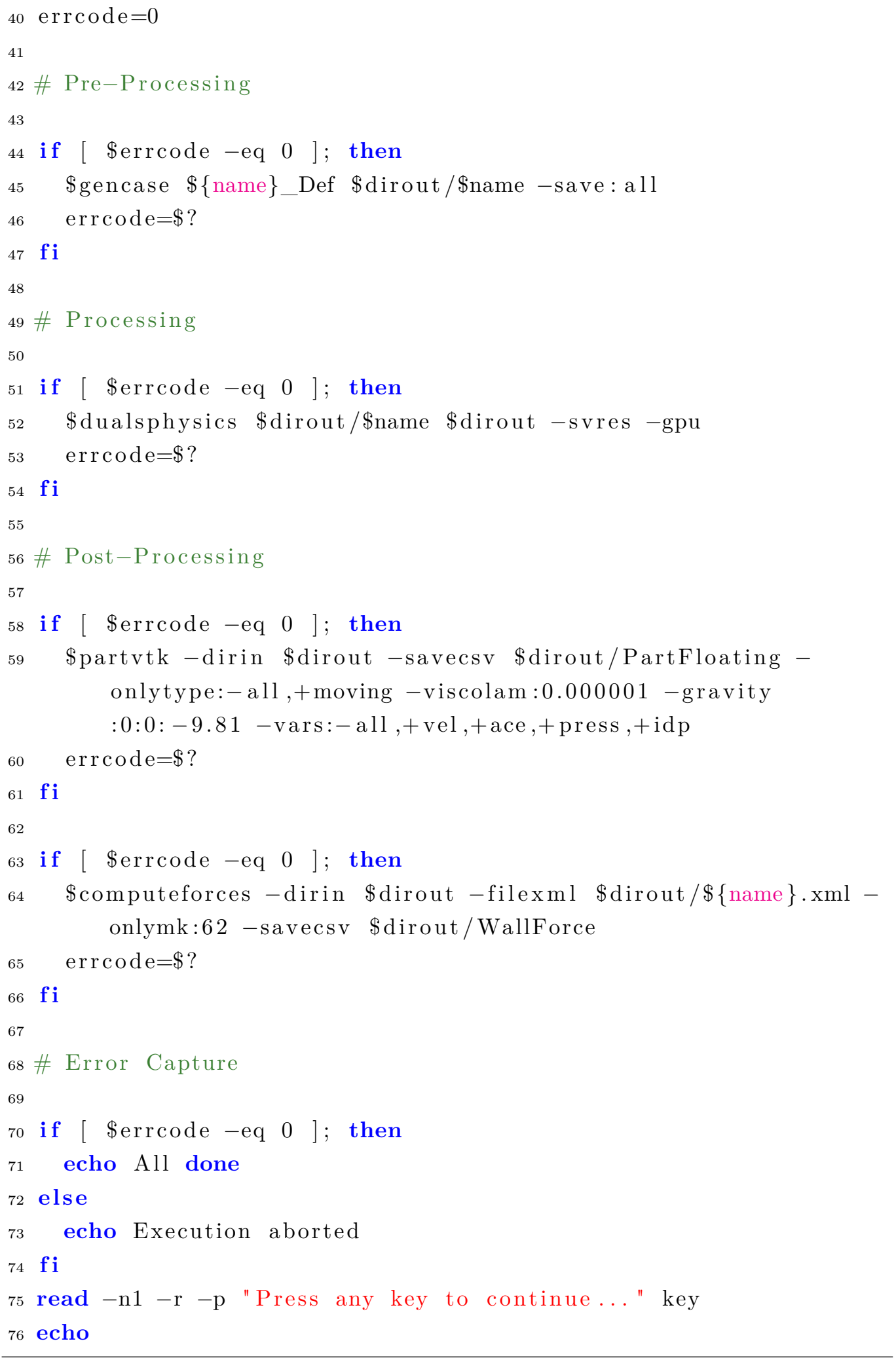


D

\section{Summary of Simulation Cases}

\section{Cases A Free fall of cylinder}

A1 Cylinder with density $500 \mathrm{~kg} / \mathrm{m}^{3}$

A2 Cylinder with density $1,000 \mathrm{~kg} / \mathrm{m}^{3}$

Case B Free fall of $30^{\circ}$ wedge

Cases C Constant velocity water entry of wedge

$\mathrm{C} 15^{\circ}$ wedge at $0.94 \mathrm{~m} / \mathrm{s}$

$\mathrm{C} 210^{\circ}$ wedge at $0.94 \mathrm{~m} / \mathrm{s}$

C3 $15^{\circ}$ wedge at $0.94 \mathrm{~m} / \mathrm{s}$

Cases D Analysis of the effect of particles distance

D1 $d p=0.01 m$

D2 $d p=0.005 m$

D3 $d p=0.0025 m$

D4 $d p=0.001 m$

D5 $d p=0.002 m$

D6 $d p=0.003 m$

Cases E Analysis of the effect of kernel function

E1 Kernel Wendland and $d p=0.001 \mathrm{~m}$

E2 Kernel Wendland and $d p=0.00075 \mathrm{~m}$

Cases F Analysis of the effect of smoothing length

F1 coef $h=0.8$

F2 coefh $=1.0$

F3 coefh $=1.6$

F4 coefh $=2.0$

Cases G $5^{\circ}$ wedge on waves at $-0.2 \mathrm{~m} / \mathrm{s}$

G1 $5^{\circ}$ wedge entering into calm water

G2 $5^{\circ}$ wedge entering before the wave crest

G3 $\quad 5^{\circ}$ wedge entering after the wave crest

Cases H Scaled model on waves $(l / \lambda=0.216$ and $H / \lambda=0.05)$ at $-0.75 \mathrm{~m} / \mathrm{s}$

H1 Model reaches the water surface at wave origin

H2 Model reaches the water surface delayed in $1 / 4$ of wave period

H3 Model reaches the water surface delayed in 2/4 of wave period 
H4 Model reaches the water surface delayed in 3/4 of wave period

Cases I Scaled model on waves $(l / \lambda=0.216$ and $H / \lambda=0.05)$ at $-1.5 \mathrm{~m} / \mathrm{s}$

I1 Model reaches the water surface at wave origin

I2 Model reaches the water surface delayed in $1 / 4$ of wave period

I3 Model reaches the water surface delayed in $2 / 4$ of wave period

I4 Model reaches the water surface delayed in $3 / 4$ of wave period

Cases J Scaled model on waves $(l / \lambda=0.131$ and $H / \lambda=0.01)$ at $-0.1 \mathrm{~m} / \mathrm{s}$

J1 Model reaches the water surface at wave origin

J2 Model reaches the water surface delayed in $1 / 4$ of wave period

J3 Model reaches the water surface delayed in 2/4 of wave period

J4 Model reaches the water surface delayed in 3/4 of wave period

Cases K Scaled model on waves $(l / \lambda=0.067$ and $H / \lambda=0.01)$ at $-0.1 \mathrm{~m} / \mathrm{s}$

K1 Model reaches the water surface at wave origin

K2 Model reaches the water surface delayed in $1 / 4$ of wave period

K3 Model reaches the water surface delayed in 2/4 of wave period

K4 Model reaches the water surface delayed in 3/4 of wave period 